\title{
Personal culture orientations and consumer cosmopolitanism: The moderating effects of product involvement
}

\author{
By \\ Mu-En (Justin) CHEN \\ Supervised by \\ Dr. Matevž Rašković
}

A thesis submitted to Victoria University of Wellington in fulfilment of the requirements for the degree of Master of Commerce in International Business

Victoria University of Wellington

2019 



\begin{abstract}
Cosmopolitan consumers generally refer to individuals who are open and unbiased towards foreign products and identify as citizens of the world. Despite growing relevance of understanding consumer cosmopolitanism (COS) in today's changing international landscape, both the construct itself is still not that well understood and operationalized, as well as its social and psychographic antecedent. In terms of culture studies, recent culture studies within the IB discipline continue to debate over the appropriate definitions of culture, as well as its conceptualization, operationalization, and especially measurement. This research aims to explore the impact of personal cultural orientations (PCOs), as individual-level culture value concepts, on COS, as well as the potential moderating role of product involvement (e.g., high- vs lowinvolvement products). Young-adult consumers in Taiwan and New Zealand were chosen to provide a contrast between a typical Western, Anglo-Saxon-based perspective and a typical Eastern, Asian, Confucian-based cultural context.
\end{abstract}

Overall, this study could not fully support PCOs as having a significant impact on COS, nor product involvement as a moderator. However, COS could not be tested as a secondorder reflective latent construct as originally intended in the seminal paper by Riefler et al. (2012). Compared to Riefler et al. (2012)'s paper, differences can be observed in the sampling where Riefler et al. (2012) sampled respondents aged 19 to 93 years (mean=46.6). This suggests that young adults a generational cohort hold significantly different perspectives and dispositions to other generations and the overall population. This finding aligns with recent IB literature in looking for smaller 'containers' of culture.

Of the three PCOs tested, two displayed significant effects to COS in both country samples, but only to one dimension of the COS construct (Open-mindedness) and not the other (Diversity appreciation). Hence it is highly likely the PCOs tested in this study have significant effects on COS, if only COS could be operationalized as originally intended as discussed above. This points towards potential issues in appropriateness of the scales used for studies on young adults, as both the PCO and COS scales were developed on a wide range (age diverse) of respondents.

This study also showed that within-country differences appear to be smaller than across-country differences. This is not consistent with previous cross-cultural research in the IB literature, which suggest cultural values differ significantly at the individual level due to differences in individuals' experiences. Again, such research was done on more diverse respondent populations, not a specific demographic cohort with distinct 
social experiences. This finding has implications for the general assumption that withincountry differences are considerably larger than across-country differences, when it comes to cultural value studies. Thus, when focusing on a specific demographic generational cohort, it seems that even when it comes to representatives from two very diverse cultural backgrounds, one grounded in a more Western and Protestant-based cultural context with more independent identity construal and the other in a more Eastern and Confucian-based cultural context with more interdependent identity construal, my evidence shows grater tendency towards a generational archetype understanding of young adults.

Keywords: Consumer cosmopolitanism, personal cultural orientations, young-adult consumers, culture, social identity, agriculture to global consumer culture, New Zealand, Taiwan. 


\section{Acknowledgements}

Writing this thesis has been such an amazing journey for me - with all its highs and lows; from the beginning to the end. Here, I would like to thank all those who have helped me on this journey.

To my friends, too many to name, thank you for all your guidance, patience, and support.

To my family, my parents, thank you for supporting me on this journey whilst I studied abroad, providing me encouragement and supporting me in any way possible to ensure I stay motivated and sane.

To my partner, Rina. I can't thank you enough for the amount of time you've spent helping me on my journey - staying up late with me to ensure I'm OK. Discussing and brainstorming ideas with me despite having no commerce background and providing support to me during times of hardship. Thank you.

Lastly, and most importantly. To my supervisor, Dr. Matevž Rašković. Thank you for enlightening me and sharing with me your knowledge and your academic experience. I have learned so much from you about our world and culture over the past year. For that, I will be forever grateful. This has been a long and difficult journey and you have guided me every step of the way to ensure I'm never too far off-track. Your humble, caring, and positive personality helped me to stay motivated and made this an enjoyable journey, especially during times of difficulty. No matter how busy you may be with other matters, you always set aside time for me, from very early in the mornings to very late at night. From the bottom of my heart, thank you. 


\section{Table of Contents}

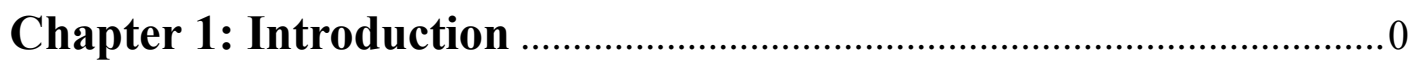

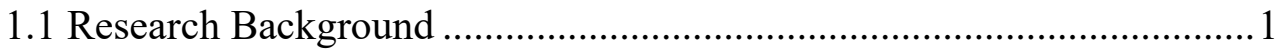

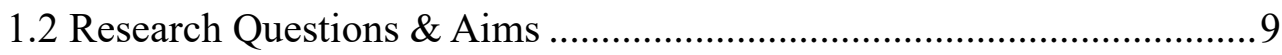

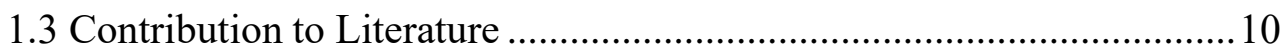

1.4 Organization of the Thesis ............................................................... 11

Chapter 2: Literature Review ………………………………………......12

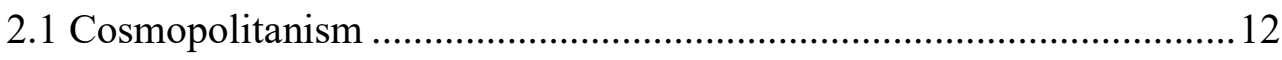

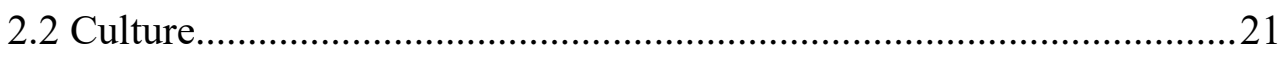

2.2.1 Young-adult Consumers ......................................................25

2.2.2 Selected countries: Taiwan \& New Zealand ..........................27

Chapter 3: Hypothesis Development ………………………………….....29

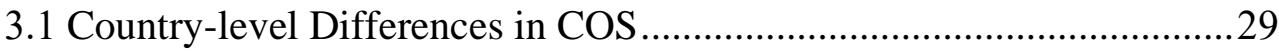

3.2 Personal Cultural Orientations and COS ..............................................30

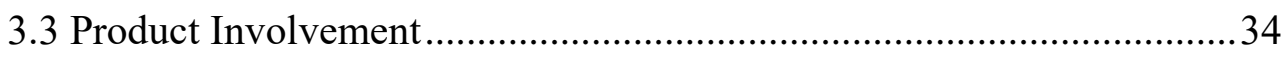

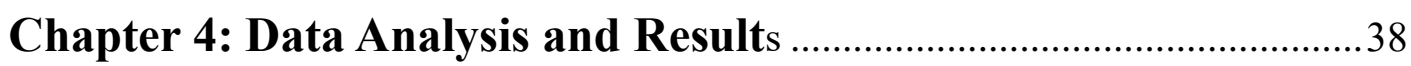

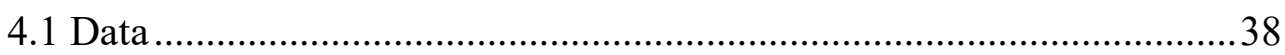

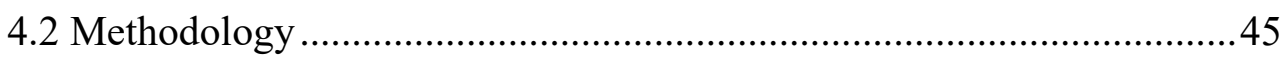

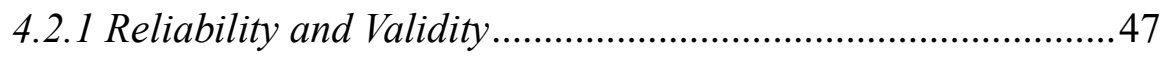

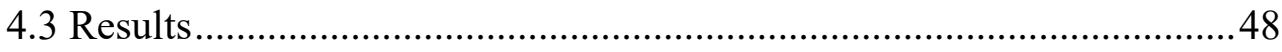

4.3.1 Survey instrument and general descriptive statistics....

4.3.2 Testing for effect size differences in data collection modes in

New Zealand .55 
4.3.4 Testing consumer cosmopolitanism as a second-order latent

construct. .58

4.3.5 Measurement Model Testing ..............................................62

4.3.5 Structural model testing ................................................... 70

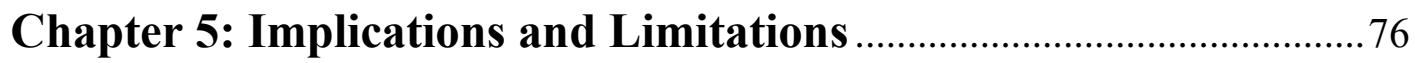

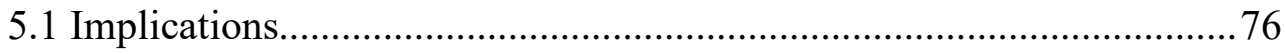

5.1.1 Theoretical Implications ................................................... 76

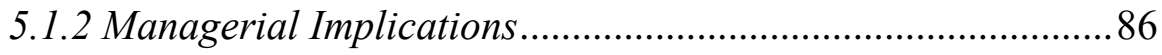

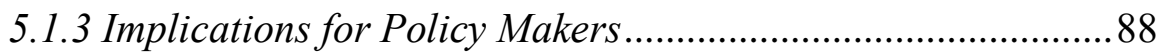

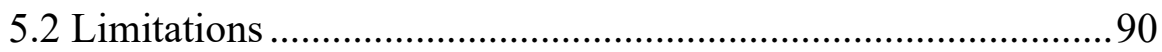

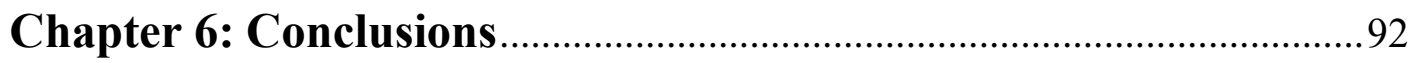

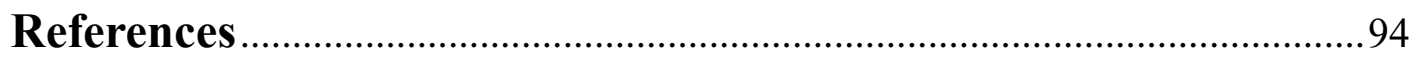

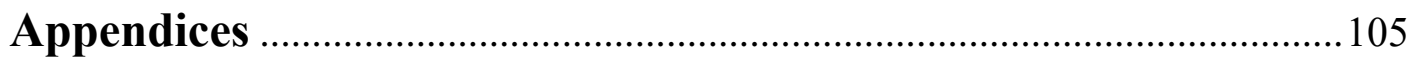

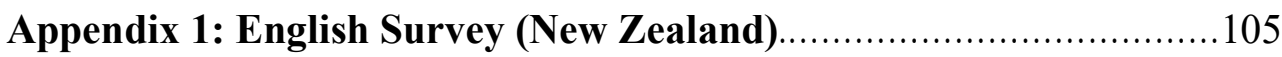




\section{Chapter 1: Introduction}

\subsection{Research Background}

During the 1970s and 1980s, American multinational companies (MNCs) were starting to lose their dominance in the global market due to higher levels of international investment and competition from Japanese, Swedish, and West German MNCs (Grimwade, 2000). Japanese MNCs became particularly challenging to American MNCs; with widespread foreign direct investments into the US market, especially in the automobile industry (Hout, Porter \& Rudden, 1982). This called for a new way of thinking and analysing strategic and managerial problems when operating abroad. It sparked research into global strategy and the globalization of markets (Raskovic, Makovec Brencic \& Jaklic, 2013); something that is once again becoming increasingly relevant due to globalization developments over the last couple of years (Witt, 2019). When globalization became a focal point across business disciplines, the issue of the nature and degree of market convergence became an important area of research within the international business (IB) and marketing literatures (Levitt, 1983). As foreign products became more common in domestic markets, research began exploring various consumer dispositions towards foreign products (Balabanis \& Diamantopoulos, 2004). As globalization intensified, the ease of international travel for individuals and mass media penetration exposed consumers to foreign cultures and consumption styles (Beckmann et al., 2001). For research looking at consumer attitudes towards foreign products, a common belief was that this exposure facilitated consumers to develop more positive attitudes towards foreign products and services (Riefler \& Diamantopoulos, 2009). This belief is largely underpinned by Contact Theory (CT), which suggests frequent exposure helps develop familiarity and preference towards foreign products 
(Bornstein \& D’Agostino, 1992). Researchers like Cannon, Yoon, McGowan \& Yaprak (1994) began to explore the concept of consumer cosmopolitanism (COS), as a means to label and identify consumer's degree of identification and connectedness to the socalled global consumer culture (GCC) grounded in the concept of consumer selfidentity. In recent years, this topic has increased in relevance and is being researched in greater depth, as the IB and marketing landscape is fundamentally changing, and consumers have developed complex dispositions to products, brands and countries based on their origin (see Bartsch, Riefler \& Diamantopoulos, 2016; Steenkamp, 2019).

More recent research on the phenomenon of globalization points towards less desirable outcomes, such as increasingly unequal distribution of wealth and constraints on national sovereignty; leading to an increase in anti-globalization trends (Meyer, 2017; Witt, 2019). These complex processes have led to the re-questioning of the antecedents, determinants and moderators behind the concept of so-called consumer cosmopolitanism (COS) (Bartsch et al., 2016) and its consumer behaviour outcomes in what has come to be known as an "inside-out" model of consumer behaviour in international markets (Diamantopoulos, Davydova \& Arslanagic-Kalajdzic, 2018). COS has been defined widely across different fields of literature, but its definition commonly revolves around having a general openness towards foreign products (Riefler \& Diamantopoulos, 2009).

As a result, some began questioning the effectiveness of relying on standardized global strategies built upon the assumption of a globalized consumer culture catering to consumers in different parts of the world (Steenkamp, 2019; Cleveland \& Bartsch, 2018). For international firms to succeed, understanding the impact of this changing 
globalization landscape has on consumer behaviour and how it affects consumers differently at macro (country-level, community-level etc.) and micro levels (grouplevel, individual level etc.) is crucial for understanding the many changes in their consumption behaviour we are witnessing day (Cleveland \& Laroche, 2007; Peterson, Sondergaard \& Kara, 2018). Understanding consumers and the forces that may change their consumption behaviour carry important implications for market segmentation and the implementation of effective international marketing strategies (Raskovic, Ding, Skare, Dosen \& Zabkar, 2016). Additionally, they also offer us insights into the sociology and psychology of globalization and carry implications for culture studies, as well.

The interaction of different cultures is said to have two opposing, yet simultaneous effects. The first one relates to the so-called homogenization (convergence) of culture, where ease of international travel, MNC marketing strategies, and global mass media interact with local cultures of individuals to blur cultural boundaries (Ger, 1999) and one's (global) identity (Raskovic et al., 2016). The other effect relates to the differentiation (divergence) of culture, where cultural differences experienced through globalization revitalize "national, ethnic, and communal identities; and the pattern of interrelationships fuel a hybridization of social life" (Ger, 1999, p.65). They might also trigger an apathy towards foreign cultures in favour of ideologies such as nationalism and protectionism (Steenkamp, 2019).

We can see these effects play out more frequently today, through various phenomena such as Brexit, rising anti-globalization movements, increasing protectionism and economic nationalism perhaps best symbolized by the election of the 45th president of 
the United States, Donal J. Trump (Inglehart \& Norris, 2016; Contractor, 2017; Witt, 2019). All this indicates that globalization may not just be blurring national cultures but may also promote cultural difference, in the process reviving the age-old question of "glocalization" - as a simultaneous interaction between the "global" and the "local" (Steenkamp, 2019; Douglas \& Craig, 2011). As a result, the homogeneity of cultures within countries is decreasing, as globalization continues to play out in an increasingly changing and complex manner, whilst commonality of cultures across countries seem to be increasing; but manifested in various ways, shapes and forms (Cleveland \& Laroche, 2007). This trend has been particularly observed within culture studies in the IB literature. For example, Taras, Steel and Kirkman (2016) have observed that $80 \%$ of cultural value variability can be observed within countries, while only $20 \%$ can be explained by country-level differences. The question of so-called transnational archetypes has recently emerged within IB literature and is becoming increasingly relevant (Venaik \& Midgley, 2015). This lends itself particularly well to a growing research stream in international marketing and business employing a much more consumer-centric approach, as opposed to a traditional market-centric approach (Raskovic, Ding, Hirose, Zabkar \& Fam, 2019; Prince, Davies, Cleveland \& Palihawadana, 2016; Riefler, Diamantopoulos, \& Siguaw, 2012; Cleveland, Erdogan, Arikan \& Poyraz, 2011).

In order to understand the culture of different consumers around the world and in turn understand their consumption behaviours, it may no longer be appropriate to analyse culture at the national level, but instead at the personal level (Taras et al., 2016; Tung \& Stahl, 2018; Peterson et al., 2018). This is not just to avoid issues like ecological fallacy, but actual validity (Brewer \& Venaik, 2014). Whereas national culture is suited 
for studying nations and societies as a whole, personal culture orientations (PCOs) are more important and relevant for firm-level strategies (Yoo, Donthu \& Lenartowicz, 2011; Sharma, 2010) and markets, which transcend geographical boundaries. Within marketing, this shift towards consumer-level socio-psychographic determinants has been especially prevalent in exploration of consumer dispositions towards foreign or domestic products (and brands), which is becoming increasingly relevant in recent years under the changing global landscape (Raskovic et al., 2019; Bartsch et al., 2016; Zeugner-Roth, Zabkar \& Diamantopoulos, 2015; Witt, 2019).

During the mid and late 2000's when globalization was on the rise, COS received increasing attention as a possible international segmentation tool (Terasaki, 2016). A cosmopolitan consumer generally refers to an individual who is open and unbiased towards foreign products. This acceptance and (perhaps) disposition towards foreign products are usually grounded in a person's sense of social identity (Raskovic et al., 2016). COS has found itself to be the focal point of research more frequently from the late 1990's to today, seemingly sharing a positive relationship with the level of globalization worldwide (Cannon \& Yaprak, 2002). For international firms, cosmopolitan consumers present a highly attractive segment in overcoming the proverbial liability of foreignness (Zaheer, 1995). However, with cosmopolitan consumers, having a foreign identity becomes a valuable resource that can be used to a firm's advantage, reducing costs associated with foreignness and increasing likelihood of sales (Beckmann et al., 2001; Nijssen \& Van Herk, 2005). Furthermore, researchers suggest that the global cosmopolitan consumer segment has been growing due to increasing levels of international travel, global media, global identification and citizenship. (Szerszynski \& Urry, 2002; Grinstein \& Wathieu, 2012). All this suggest 
that COS can be used as a powerful segmentation variable across international markets allowing for greater levels of marketing strategy standardization (Cannon \& Yaprak, 2002; Jaffe \& Nebenzahl, 2006; Thompson \& Tambyah, 1999). Many researchers in this field agree that COS should be thought of as a journey rather than the destination (Hannerz, 1990; Cannon et al., 1994; Thompson \& Tambyah, 1999). This indicates the need for understanding the processes of becoming cosmopolitan, which is a continuous process. However, past research has mainly focused on COS as the independent variable. It has also tended to be preoccupied with its relationship to other variables (e.g. consumer ethnocentrism) to create a better profile of a cosmopolitan consumer. Much less research has focused on the antecedents of COS, especially sociopsychographic characteristics of consumers at the individual-level (Cleveland et al., 2011; Han \& Won, 2018). Until the formation processes of a cosmopolitan consumer are better understood, marketers will not be able to properly identify cosmopolitan consumers and implement effective international marketing strategies that are targeted at them (Terasaki, 2016); as it will be difficult to predict actual cosmopolitan behaviour.

COS is a learned disposition influenced by experience under CT and grounded in Social Identity Theory (SIT) with the idea of belonging to a global in-group of cosmopolitan global citizens (Raskovic et al., 2019). Identity theory suggest two views of the self, an independent sense of self and an interdependent sense of self (Markus \& Kitayama, 1991). Quite common to many Western cultures, an independent view of the self emphasizes an inherent separation between individuals and "to discover and express one's unique attributes" (Markus \& Kitayama, 1991, p. 226). More common in nonWestern cultures, an interdependent sense of self emphasizes the fundamental connectedness between individuals and how one maintains interdependence with others. 
In this type of identity construal, one is actually defined through one's social relationships (Markus \& Kitayama, 1991). Regardless of the source of identity construal, both views rely on others for social comparison and self-validation (Markus \& Kitayama, 1991). Therefore, belonging to a group with other individuals is fundamental, and SIT suggests the need for individuals to belong to social groups as a source of self-esteem and self-identity (Tajfel \& Turner, 1979). An individual and others in the same social group are considered members of the in-group, whereas others are considered the out-group (Tajfel, 1982). Preference and priority are often given to ingroup members over out-group members. Exclusivity and negative attributes assigned to out-group members may vary from purely pro-in-group (e.g. nationalistic identity) to in-group superiority coupled with inferiority toward all out-groups (e.g. ethnocentrism) (Zeugner-Roth et al., 2015; Tajfel, 1982). In this sense, COS reflects a mixture of cognition and emotion held by an individual that encourages them to be open-minded towards foreign products and be interested in trying products used in different cultures in order to feel a sense of belonging (Cleveland \& Laroche, 2007; Bartsch et al., 2016).

Thus, to understand what might make an individual more cosmopolitan, variables that influences an individual's values and beliefs regarding foreign countries/cultures need to be considered. Firstly, as an individual's own culture directly relates to their values and beliefs, cultural factors have often been considered in studies concerning consumers' dispositions towards foreign countries and globalization. Such dispositions are shaped at different levels of the environment by various types of factors and may also be significantly moderated by attitudes (Bartsch et al., 2016). Secondly, CT suggests familiarity with and exposure to an object can cause individuals to develop 
positive dispositions (Bornstein and D'Agostino 1992). In the context of COS, this suggests that an individual's past experiences, such as someone who is frequently exposed to global media, travel, and/or interacting with people from other countries are more likely to develop cosmopolitan behaviours (Oberecker, Riefler \& Diamantopoulos, 2008; Alden, Steenkamp \& Batra, 1999; Durvasula \& Lysonski, 2008). Lastly, key socio-demographic variables such as age (Cleveland et al., 2009; Riefler et al., 2012; Lee, Lee \& Lee., 2014), level of education (Cleveland et al., 2009; Riefler et al., 2012; Phillips \& Smith, 2008), and gender (Cleveland et al., 2009; Bartsch et al., 2016) have been shown to have an importance influence on COS, due to their links to an individual's identity formation and sense of belonging. Overall, to understand the formation process of a cosmopolitan consumer, these variables must also be considered.

The purpose of this research is to explore the impact of four types of PCOs on COS, as well as the moderating role of product involvement. We analyse this by focusing on young-adult consumers (so-called Millennials, in their early 20's) in Taiwan and New Zealand. Young adults were chosen as the focus of this study due to their high exposure to globalization (Kjeldgaard \& Askegaard, 2006) and belief that are an archetypal global consumer segment relative to other consumer cohorts (Sobol, Cleveland \& Laroche, 2018). This is because of their high consumption of global mass and social media and popular culture, as well as their travel, use of English language and greater education opportunities (Raskovic et al., 2016). All this makes them more likely to acculturate towards some type of GCC (Durvasula \& Lysonski, 2016; Cleveland \& Laroche, 2007). In this regard, my contribution to the existing international marketing and IB literature is twofold. First, I approach COS as a dependent variable and test 
individual-level psychographic antecedents related to culture (as PCOs). Second, by testing a PLS Structural Equation Model (SEM) in two different national cultural

contexts (a specific East-West comparative setting), I also contribute to research on young-adult consumers as an "archetypal global consumer segment” (Sobol et al., 2018, p. 324); particularly as some recent intra-regional research has shown that this may not be the case when it comes to consumer-decision making styles (Raskovic et al., 2019). Additionally, I also contribute to existing research cross-cultural research and the growing discourse on appropriate "containers" of culture (Taras et al., 2016) and crosscultural variability.

\subsection{Research Questions \& Aims}

Based on the above, this research aims to answer the following research questions:

1. What is the level of difference (similarity) in the level of COS between young-adult consumers in Taiwan and New Zealand?

2. Are there different sub-groups of cosmopolitan consumers in the two countries?

3. To what extent can these differences be related to specific personal culture orientations?

4. Is product involvement a moderator of the relationship between personal cultural orientations and COS?

Investigating the above research questions will lead to the following objectives:

1. To analyse similarities and differences in COS of young-adult consumers in Taiwan and New Zealand, as well as to identify possible consumer archetypes.

2. To analyse the relationship between different personal cultural orientations 
and COS.

3. To test the moderating role of product involvement on the relationship between personal cultural orientations and COS by distinguishing between:

A. High (enduring) product involvement (e.g. Smart phone).

B. Low (situational) product involvement (e.g. A fast-moving consumer good).

\subsection{Contribution to Literature}

Consumer cosmopolitanism is a relatively new and developing field. While studies on cosmopolitanism in business contexts began in the 1950's, researchers have only recently begun to realize its importance to segmentation and marketing potential (Terasaki, 2016). Up to a decade ago, antecedents of COS have been mostly just hypothesized but rarely empirically tested. The few empirical studies available have provided mixed results (Riefler \& Diamantopoulos, 2009). This research aims to contribute towards understanding the socio-psychological antecedents of COS by examining COS as a dependent variable. I will specifically test PCOS as potential socio-psychographic antecedents of COS. Understanding such antecedents will allow us to understand the formation processes of a cosmopolitan consumer. It will enable marketers to better identify cosmopolitan consumers, predict their behaviour and implement more effective international marketing strategies (Terasaki, 2016; Raskovic et al., 2016).

In the past, international companies have mainly been utilizing traditional countrycentric marketing strategies, segmenting markets based on national culture and other macro-environment factors. Recently, they have begun to recognize the importance of 
replacing these kinds of strategies with more customer-centric approaches due to greater within country-level differences than between-country variability in terms of cultural values (Taras et al., 2016). Hence, the IB literature has had repeated calls for research on studying culture at the individual level and connecting it to consumer behaviour (Reynolds, Simintiras \& Diamantopoulos, 2003; Riefler et al., 2012). Understanding individual-level traits is crucial for the development of marketing and segmentation strategies that are more consumer-centric. This research aims to contribute towards these demands by improving our understanding of cosmopolitan consumers and presenting cosmopolitanism as a potential tool for international segmentation and developing international marketing strategies.

\subsection{Organization of the Thesis}

The thesis is organized as follows. I first start with a literature review of COS, PCOs, and product involvement; providing an understanding of each of the three key concepts in this study. I then discuss my research hypotheses, where each hypothesis between the dependent (COS), independent, and moderating variables is discussed in detail. A full conceptual model is then introduced to clarify the overall relationship. I next describe my research design, my data and the employed methodology in this research, where I had to become familiar with a novel methodology (PLS SEM). I then present my data and discuss the results of my hypotheses testing. A discussion of the findings is presented afterwards in terms of theory, practice and policy. I follow up this by a discussion of the research limitations and some recommendations for future research. The thesis ends with a short conclusion. 


\section{Chapter 2: Literature Review}

\subsection{Cosmopolitanism}

Cosmopolitan, stemming from the Greek word "kosmopolitês" can be literally translated as "citizens of the world" (Cleveland et al., 2011; Tambyah \& Chen, 2012). The concept of cosmopolitan was brought into the business context in the late 1950's. At the time, it was defined as individuals with orientations beyond their immediate circle or someone with low loyalty to his/her organization (Merton, 1957; Gouldner, 1957). Subsequent definitions found cosmopolitan individuals to be intellectuals comfortable in the cultures different to their own, as well as a general belief and attitude towards accepting and appreciating foreign cultures (Konrad, 1984; Kurasawa, 2004). Cosmopolitans can therefore be thought of as individuals with a global mindset, where individuals have an "openness to and awareness of diversity across cultures... with a propensity and ability to synthesize across this diversity" (Gupta \& Govindarajan, 2002, p. 117). In these early studies, cosmopolitanism can was thought of as a mindset, whereby only selected individuals who'd gone through rare and specific events would develop a sense of cosmopolitanism.

Only three types of individuals were considered cosmopolitan in these early studies, namely: global business elites, refugees and expatriates. They were considered to be the only types of individuals who have travelled and been either exposed to a significantly different culture or had been frequently exposed to different cultures (Skrbis, Kendall \& Woodward, 2004). According to CT, such exposure caused these three types of individuals to develop greater familiarity and open-mindedness towards foreign cultures, as it shifted in-/out-group boundaries and identification (Bornstein \& D’Agostino, 1992). However, as technology advanced, multiple forms of media (e.g., 
Television, World Wide Web), global pop culture, ease of travel, and increasing levels of migration made it increasingly possible for all individuals to be exposed to different cultures and develop cosmopolitan traits and behaviours without needing to be physically in a different culture; or have prolonged contact with another culture (Hannerz, 1992; Kjeldgaard, \& Askegaard, 2006; Raskovic et al., 2016). At the same time, global travel and mobility have also exponentially increased, leading to the emergence of a GCC, as a powerful social and market force (Steenkamp, 2019). From this point, whether an individual was affected and assimilated towards this global culture was no longer a mindset issue, like earlier studies suggested, but rather an identity issue, deeply personal to each individual. This can, thus, be directly related to SIT, as individuals may choose to assimilate towards a GCC, as opposed to their local culture in order to become a "global citizen", thus gaining a sense of self-esteem and belonging (Tajfel \& Turner, 1979). For the individual, their self-identity merges with the global identity as they become "global citizens".

In marketing and the related sub-field of consumer studies, very few scales were developed for COS compared to other social disciplines (see Dye, 1963; Jennings, 1967; Earle \& Cvetchkovich, 1997). There are three notable scales for COS, which have so far been used in the marketing literature (See Table 1 below). The first one, the CYMYC scale, was developed by Cannon et al. (1994). The CYMYC scale included four conceptual dimensions, namely: (1) search and evaluation of decision-related information, (2) organizational cosmopolitanism, (3) communication behaviour, and (4) hunger for diversity (Cannon et al., 1994; Riefler \& Diamantopoulos, 2009). For each dimension, Cannon et al. (1994) provided three items for cosmopolitan and three for a local perspective (Riefler \& Diamantopoulos, 2009). 
Table 1: COS Scales Developed in Past Studies

\begin{tabular}{|c|c|c|c|}
\hline Scale & Items & Dimensions & Data \\
\hline $\begin{array}{l}\text { CYMYC Scale } \\
\text { (Cannon et al., 1994) } \\
\text { Annual meeting of the } \\
\text { Academy of International } \\
\text { Business }\end{array}$ & 24 & $\begin{array}{l}\text { Four dimensions: } \\
\text { - } \quad \text { Search and evaluation of decision-related information } \\
\text { - } \quad \text { Organizational cosmopolitanism } \\
\text { - } \quad \text { Communication behaviour } \\
\text { - } \quad \text { Hunger for diversity } \\
\text { "I like to have contact with people from different cultures." } \\
\text { "Foreigners often leave me uncomfortable." }\end{array}$ & U.S. Consumers \\
\hline $\begin{array}{l}\text { AGCC Scale } \\
\text { (Cleveland \& Laroche, 2007) } \\
\text { Journal of Business Research }\end{array}$ & 11 & $\begin{array}{l}\text { COS as a dimension of AGCC. } \\
\text { "I am interested in learning more about people who live in } \\
\text { other countries." } \\
\text { "When travelling, I like to immerse myself in the culture of } \\
\text { the people I am visiting." }\end{array}$ & $\begin{array}{l}\text { Study 1-Initial Pool: } \\
162 \text { university students from Montreal, 56\% female, } 75 \% \text { aged 20-29. } \\
\text { Study 2-Reliability and validity: } \\
400 \text { undergraduate and graduate students, } 64 \% \text { born in Canada. }\end{array}$ \\
\hline $\begin{array}{l}\text { C-COSMO Scale } \\
\text { (Riefler, Diamantopoulos \& } \\
\text { Siguaw, 2012) } \\
\text { Journal of International } \\
\text { Business Studies }\end{array}$ & 12 & $\begin{array}{l}\text { Three dimensions: } \\
\text { - Open-mindedness } \\
\text { "I have got a real interest in other countries." } \\
\text { - Diversity appreciation } \\
\text { "I enjoy being offered a wide range of products coming } \\
\text { from various countries." } \\
\text { - Consumption transcending borders } \\
\text { "I like trying original dishes from other countries." }\end{array}$ & $\begin{array}{l}\text { Study 1-Scale Purification: } \\
442 \text { Austrian consumers responded from questionnaires sent to homes based upon } \\
\text { post code, } 58 \% \text { female, average age } 46.6 \text { years. } \\
\text { Study 2-Replication and Validation: } \\
222 \text { Austrian consumers from online surveys, } 42 \% \text { female, average age } 29 \text { years. } \\
\text { Study 3-Known-group Validity and Social Desirability Bias: } \\
444 \text { United World College alumni members, } 60 \% \text { female, average age } 28.85 \text { years. } \\
\text { Study 4-Test-Retest Reliability: } \\
43 \text { university students. }\end{array}$ \\
\hline
\end{tabular}


Although notable and replicated on many occasions, the CYMYC scale was often reported to have very low internal consistency and unclear dimensionality (Yoon, Cannon \& Yaprak, 1996; Yoon, Cannon \& Yaprak, 2002; Riefler and Diamantopoulos, 2009). Another notable scale is the COS scale, developed as a part of the much more complex AGCC scale (Acculturation to Global Consumer Culture) by Cleveland and Laroche (2007), which consisted of close to a dozen dimensions. In response to the scales developed by Cleveland et al. (2007), Riefler et al. (2012) developed the CCOSMO scale, which, to date, is still the most reliable scale to test COS. Riefler et al. (2012) criticized the scales developed by Cleveland et al. (2007) as being unidimensional and not parsimonious in terms of cross-national research. In their review of the AGCC scale, Riefler et al. (2012) highlighted the unclear conceptualization of the AGCC scale and its sub-dimensions, inconsistency in item generation, and a lack of other critical theoretically relevant dimensions. Hence, in response to the work by Cleveland et al. (2007), Riefler et al. (2012) officially theorized three core dimensions of COS and operationalized a manageable C-COSMO scale. The C-COSMO scale reflects the following three dimensions: open-mindedness (openness towards foreign countries and cultures), diversity appreciation (appreciates the availability of products from foreign countries and cultures), and consumption transcending borders (holding a positive disposition towards consuming products from foreign countries and cultures) (Dogan \& Yaprak, 2017).

This conceptualization and operationalization of the scale by Riefler et al. (2012) was an important step for consumer culture research, as it moved the field forwards from overreliance on a general openness towards foreign countries and cultures, as the basis for identifying COS (Dogan \& Yaprak, 2017; Terasaki, 2016). One must note also note 
that Riefler et al.'s (2012) original categorization does not explicitly identify the relationship between each dimension. It merely suggests each dimension as a key characteristic that cosmopolitan consumers exhibit.

Not all cosmopolitan consumers are, however, the same. Past literature suggests cosmopolitan consumers can be segmented based on their global-local orientations (Riefler, 2012), which is also consistent with the wider debate on the relationship between global and local consumer cultures (Steenkamp, 2019; Cleveland \& Bartsch, 2018). This suggests that there are different sub-types of cosmopolitan consumers, who may pursue different levels and/or avenues of cosmopolitan consumption based upon their different needs or attitudes (Cannon \& Yaprak, 2002).

To understand this, "localism" must first be discussed. Localism can be thought of as the opposite of cosmopolitanism, where one's preference is generally locally-bounded (Featherstone, 1990). Earlier studies thought of cosmopolitanism and localism as opposites on the same continuum. One became more cosmopolitan only by being less locally-bound (Cannon et al., 1994). However, later literature found cosmopolitanism and localism to be two distinct and independent constructs that can interact (Riefler \& Diamantopoulos, 2009). Hence, one can adopt cosmopolitan behaviours whilst maintaining ties to their local community (Riefler et al., 2012). This seems to be a particular feature within the so-called dialectic view of Asian consumers (Zhou, Arnold, Pereira \& Yu, 2010; Zhou \& Belk, 2004; Davies \& Raskovic, 2017) and very much grounded in SIT (Raskovic et al., 2019). In this regard, different types of cosmopolitan consumers can exist and can be based on different aspects of corresponding cosmopolitanism and localism (Riefler, 2012; Riefler et al., 2012; Zeugner-Roth et al., 
2015). For example, Riefler et al. (2012) made a clear distinction between global and local cosmopolitan consumers, when segmenting consumers in Austria and crossvalidating the C-COSMO scale.

In their 2002 paper, Cannon and Yaprak discussed two types of cosmopolitans, local cosmopolitans and global cosmopolitans. Cannon and Yaprak (2002) described local cosmopolitans as individuals that are not prejudiced against foreign cultures and are not ethnocentric. However, they are still able to maintain strong ties to their local cultures. Unlike local cosmopolitans, global cosmopolitans disregard or maintain weak ties to their local culture and actively pursue foreign culture (Cannon \& Yaprak, 2002). Later works kept these two concepts. However, the renamed global cosmopolitans to "pure" cosmopolitans (Riefler, 2012; Zeugner-Roth et al., 2015). These works also identified new types of cosmopolitan consumers based on a sense of direction; such as domestically-oriented consumers (high local orientation, low cosmopolitan orientation) (Zeugner-Roth et al., 2015), moderately-attached consumers (medium local orientation, medium cosmopolitan orientation) and so-called alienated consumers (low local orientation, low cosmopolitan orientation) (Riefler, 2012). Such different types of cosmopolitan consumers are segmented based on their various orientations, which causes them to have varying needs and wants (Cannon \& Yaprak, 2002). This suggests that marketers looking to target cosmopolitans should be aware of the different subtypes of cosmopolitan consumers, and to implement different marketing strategies when targeting these different sub-types.

Until the late 1990's, business research investigating COS and its relationship with other variables only tested COS against basic demographic variables. This was done in 
an attempt to profile cosmopolitan individuals. Such basic demographic variables included age, gender, income, education, international experience, and basic resident background variables, such as rural vs. urban background (Terasaki, 2016). As the level of globalization intensified, consumer dispositions toward foreign countries and globalization became a focal point in IB research due to the need for businesses and researchers to understand consumers beyond the local market (Bartsch, Riefler \& Diamantopoulos, 2016). Again, the purpose of this was to develop appropriate marketing and business strategies which transcend national borders (Raskovic et al., 2019). Similarly, for researchers looking at COS, globalization and so-called glocalization brought on the need for more in-depth profiling of cosmopolitan consumers and their characteristics. Hence, research began to investigate COS and its relationships with psychographic variables, like consumer innovativeness (Riefler et al., 2012), consumer ethnocentrism (Cleveland, Laroche \& Papadopoulos, 2009), national culture (Cleveland et al., 2011), and economic nationalism (Lee et al., 2014). Yet, consumer cosmopolitanism and its relationship with psychographic variables did not come fully in motion until the late 2000's. Even today, surprisingly few studies have extensively tested the relationships between COS and important psychographic variables, which have been examined in greater detail within psychology and sociology (Terasaki, 2016; Han \& Won, 2018).

In general, studies of COS are still relatively rare (Prince, 2012; Prince et al., 2016). This is at least compared to other types of consumer dispositions towards foreign/domestic products, such as ethnocentrism or xenocentrism (Prince et al., 2016; Bartsch et al., 2016). Most studies to date typically embraced COS as an independent or moderating/mediating variable. It has been rarely studied as a dependent variable 
(Cleveland et al., 2011; Han \& Won, 2018; Cleveland, 2018; Cleveland \& Bartsch, 2018). Although some limited studies looking at the antecedents of COS exist, most of these studies have shown inconsistent results in attempts to confirm a negative or positive relationship between COS and its various antecedents (Han \& Won, 2018).

Where COS considers consumers having a positive disposition towards foreign cultures and products, there are other consumer culture studies that considers varying dispositions (including negative) and perspectives towards foreign products (Bartsch et al., 2016; Prince et al., 2016). While COS considers a consumer's openness, appreciation, and consumption of foreign products, concepts such as ethnocentrism consider a consumer's preference for local products as a moral issue (Shimp \& Sharma, 1987). This is closely related to xenocentrism, which is seen as a negative attitude towards foreign products; something we can also observe in peoples' attitudes to foreign nationals (Balabanis \& Diamantopoulos, 2016). Consumer animosity, on the other hand, is more narrowly directed towards a specific nation or group (Riefler \& Diamantopoulos, 2007). Again, similar to COS, many of these concepts lack consistent results when testing for their antecedents, especially psychographic antecedents (Shankarmahesh, 2006; Han \& Won, 2018). Without knowing the antecedents to these concepts, it will be difficult to predict cosmopolitanism (and other related concepts). A number of studies testing for antecedent relationship failed to find a definitive solution. They often point towards scales and current conceptualizations being unidimensional, as one of the main causes (Riefler \& Diamantopoulos, 2007; Mueller, Wang, Liu \& Cui, 2016). Similarly, many studies point towards individual-level differences, as cause for such inconsistencies; due to diverse individual differences in experience, personal characteristics and various social environment backgrounds (Riefler \& Diamantopoulos, 
2007; Mueller, Wang, Liu \& Cui, 2016).

These individual differences should not be considered as "messy noise", but rather as endogenous aspects of COS and related phenomena; particularly as we increasingly realize that nations are poor containers of culture and shared experiences. Currently, there is still an ongoing debate whether nations should be defined by countries or their cultural groups (Peterson et al., 2018). Studies on GCC and Local Consumer Culture (LCC) often look into the forces that push/hinder GCC. Of particular interest are questions, like, under what circumstances may LCC become more relevant than GCC (Steenkamp, 2019; Ozsomer \& Altaras, 2008; Schuiling \& Kapferer, 2004).

Previous studies also suggest that until recently, GCC has been dominated by Westerntype thinking and legacies, where consumers from emerging Asian and African nations view Western consumer culture as ideal and naturally try to gravitate towards it and acculturate into it (Steenkamp, 2019). However more recent developments, such as, the rising global popularity of East Asian pop culture (Chua, 2012), Brexit, rising antiglobalization movements and rising economic nationalism (Inglehart \& Norris, 2016; Contractor, 2017), have all contributed towards a shift in the Western dominance of GCC. They have facilitated a move away from Western-type GCC archetypes and provided some credible alternatives. Furthermore, although a majority of consumers may still display tendencies to assimilate towards a common GCC type, individual consumers assimilate at a difference pace and to different degrees. This is because individual differences and backgrounds cause each consumer to interpret and internalise the influence of cultural stimuli differently (Tung \& Stahl, 2018; Cleveland \& Bartsch, 2018). This difference in influence at the individual level not only applies 
to a global (consumer) culture. It also applies to regional and, particularly, local culture(s). Recent studies in IB have seen scholars encouraging the cultural studies field to move away from equating nations with culture in favour of smaller "containers" of culture, down to the individual level; at least when it comes to values (Taras et al., 2016; Peterson et al., 2018). Similar to the above, although an individual's surrounding societal environment will carry specific behaviours and values, acceptance of these societal values will differ across individuals based on personal characteristics, experiences and be, increasingly, shaped by personality (Peterson, 2016; Peterson \& Barreto, 2014; Peterson et al., 2018).

\subsection{Culture}

Recent culture studies within the IB discipline continue to debate over the appropriate definitions of culture, as well as its conceptualization, operationalization, and measurement (see, e.g., Tung \& Stahl, 2018). In their "stocktake" of recent IB literature, Tung and Stahl (2018) point towards issues such as very narrow conceptualizations of culture and a tendency to equate nation with culture. Peterson et al. (2018) also highlight IB's struggle to theorize the boundaries between country and cultural groups. They suggest scholars to consider the different kinds of interaction at different levels (e.g., between country and ethnic groups, within country regions and emergent cultural areas, such as cities). They also encouraged scholars to discard the traditional way of thought regarding countries and cultural groups, suggesting instead how both may have an influence on what shapes a nation, and to more importantly focus on the interplay between the two (Peterson et al., 2018). Taras et al. (2016) have been particularly critical of the latter and have shown that some 80 per cent of "cultural variability" in values occurs within countries, while only about 20 per cent of variability in values 
occurs across countries. To move away from the national level and probe more in-depth into culture, as pointed out by Peterson et al. (2018), many IB scholars looked at smaller “containers”, such as within-country regions, ethnic groups or generations (Raskovic et al., 2019). However, scholars analysing culture from this angle typically only repackaged our understanding of culture and most often simply approached regional cultures in the same vein as national cultures; but on a smaller geographic scale (Peterson et al., 2018).

A recent paper on global-local consumer culture and GCC by Cleveland and Bartsch (2018) defined GCC for the first time as a vortex. In this novel conceptualization, consumers are drawn in and acculturate towards a GCC due to various forces, such as cultural and geographic specific entities and global culture flows (Appadurai, 1990). Global cultural flows, such as ethnoscapes (movement of immigrants and tourists etc.), mediascapes (global production of information by print and electronic means), and ideoscapes (transnational social and philosophical movements e.g. \#metoo) increasingly spread cultural values worldwide, thus, simultaneously contributing to the so-called structuration of a GCC (Cleveland \& Bartsch, 2018). As a result, "deterritorialization" occurs, where culture becomes less and less bounded by geographical and physical scape, as well as language (Cleveland \& Bartsch, 2018). Furthermore, although cultural values dictate what behaviours and attitudes are considered acceptable within different societies, an individual's personal acceptance of societal values will vary from person to person. This is due to personal characteristics, such as experiences, gender, and personality (Peterson, 2016; Peterson \& Barreto, 2014). It is for all these reasons that culture should be conceptualized and measured at the individual level, with the IB and marketing literatures needing to catch up on the 
“trend” (Tung \& Stahl, 2018; Carpar, Devinney, Kirkman \& Caligiurim, 2015).

To look at culture at the individual level, papers by Sharma (2010) and Yoo, Donthu, and Lenartowicz (2011) independently developed alternative personal cultural orientation $(\mathrm{PCO})$ scales for measuring cultural values at the individual level. At the same time, both also allowed for compatibility with existing national culture typologies (e.g. Hofstede's work). Both seminal papers started from Hofstede's cultural dimensions, which performed stable at the country level, but poorly at the individual level (Sharma, 2010; Yoo et al., 2011). Testing showed that due to its unidimensional measures, Hofstede's cultural dimensions were unable to provide stable results at the individual level compared to multidimensional measures (Bearden, Money \& Nevins, 2006). To overcome this issue, Sharma (2010) reconceptualized Hofstede's original five cultural dimensions into ten dimensions, adding several dimensions which were particularly relevant for non-Western cultures (e.g. prudence and tradition corresponding to Confucian dynamism). Using Hofstede's Individualism-Collectivism scale as an example, Schwartz's (1994) study showed that most societies simultaneously display levels of both individualism and collectivism (Oyserman, Kemmelmeier \& Coon, 2002). This indicates that using Hofstede's national cultural values in order to predict individual-level behaviours becomes highly problematic, as there are multiple non-cultural factors (social, demographic, environmental etc.) that differ among individuals. To overcome this issue, Sharma (2010) relied on crosscultural psychology and consumer literature to review the polar issues plaguing Hofstede's original five dimensions. Sharma (2010) split each dimension into two positively or negatively correlated dimensions. For example, in Hofstede's original dimensions, individualism and collectivism existed on two ends of the same spectrum. 
This suggests one can only become more individualistic by being less collectivistic. However, Sharma's (2010) review of the literature suggests most people may exhibit some levels of individualism and collectivism at the same time. This is also consistent with how individualism-collectivism are conceptualized in the GLOBE project study (Javidan, House, Dorfman, Hanges \& De Lugue, 2006). Because of this, Sharma (2010) reconceptualized this dimension into two negatively correlated dimensions, namely independence and interdependence. In the end, Sharma's empirical testing showed the PCO scale provided high levels of reliability, validity, and cross-cultural generalizability. This indicated his reconceptualization of the dimensions was more appropriate for analysis of culture values at the individual level.

Similarly, Yoo et al. (2011) had to overcome the problem of unidimensional measures not being stable at the individual level. Unlike Sharma, however, Yoo et al. (2011) kept Hofstede's original five dimensions, and added items from Hofstede's other works, Hofstede related scales, and non-Hofstede works. As Hofstede's original measures were highly work related, various items were modified and re-added to provide a better balance and ensure the resulting scale could be applicable at the individual level (Yoo et al., 2011). Testing of their scale showed adequate levels of reliability, validity, and cross-cultural generalizability, which also indicates their approach was appropriate to analyse culture at the individual level. However, while Hofstede's original framework related the masculinity-femininity dimension to dominance of male vs female values, the reconceptualization by Yoo et al. (2011) at the individual level related this aspect more to gender equality. This turned out to be a particular issue in my study, which I discuss later on in the empirical sections. 


\subsubsection{Young-adult Consumers}

As consumers, young-adults' consumption habits are determined by social learning, sensation seeking and identity construal (Raskovic et al., 2016). It is accompanied by higher levels of experimentation (Foxall \& Goldsmith, 1994). Young-adult consumers are more likely to try unfamiliar products and brands than other age groups, corresponding to higher levels of consumer innovativeness (Tellis, Yin \& Bell, 2009). Consumption habits of young-adult consumers are highly individualized, but at the same time strongly influenced by peers and popular culture (Kjeldgaard \& Askegaard, 2006; Hung, Gu \& Yim, 2007). In terms of decision-making styles, young-adult consumers are more price sensitive and heavily influenced by brands (Raskovic et al., 2019). Furthermore, young-adult consumers generally show lower levels of consumer ethnocentrism (Tellis et al., 2009) and higher levels of consumer cosmopolitanism (Riefler \& Diamantopoulos, 2009).

Young-adult consumers are often the cohort of interest when it comes to research on GCC (Raskovic et al., 2019; Ding et al., 2018; Raskovic et al., 2016). They are in many ways seen as an archetypal global consumer segment (Sobol et al., 2018; Kjeldgaard, \& Askegaard, 2006). As a consumer segment, young-adult consumers are characterized by higher tendency to pursue novel and creative experimentations (Raskovic et al., 2016), which is a part of their social learning and identity construal/exploration process (Foxall, \& Goldsmith, 1994; Gentina, Butori, Rose \& Bakir, 2014). Young-adult consumers are found to be less consumer ethnocentric (Yen, 2018; Shankarmahesh, 2006), meaning they're less likely to be biased against foreign products and brands (Tellis et al., 2009), which is linked to higher levels of COS (Riefler \& Diamantopoulos, 2009). As recent evidence by Raskovic et al. (2019), suggests, this may have less to do 
with a belief that purchasing foreign products is not immoral. It may simply be a matter of visibility and familiarity.

Young-adult consumers' increasingly use English as their lingua franca, have high levels of mass media consumption, and share similar patterns of social interaction (technology, travel, study etc.) develops their propensity to acculturate towards a GCC, without even realizing it (Cleveland \& Laroche, 2007; Durvasula \& Lysonski, 2016; Raskovic et al., 2016). However, more recent evidence suggests a majority of this research was conducted with a focus on Western consumers (Raskovic et al., 2016; 2019). Although noted by Kjeldgaard and Askergaard (2006) in their seminal paper, this limitation was often forgotten by subsequent papers (Raskovic et al, 2016; Ding, et al., 2018; Raskovic et al., 2019). As a result, papers following this idea that examined the concept at an international level branched into looking at young-adult consumers as global consumer cohorts and generational "constellations" within the so-called sociology of globalization (Beck \& Beck-Gernsheim, 2009). Furthermore, various other researchers have found evidence for significant differences among young-adult consumers within the same country (Zhou et al., 2010), same region (Anic et al., 2016) and across regions (Ding et al., 2018; Raskovic et al., 2019).

With evidence suggesting young adults may be seen as an "archetypal global segment" (Sobol et al., 2018, p. 342; Kjeldgaard, \& Askegaard, 2006), while also exhibiting higher levels of differences within countries (Raskovic et al., 2016; Raskovic et al., 2019), reinforcing the prior idea that national-level analyses may no longer be appropriate when conducting research related to culture and globalization; particularly when it comes to behaviours and attitudes of individuals. Instead, more individual-level 
“containers" of culture should be looked at (Reynolds, Simintiras \& Diamantopoulos, 2003; Riefler et al., 2012); or taking into account a smaller sub-groups (Kirkman, Lowe \& Gibson, 2017).

\subsubsection{Selected countries: Taiwan \& New Zealand}

As countries, New Zealand and Taiwan make for ideal choices when conducting comparative study of COS due to their specific similarities and unique differences. With regards to the above-mentioned assumption of young-adult consumers as a global segment, comparing Taiwan and New Zealand is particularly valuable. New Zealand is a typical Western and Anglo-Saxon dominant society, whilst Taiwan is a typical Eastern society guided by Confucian philosophy and an interdependent-type of identity construal (Tu, 2000). In terms of similarities, similar economic and societal conditions (e.g., on the Human Development Index) between the two countries would indicate young-adult consumers in both New Zealand and Taiwan have similar resources and opportunities available to them to partake in the global consumption culture. Furthermore, as both New Zealand and Taiwan are island nations, their economy and market structure share a similar goal of wanting to connect with other economies as much as possible, due to the high transaction costs they face accessing world markets (Tisdell, 2006). Being in the presence of large and powerful neighbours, as well as home to indigenous populations, both countries also represent unique settings for identitybased research. A table has been provided below to offer additional country-level statistics, which build the case for such comparative research, as COS and other consumer dispositions have been shown to be impacted by country level of development and type (Jin et al., 2015) (See Table 2). 
Table 2: Basic Demographic Information on Taiwan \& New Zealand

\begin{tabular}{|c|c|c|}
\hline & Taiwan & New Zealand \\
\hline Population * & $23,545,963$ & $4,545,627$ \\
\hline GDP per capita PPP $* *$ & $\$ 49,827$ & $\$ 38,502$ \\
\hline Export / \% of GDP $* * *$ & $60.3 \%$ & $26.4 \%$ \\
\hline Hofstede - Power Distance $* * * *$ & 58 & 22 \\
\hline Hofstede - Uncertainty Avoidance & 69 & 49 \\
\hline Hofstede - Masculinity & 45 & 58 \\
\hline Hofstede - Individualism & 17 & 79 \\
\hline Average (Median) Age & 38 years $* * * * *$ & 42.2 years $* * * * * *$ \\
\hline$\%$ of Population Aged 20-30 & Approx. $15.5 \% \wedge \wedge$ & Approx. $23.5 \% \wedge$ \\
\hline Migrants as $\%$ of population & Approx. $3.3 \% \wedge \wedge \wedge \wedge$ & Approx. $11.1 \% \wedge \wedge \wedge$ \\
\hline
\end{tabular}

Notes:* CIA World Fact Book.

** IMF (2017) World Economic Outlook Database.

*** CIA World Fact Book.

**** Hofstede Insights. Compare Countries.

***** Stats NZ.

$* * * * * *$ Statista.

$\wedge$ Figure.nz

м http://host.dsjh.tyc.edu.tw/ chua/html/taiwan-man.htm

M Stats NZ.

$m$ Ministry of the Interior National Immigration Agency Republic of China (Taiwan). 


\section{Chapter 3: Hypothesis Development}

\subsection{Country-level Differences in COS}

Beckmann et al. (2001) argued that as globalization became more and more intensive, the ease of travel and mass media penetration meant consumers around the world were being exposed to foreign cultures and consumption styles more frequently. This generally leads to the development of a positive attitude towards foreign products and services, as per CT (Riefler \& Diamantopoulos, 2009). Based on their study of youngadult consumers in Denmark and Greenland, Kjeldgaard and Askergaard (2006) believed young-adult consumers are highly sensitive when it comes to the effects of globalization processes. Additionally, when coupled with low consumer ethnocentrism and high levels of innovative consumer behaviour, they concluded that these consumers are at the forefront of globalization. This has been recently reinforced by Sobol et al. (2018) and also supported by Raskovic et al. (2019). Both studies discuss in relative terms, the context of benchmarking this particular consumer demographic cohort to other demographic cohorts.

Although not affirmative, contrary to the above, recent studies have provided evidence that suggests differences between young-adult consumers do not only exist at the national level, but also at the regional level and even within specific countries (see Ding et al., 2018; Zhou et al., 2010; Wong, Polonsky, \& Garma, 2008; Tellis et al., 2009). As mentioned above, the study by Taras et al. (2016) suggests that approximately $80 \%$ of variation in the cultural values occurs at below the national level, whilst only $20 \%$ of variation is accounted for at the cross-national level. Overall, if indeed differences exists within and across young-adult consumers in different countries (and regions), this should indicate a relationship contrary to the above mentioned, and the following 
hypotheses can be made (as sort of general null-type hypotheses):

H1a: There will be differences in the level of COS between young-adult consumers between the two countries.

H1b: There will be differences in the level of COS between young-adult consumers within both countries.

\subsection{Personal Cultural Orientations and COS}

Cosmopolitanism should not be thought of as an innate characteristic, but rather "a general disposition reflecting a specific set of values, opinions, and competencies held by an individual" - more specifically, an individual that has "a genuine, humanitarian appreciation for, desire to learn from, and ability to engage with, peoples of different cultures" (Cleveland \& Laroche, 2012, p.55). SIT is one underlying theory of COS and other related concepts (e.g. xenocentrism, ethnocentrism) which considers an individual's disposition towards foreign countries (Bartsch, Riefler \& Diamantopoulos, 2016). Recent research on consumer centrism has shown that various social identity bases shape consumer behaviour in foreign markets (Prince et al., 2016; Raskovic et al., 2019). According to this theory, individuals seek to interact with foreign cultures to identify with those foreign cultures or the world as a whole, as a part of their selfidentity (Bartsch, Riefler \& Diamantopoulos, 2016). An individual's cultural values, beliefs, and behaviours are fundamentally drawn from their social environment, such as their "family, peers, religion, education, economic and legal systems, and also indirectly through media" (Cleveland \& Laroche, 2012, p.67). As an individual's culture determines their attitudes, behaviours, and lifestyle choices, culture therefore 
also dictates the individual's needs and wants as a consumer (Cleveland \& Laroche, 2012), since consumption is increasingly becoming a manifestation of post-modern culture. (Raskovic et al., 2019). Hence cosmopolitan consumption behaviours are likely to be preceded by an individual's familiarity or curiosity in anything foreign, due to a culturally-related need or want. Past studies have also speculated that "the stronger driver of any divide in cosmopolitans at the level of the individual might be a cultural rather than occupational or stratification factor" (Cleveland \& Laroche, 2012, p. 63). Furthermore, anthropology studies suggest culture and the process of acculturation are likely to be fundamental factors for creating specific individual characteristics (such as, e.g., cosmopolitanism) (Hofstede \& McCrae, 2004; Miller, 1999). Overall, culture at the individual level is likely to have an influence on COS. This implies that if national culture acts as an increasingly "poor container" for "culture", PCOs should be tested as a possible antecedent to COS.

To my knowledge, only two papers in mainstream scientific journals have extensively tested cultural values as possible antecedents of COS. The first one is by Cleveland et al. (2011) and the second is by Han and Won (2018). Although both papers only tested cultural values at the national level, they both used Hofstede's cultural dimensions and found statistically significant relationship between COS and specific cultural values (Cleveland et al., 2011; Han \& Won, 2018). Although other cultural dimensions are available and may also relate to COS (such as Schwartz's work (2011)), this study has opted to use Hofstede's cultural framework, to allow us to compare with the studies by Cleveland et al. (2011) and Han \& Won (2018); as well as directly build on the work by Sharma (2010) and Yoo et al. (2011). Next, I frame my research hypotheses related to individual relationships between specific cultural dimensions and COS, as per 
available literature on national culture.

Hofstede $(1980 ; 1991)$ defines uncertainty avoidance (UA) as the degree to which a society feels threatened by change or the unknown. As a result, cultures that are higher in UA would avoid potential risks and take greater precaution before stepping out of comfort and venturing into the unknown. In contrast, cultures lower in UA would be more accepting of cultures, religions, behaviours, and opinions that are different from their own, as they are more open to change and are more comfortable with the unfamiliar (Han \& Won, 2018). Building upon the dimension of "open-mindedness" (Riefler et al., 2012), consumers with lower UA would be more open towards change, and therefore be more open-minded and be un-prejudiced towards products and services of foreign origin. This holds even if the product/service is significantly different to a domestic product within the same product class, and vice versa. With this in mind, I have formulated the following general research hypothesis:

H2a: Individuals who have higher uncertainty avoidance will be less cosmopolitan (and vice versa).

Individualism is often regarded as the most prominent dimension within Hofstede's framework (Triandis, 1994). It relates to the degree to which members of a society take others into consideration and is particularly strongly related to type of identity construal. Societies with high levels of individualism are characterized by a greater level of concern for the self and the immediate surrounding group, such as family and friends. In highly individualistic societies, people are able to make decisions based on their own judgement and choices, allowing them to explore the perspectives and identities of 
others (Cleveland et al., 2011). Research by Cleveland et al. (2011) on Canadian and Turkish university students (predominantly aged between 20-29) showed that individuals showing higher levels of individualism are more likely to be accepting of foreign cultures and products. Similar results were shown in a later study by Carpenter, Moore, Alexander, and Doherty (2013) sampling US consumers aged 18 or older. It pointed to a direct positive relationship between individualism and COS. On the contrary, societies with low individualism are classified as collectivistic societies, where a greater emphasis is placed on the well-being of the in-group over individual preferences. In collectivistic societies, it is important to ensure local traditions and norms are upheld (Cleveland et al., 2011). Therefore, collectivistic individuals are less likely to be open-minded towards products and services that are not a part of local culture, and vice versa, which suggests:

H2b: Individuals scoring higher on individualism will display higher levels of cosmopolitanism (and vice versa).

Power distance (PD) relates to the degree of respect given to hierarchy, where high PD societies show high levels of obedience and respect for higher ranked members and vice versa (Hofstede, 1980; 1991). In low PD societies, individuals are likely to be more assertive. They are more likely to challenge traditions and embrace new perspectives, such as exploring different cultures; which suggests high levels of COS (Cleveland et al., 2011; Han \& Won, 2018). Cleveland et al. (2011) suggest that high PD societies are more likely to embrace "traditional notions of dominance and rigidity" (p. 935), which should cause them to be more cautious towards different cultures. Overall this suggests: 
H2c: Individuals with higher levels of PD will be less cosmopolitan compared to individuals with lower levels of PD.

Masculinity refers to the clarity of gender characteristics in a society, where highly masculine societies value traits such as competition, ambition, and assertiveness, and less masculine societies value feminine traits such as modesty, nurturing others, improving quality of life, and also exhibit more fluid gender roles (Hofstede, 2001). Cleveland et al. (2011) argues that COS is more likely to be associated with a relationship-orientated low masculinity society as opposed to an agentic-orientated high masculinity society, hence the following:

H2d: Individuals that score higher on masculinity will be less cosmopolitan (and vice versa).

\subsection{Product Involvement}

Depending on the level of product involvement, the complexity and range of variables considered during the purchase decision-making process will change significantly (Houston \& Rothschild, 1978). For products with enduring (higher) involvement, greater care is placed on the purchase decision-making process to ensure potential risks are considered and compared. This is because enduring involvement products are often of higher value and purchased less often (Holmes \& Crocker, 1987). In comparison, situational involvement products, or low-involvement products, are purchases that are made more frequent and often involve products that are lower in value. Therefore, less importance is placed on the purchase decision-making process, as the risks involved with a low-involvement purchase are often inconsequential or negligible (Holmes \& 
Crocker, 1987).

In relation to open-mindedness, purchasing products which require higher levels of involvement will be met with a more complex and risk-based decision-making process. Therefore, foreign products (and brands) that an individual is less familiar with are less likely be considered. This is because the risk associated with it will be much higher compared to a local alternative that the individual is more familiar with. Overall, the level of product involvement is likely to cause individuals to place various levels of consideration and risk assessment before making a purchase, which is likely to change the level of willingness to try new and foreign products. Thus:

H3: Product involvement will have a moderating effect on the relationship between PCOs and COS.

Given that I examine specific PCOs, I have broken down H3 more specifically into a series of sub-hypotheses corresponding to each PCO.

Uncertainty avoidance relates to the degree to which an individual avoids risk, which suggests in relation to the open-mindedness dimension of COS a negative relationship. To test product involvement as a moderator of this relationship, the following hypothesis will be tested:

H3a: The negative relationship between uncertainty avoidance and COS will be moderated by product involvement. 
Individualism relates to the degree to which an individual considers others. For more individualistic persons, less concern is placed on others. This allows the individual to make freer decisions, as they need to take into account less actors and their wellbeing. In relation to the dimensions of consumption transcending border dimension, an individualistic person is hence more likely exhibit cosmopolitan consumption behaviours; which suggests a positive relationship. To test product involvement as a moderator of this relationship, the following hypothesis will be tested:

H3b: The positive relationship between individualism and COS will be moderated by product involvement.

PD relates to the degree to which an individual respects hierarchy. Individuals with lower levels of PD are more likely to challenge traditions and accept new perspectives. This suggests higher levels of COS, whereas individuals with higher levels of PD are often more likely prefer traditional notions and are more cautious towards foreign cultures which suggests a negative relationship. To test product involvement as a moderator of this relationship, the following hypothesis will be tested:

H3c: The negative relationship between power distance and COS will be moderated by product involvement.

Masculinity refers to specific types of gender-associated values. Past research suggests a negative relationship, as a lower level of masculinity is linked to more fluid gender roles. This can be in turn be linked to higher levels of open-mindedness towards differing perspectives. To test product involvement as a moderator of this relationship, 
the following hypothesis will be tested:

H3d: The negative relationship between masculinity and COS will be moderated by product involvement.

With the above hypotheses in mind, Figure 1 provides an overview of the full conceptual model and underlying research hypotheses.

Figure 1: Overall Model

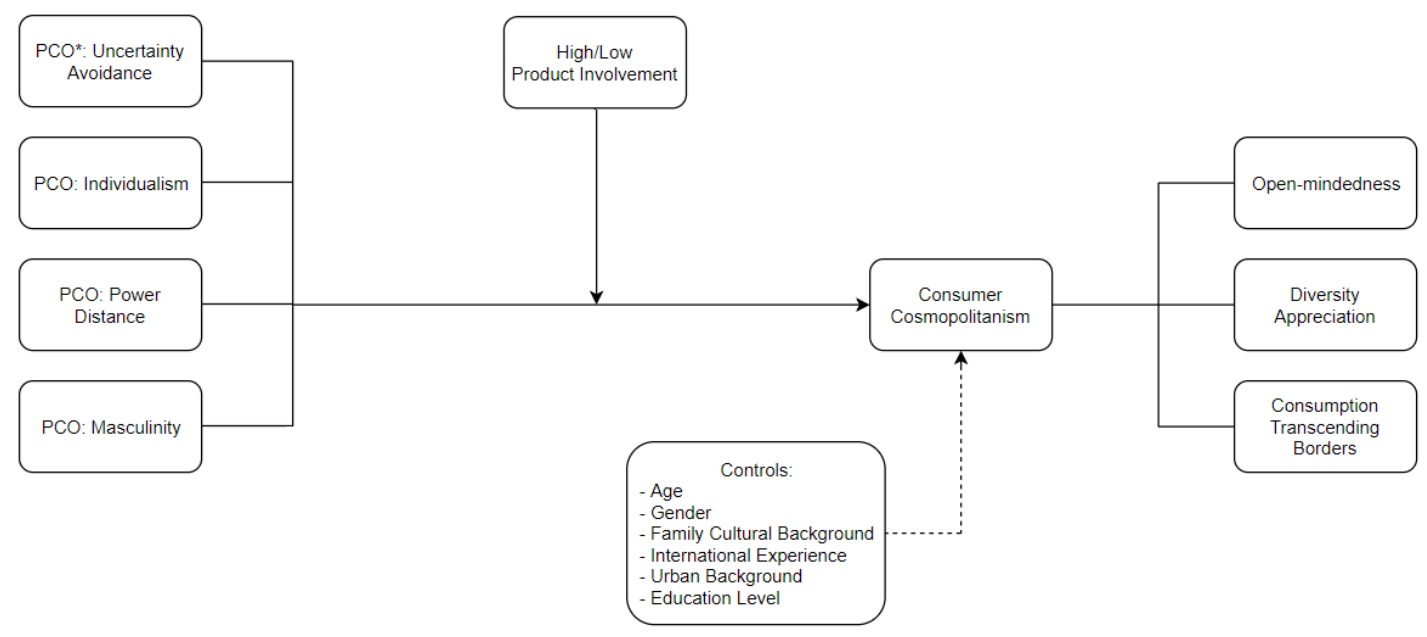

*PCO - Personal Cultural Orientation 


\section{Chapter 4: Data Analysis and Results}

\subsection{Data}

An English version of the questionnaire employed in the New Zealand study (See Appendix 1) was designed first. It subsequently provided the basis for the translation/back-translation procedure into Mandarin for the Taiwanese study. The questionnaire drew on cross-validated scales from the mainstream international business and marketing literature. Four aspects of individual-level culture values in the form of so-called Personal Culture Orientations (PCOs) were operationalized as 5-point Likert-type ordinal scales based on the survey instrument developed by Yoo et al. (2011), which is in turned based on Hofstede's national culture framework. They pertained to the cultural dimensions of (a) individualism, (b) uncertainty avoidance, (c) power distance and (d) masculinity. They are analogous to the original Hofstede national culture values' framework; but correspond to individual-level cultural orientations instead of national-level cultural dimensions as per development of the culture studies literature within the IB literature. Consumer cosmopolitanism (COS) was operationalized as a second-order three-dimensional reflective latent construct, as conceptualized and operationalized by the C-COSMO scale (Riefler \& Diamantopoulos, 2009) and empirically tested by Riefler et al. (2012) on a sample of Austrian consumers. It included the following three dimensions of consumer cosmopolitanism: (a) openmindedness, (b) diversity appreciation and (c) consumption transcending borders. Again, a 5-point Likert-type ordinal scale was employed. Product involvement was operationalized based on an adaptation of the scale by Mittal (1989), distinguishing between a low-involvement (i.e. bodywash) and high-involvement products (i.e. smart phone). A 5-point Likert-type ordinal scale was again employed. In addition, several control variables were also included to control for the respondents' cultural background 
and international experience (exposure). Similar control variables had been employed also in studies of consumer cosmopolitanism by Riefler et al. (2012) and Cleveland and Laroche (2012). Table 3 presents an overview of all the constructs within this study. The table further includes author references and the journal in which the scale was first published. It clearly shows that all scales were taken from high-quality and reputable international business and marketing journals. The table also includes an illustrative statement from the questionnaire for each construct and/or sub-dimension. 
Table 3: Overview of Constructs used and example statements

\begin{tabular}{|c|c|c|c|c|}
\hline Concept & Authors \& Journal & No. items & Type of Scale & Example Statement \\
\hline $\begin{array}{l}\text { C-COSMO Scale } \\
\text { (Cosmopolitanism) } \\
\text { - Open-mindedness } \\
\text { - Diversity appreciation } \\
\text { - Consumption transcending } \\
\text { borders }\end{array}$ & $\begin{array}{l}\text { Riefler, Diamantopoulos \& } \\
\text { Siguaw (2012) } \\
\text { Journal of International } \\
\text { Business Studies }\end{array}$ & 12 & $\begin{array}{l}\text { 5-Point Ordinal } \\
\text { Likert-type } \\
\text { scale }\end{array}$ & $\begin{array}{l}\text { - Open-mindedness } \\
\text { "I like having the opportunity to meet people from many different cultures." } \\
\text { - Diversity appreciation } \\
\text { "I enjoy being offered a wide range of products coming from various countries." } \\
\text { - Consumption transcending borders } \\
\text { "I like trying ordinal dishes from other countries." }\end{array}$ \\
\hline $\begin{array}{l}\text { CVSCALE } \\
\text { (Personal Cultural Orientations) } \\
\text { - Power Distance } \\
\text { - Uncertainty Avoidance } \\
\text { - Collectivism } \\
\text { - Masculinity }\end{array}$ & $\begin{array}{l}\text { Yoo, Donthu \& Lenartowicz } \\
\text { (2011) } \\
\text { Journal of International } \\
\text { Consumer Marketing }\end{array}$ & 19 & $\begin{array}{l}\text { 5-Point Ordinal } \\
\text { Likert-type } \\
\text { scale }\end{array}$ & $\begin{array}{l}\text { - Power Distance } \\
\text { "People in higher positions should make most decisions without consulting } \\
\text { people in lower positions." } \\
\text { - Uncertainty Avoidance } \\
\text { "It is important to closely follow instructions and procedures." } \\
\text { - Collectivism } \\
\text { "Individuals should stick with the group even through difficulties." } \\
\text { - Masculinity } \\
\text { "It is more important for men to have a professional career than it is for women." }\end{array}$ \\
\hline Product Involvement & $\begin{array}{l}\text { Mittal (1989) } \\
\text { Advances in Consumer } \\
\text { Research }\end{array}$ & $\begin{array}{c}10 \\
(5 \text { per } \\
\text { product })\end{array}$ & $\begin{array}{l}\text { 5-Point Ordinal } \\
\text { Likert-type } \\
\text { scale }\end{array}$ & "Which (Product) I buy matters a lot to me." \\
\hline Control Variable - Gender & & 1 & Nominal scale & "Your Gender:" \\
\hline Control Variable - Age & & 1 & Numeric & “Your Age:" \\
\hline
\end{tabular}




\begin{tabular}{|l|l|l|l|l|}
\hline $\begin{array}{l}\text { Control Variable - } \\
\text { Family Cultural Background }\end{array}$ & $\begin{array}{l}\text { Adapted from Cleveland \& } \\
\text { Laroche (2012) }\end{array}$ & 4 & $\begin{array}{c}\text { Nominal scale } \\
\text { Written Answer }\end{array}$ & "Do you come from a mixed-cultural family background?" \\
\hline $\begin{array}{l}\text { Control Variable - } \\
\text { International Experience }\end{array}$ & $\begin{array}{l}\text { Adapted from Riefler, } \\
\text { Diamantopoulos \& Siguaw } \\
(2012)\end{array}$ & 4 & $\begin{array}{l}\text { Nominal scale } \\
\text { Written Answer }\end{array}$ & $\begin{array}{l}\text { "Have you ever lived in another country (spent more than } 3 \text { months away from } \\
\text { home in anther country as a child, for study, travel and/or work, or simply } \\
\text { living? }\end{array}$ \\
\hline $\begin{array}{l}\text { Control Variable - } \\
\text { Education Level }\end{array}$ & $\begin{array}{l}\text { Adapted from Riefler, } \\
\text { Diamantopoulos \& Siguaw } \\
(2012)\end{array}$ & Ordinal scale & $\begin{array}{l}\text { Controlled for through matched sampling - selecting university students as } \\
\text { respondents. }\end{array}$ \\
\hline
\end{tabular}


Next, the questionnaire was translated into Mandarin and back-translated into English for the Taiwanese study, following the procedure outlined by Brislin (1970). The questionnaire was first translated by a Mandarin native speaker fluent in English. Then, the questionnaire was back-translated into English and checked for understanding and translation consistency. The back-translation process ensures measure equivalence between samples when different languages are used and is the most often utilized technique in cross-cultural research (Buil, de Chernatony \& Martinez, 2012). After back-translation, a few minor changes need to be made in the wording of the Chinese version of the questionnaire to ensure greater accuracy between the translation and back-translation. After checking for consistency and accuracy, the Mandarin translation was additionally double checked against another Mandarin version translation from a different study, which used the same scales and was provided to me by my supervisor (Ding, 2020). Since my research involved human subjects and primary data collection I also had to submit an ethics application to the Human Ethics Committee (HEC) at my University (VBS HEC Pipitea Committee). Based on initial screening, my application was classified as a B-type (low-risk) application. It was reviewed by a peer reviewer and subsequently processed by the HEC with some minor changes to the original application. After HEC approval, both the English and Mandarin versions of the questionnaire were pilot-tested on tentative samples of respondents in both countries to test for comprehension. No major issues were identified in the pilot testing phase. Therefore, I proceeded with data collection.

For data collection, both questionnaires were uploaded onto the online surveying platform Qualtrics. An anonymous, untraceable, and re-usable web link was generated, which was used to lead potential respondents to the information page of the study and 
an invitation for participation in the study. The information page highlighted the requirements for participants to ensure undesired respondents were not included in the sample (i.e. age and nationality criteria). The web link was distributed through a nonprobability convenience-based snowball sampling approach, by sending family members and friends information on the study with a web link to fill out the survey (if they fulfilled the requirements). These initial respondents were further instructed to pass on the request to any potential respondents they believed to be suitable for the study (e.g. snowball approach).

Given the comparative nature of the study across two countries and diverse cultural environments, a matched sampling framework was pursued, which is standard practice in such cross-cultural research (Minkov, 2013). Respondents were matched on key demographic characteristics, such as age, gender, education level and urban background - following previous comparative studies examining cross-cultural consumer behaviour (i.e. Raskovic et al., 2019; Raskovic et al., 2016) and research on consumer cosmopolitanism (Cleveland et al., 2011). Non-probability matched sampling is commonly employed in such comparative cross-cultural research, as it allows researchers to ensure that the observed differences are not caused by respondent characteristic/sample differences (Sin, Cheung \& Lee, 1999; Reynolds, Simintiras \& Diamantopoulos, 2003; Peterson \& Merunka, 2014). Although student samples have often been criticized for low generalizability (Bellow, Leung, Radebaugh, Tung \& van Witteloostunijn, 2009; Ford, 2016), this study addresses specifically the young-adult consumer demographic cohort. Thus, no generalizability was assumed with regards to the overall consumer population. In this regard, using students as representatives of the young-adult consumer demographic cohort was justified and met the sampling 
considerations by Reynolds et al. (2003). It is at this point also important to stress that we do not aim to make any generalizations of our findings to overall consumer populations in New Zealand and/or Taiwan, but simply compare a specific consumer generational cohort across two markets. This study focuses on consumer characteristics as drivers of consumption behaviours of young-adult consumer only. Given the scope of the research, university students are seen as reasonable representatives of this consumer demographic cohort (Xu et al., 2004; Raskovic et al., 2019). University students are also frequently employed in cross-cultural psychology studies; particularly when it comes to national culture research (Flere \& Lavric, 2008).

Both surveys were made available via Qualtrics on March 6 ${ }^{\text {th }}, 2019$ and were set to terminate response collection on April $20^{\text {th }}$ (open for 45 days). Reminders were sent out every fortnight and actual completion rate for the questionnaire was 35\% for the Taiwan sample and $17.5 \%$ for the New Zealand sample. In both countries, target samples of about 150 respondents were pursued, which could allow for subsequent Structural Equation Model (SEM) testing given the complexity of the tested models and appropriate item-sample ratios. The Taiwan sample quickly reached the target sample size, mostly due to having family and friends who are business students and professors at some universities in Taiwan. My supervisor further helped in data collection in Taiwan, by arranging the survey link to be sent to his colleagues at six different universities in Taiwan. The New Zealand sample progressed more slowly, despite increasing the frequency of reminders from fortnightly to weekly. It is because of this, that the initial online approach was supplemented also with paper-based questionnaires to ensure a satisfactory and comparable sample size was achieved in the end. I discuss this issue under the limitations' section of my study, but testing for significant 
differences between the on-line version and the paper-based version of the questionnaires did not reveal any major effect size difference issues (presented in the Results'section).

For the paper-based data collection in New Zealand, questionnaires were re-formatted and printed to ensure easier comprehension and greater readability. Paper questionnaires were given out to university students at two campuses of Victoria University of Wellington (Kelburn and Pipitea campuses). Students were approached and briefed on the topic of the study, participant requirements, and estimated time to complete a survey. This screening was carried out to ensure students willing to participate met the requirements and would have sufficient time to complete the survey. Times chosen for the paper-based mode of data collection were every second day over a two-week period from April $1^{\text {st }}$ to April $12^{\text {th }}$ (to ensure each day of the week is covered) at 10:00am, 1:00pm, and 4:00pm for an hour each to reach a wider number of students coming into the university at different times. A few paper-based questionnaires were further collected from students attending lectures of IBUS 212 (International Management) by my supervisor. Overall, the New Zealand sample consisted of 41 online and 109 offline (paper-based) responses, whilst the Taiwan sample had 192 online responses. Some of them were incomplete and were subsequently removed for further analysis.

\subsection{Methodology}

The main method of analysis employed within this research is Structural Equation Modelling (SEM), variance-based SEM to be exact. I have decided to use this method, despite being unfamiliar with it, since it has been the most frequently employed method 
in the literature on consumer cosmopolitanism and generally within the international business/marketing disciplines. SEM is a method of analysing data captured by socalled latent constructs with complex structural models to test for potential theoretical relations (Martinez-Lopez, Gazquez-Abad \& Sousa, 2013). Its ability for path analysis, synthesis of latent variables and measurement models, and methods to estimate structural model parameters makes it a powerful and preferred theory-testing tool; employed frequently within marketing and international business studies (Steenkamp and Baumgartner, 2000; Shook, Ketchen, Hult \& Kacmar, 2004; Martinez-Lopez et al., 2013). Due to the cross-sectional, multidimensional, and latent nature of the constructs in this study, SEM was established as the most suitable method of data analysis and model testing (Steenkamp and Baumgartner, 2000; Martinez-Lopez et al., 2013). The application of SEM is also consistent with research practice within the marketing and international business literatures, especially given the scope of the research focusing on characteristics of individuals and their psychographic determinants (i.e. Riefler et al., 2012; Zeugner-Roth et al., 2015). As the method was previously unfamiliar to me, I had to read quite a lot about it and closely work with my supervisor to understand its application.

One type of SEM that was favoured in past studies is the so-called covariance-based SEM (CB-SEM) (Hair, Risher, Sarstedt \& Ringle, 2019). However, in recent years, around 2010, a variance-based Partial Least Squares SEM (PLS-SEM) has become an increasingly popular alternative, due to its ability to "estimate complex models with many constructs, indicator variables and structural paths without imposing distributional assumptions on the data" (Hair et al., 2019, p. 3). Unlike CB-SEM, PLSSEM emphasizes prediction and exploration. It is also more appropriate for research 
contexts based on so-called "soft theory" and explaining more complex models using smaller sample sizes (Richter, Sinkovics, Ringle \& Schlagel, 2016, p. 378). PLS-SEM focuses on a causal-predictive approach which is more suitable for estimating statistical models (Hair et al., 2019; Hair, Sarstedt, Ringle \& Mena, 2012). Wetzels, OdekerkenSchröder \& van Oppen (2009, p. 180) best summarized PLS-SEM as "path modelling [which] allows for the conceptualization of a hierarchical model through the repeated use of manifest variables". While having several drawbacks compared to CB-SEM, particularly when it comes to appropriate global optimization criteria and goodness of fit statistics (Hair et al., 2012), PLS-SEM has been shown to be particularly appropriate in testing an already known structural model based on appropriate literature and estimating its predictive power (Hair et al., 2019). It is also seen as an increasingly popular model testing methodology within the dynamic international business discipline, often dealing with complex phenomena (Richter et al., 2016).

\subsubsection{Reliability and Validity}

For the Taiwan sample, composite reliability (CR) (as a measure of internal reliability) was estimated to be acceptable (above 0.7) (Hair et al., 2019) for all constructs in the study. It was calculated in the statistical software package smartPLS, which I used for PLS-SEM. CR ranged between 0.87 for COS-Diversity appreciation, 0.88 for PCOIndividualism, 0.88 for PCO-Power Distance, 0.9 for COS-Open-mindedness, and 0.9 for PCO-Uncertainty Avoidance. CR was also acceptable for all constructs in the New Zealand sample, ranging between 0.87 for PCO-Power Distance, 0.88 for PCOUncertainty Avoidance, 0.9 for COS-Diversity appreciation, 0.91 for PCOIndividualism, and 0.92 for COS-Open-mindedness. In terms of convergent validity, based on the so-called Average Variance Extracted (AVE) measure, this too was 
estimated to be acceptable (above the 0.5 reference value) (Hair et al., 2019) for all constructs in the Taiwan sample. AVE ranged from 0.63 for PCO-Uncertainty Avoidance, 0.66 for PCO-Individualism, 0.68 for COS-Open mindedness, 0.7 for COSDiversity appreciation, and 0.71 for PCO-Power Distance. For the New Zealand sample, AVE was again acceptable for all constructs, 0.68 for PCO-Individualism, 0.73 for COS-Open mindedness, 0.74 for COS-Diversity appreciation, 0.78 for PCO-Power Distance, and 0.79 for PCO-Uncertainty Avoidance. This study also employed two 5item scales by Mittal (1989) to measure the level of product involvement. It distinguished between introducing a high-involvement (smart phone) and a lowinvolvement product (body wash); as product involvement is likely to affect various aspects of consumer behaviours, such as the complexity of purchase decisions (Houston \& Rothschild, 1978). In the New Zealand sample, CR was acceptable for both high and low product involvement ( 0.93 and 0.92 respectively). AVE statistics were also acceptable at 0.7 and 0.72 respectively. The same was also true for the Taiwan sample, with CR statistics of 0.87 and 0.93 for high and low involvement respectively. AVE statistics were at 0.57 and 0.72 for high and low involvement respectively. Later on, when presenting the construct correlation matrix, I will also show that the criteria for so-called discriminant validity have also been met (square roots of AVE on the correlation matrix diagonal were higher than pair-wise correlation coefficients between individual constructs in the model).

\subsection{Results}

As mentioned, the constructs tested in my study were all reflective latent constructs, measured with multiple items. The model was tested in PLS-SEM using the statistical software smartPLS (version 3) based on the free 30-day trial version. In this section, I 
first present basic descriptive statistics from the Taiwan and New Zealand country samples. Then, I present testing differences between the paper-based and online collection methods within the New Zealand sample, followed by a discussion of the similarities and differences between the New Zealand and Taiwan country samples. The measurement model testing process is discussed next, beginning with testing COS as a second-order reflective latent construct (as per Hair et al., 2019). This is followed by identifying and removing low-loading indicators also for other constructs in order to test the final measurement model. Model reliability and validity are presented next, followed by the results of structural model testing and estimation of the path coefficients based on a bootstrapping approach suggested by Hair et al. (2019). I conclude this section with a discussion of the results related to my research hypotheses testing and provide a final summary.

\subsubsection{Survey instrument and general descriptive statistics}

Table 4 provides an overview of the (reflective) latent constructs in my model and their original indicators for the two country samples within the first stage of measurement model testing. This is accompanied by an overview of the mean scores (measured on 5-point ordinal Likert-type scales) and corresponding standard deviations. As we can see from the table, mean scores for COS in both samples are quite high and around the 4.0 range, which is consistent with previous literature on consumer cosmopolitanism and young-adult consumers being seen as the "archetypal global segment" (Sobol et al., 2018, p. 342) at the forefront of globalization (Raskovic et al., 2016). The only exception is the item "COS8" (Always buying the same local products becomes boring over time), where both samples displayed a much lower score in comparison to other COS indicators. This may suggest that the relationship between level of consumer 
ethnocentrism and COS may be less a trade-off than suggested by existing literature; at least among young-adult consumers in my study in both countries. However, it may perhaps have less to do with the actual origin of the product (related to consumer ethnocentrism), but more with the habitual aspect of such purchases, since young-adult consumers are still in the processes of learning and exploration, often seeking novelty and excitement (Raskovic et al., 2016; Raskovic et al., 2019). Although mean scores for COS were quite high in both country samples, the New Zealand sample displays slightly higher mean scores compared to the Taiwan sample in almost all instances. However, the effect sizes of these differences are either low, or moderate at best (based on Cohen's d effect size statistic).

Both samples displayed very low mean scores for power distance, which suggests respondents in both samples are not accepting of hierarchies and power discrepancies; as expected for the young generation. Uncertainty avoidance mean scores were mostly in the 3.5-4.0 range for both samples, which suggests respondents from both samples are not accepting of ambiguity either. Individualism mean scores were mostly in the 2.5-3.0 range for the New Zealand sample and 3.5 range for the Taiwan sample. Higher scores for this construct correspond to more collectivistic behaviours, which suggests the respondents in the Taiwan sample were more collectivistic in their personal orientations, whilst the New Zealand were more individualistic. This seems to be consistent with existing evidence from Hofstede's work on national cultures, where Taiwan displays a low individualism score of just 17 and New Zealand a high individual score of 79 (Hofstede, 2019). A similar difference can be observed for masculinity, where mean scores were around the 1.5 range for the New Zealand sample and around 2.5-range for the Taiwan sample. This is somewhat opposite to national value scores 
for masculinity within Hofstede's framework, where New Zealand scored slightly higher (58) than Taiwan (45) (Hofstede, 2019). I would, however, like to discuss this particular dimension when it comes to the operationalization within the Yoo et al. (2011) scale. While Hofstede's conceptualization of masculinity and femininity at the national culture level relates to the prevalence of masculine values (i.e. power, status, achievement) vs. more feminine values (i.e. family, solidarity etc.), the conceptualization and operationalization of masculinity at the individual level by Yoo et al. (2011) relates more to gender equality (position of women). Such an operationalization seems to be more consistent with the national culture dimension of gender egalitarianism within the GLOBE project study (House et al., 2004). 
Table 4: Overview of constructs and corresponding indicators with means and standard deviations for the two country samples

\begin{tabular}{|c|c|c|c|c|c|c|}
\hline \multicolumn{2}{|c|}{ Constructs } & $\begin{array}{l}\text { Indicators (based on 5-point ordinal Likert-type scale from 1-Strongly disagree to 5-Strongly } \\
\text { agree) }\end{array}$ & \multirow{2}{*}{$\begin{array}{l}\mathrm{NZ} \\
\text { Mean } \\
4.36\end{array}$} & \multirow{2}{*}{$\begin{array}{l}\text { NZ } \\
\text { S.D. } \\
0.76\end{array}$} & \multirow{2}{*}{$\begin{array}{l}\text { TWN } \\
\text { Mean } \\
4.15\end{array}$} & \multirow{2}{*}{$\begin{array}{l}\text { TWN } \\
\text { S.D. } \\
0.72\end{array}$} \\
\hline Consumer & Open- & COS1: When traveling, I make a conscious effort to get in touch with the local culture and & & & & \\
\hline \multirow{13}{*}{$\begin{array}{l}\text { Cosmopolitanism. } \\
\text { (Riefler et al., 2012) }\end{array}$} & mindedness. & traditions. & & & & \\
\hline & & COS2: I like having the opportunity to meet people from many different countries. & 4.37 & 0.69 & 3.98 & 0.83 \\
\hline & & COS3: I like to have contact with people from different cultures. & 4.49 & 0.66 & 4.09 & 0.82 \\
\hline & & COS4: I have got a real interest in other countries. & 4.41 & 0.68 & 4.32 & 0.69 \\
\hline & Diversity & COS5: Having access to products coming from many different countries is valuable to me. & 4.18 & 0.93 & 4.10 & 0.86 \\
\hline & Appreciation. & COS6: The availability of foreign products in the domestic market provides valuable & 4.52 & 0.59 & 4.20 & 0.67 \\
\hline & & diversity. & & & & \\
\hline & & COS7: I enjoy being offered a wide range of products coming from various countries. & 4.44 & 0.77 & 4.10 & 0.80 \\
\hline & & COS8: Always buying the same local products becomes boring over time. & 2.91 & 1.15 & 3.03 & 1.11 \\
\hline & Consumption & COS9: I like watching movies from different countries. & 4.09 & 0.80 & 4.08 & 0.81 \\
\hline & transcending & COS10: I like listening to music of other cultures. & 4.13 & 0.95 & 4.07 & 0.84 \\
\hline & borders. & COS11: I like trying original dishes from other countries. & 4.69 & 0.62 & 4.21 & 0.76 \\
\hline & & COS12: I like trying out things that are consumed elsewhere in the world. & 4.55 & 0.72 & 4.09 & 0.73 \\
\hline \multirow{5}{*}{$\begin{array}{l}\text { Personal Cultural } \\
\text { Orientation. } \\
\text { (Yoo et al., 2011) }\end{array}$} & Power Distance. & PCO1: People in higher positions should make most decisions without consulting people in & 2.11 & 1.07 & 1.80 & 0.93 \\
\hline & & lower positions. & & & & \\
\hline & & PCO2: People in higher positions should not ask the opinions of people in lower positions & 1.81 & 0.91 & 1.87 & 0.93 \\
\hline & & too frequently. & & & & \\
\hline & & PCO3: People in higher positions should avoid social interaction with people in lower & 1.31 & 0.60 & 1.57 & 0.82 \\
\hline
\end{tabular}




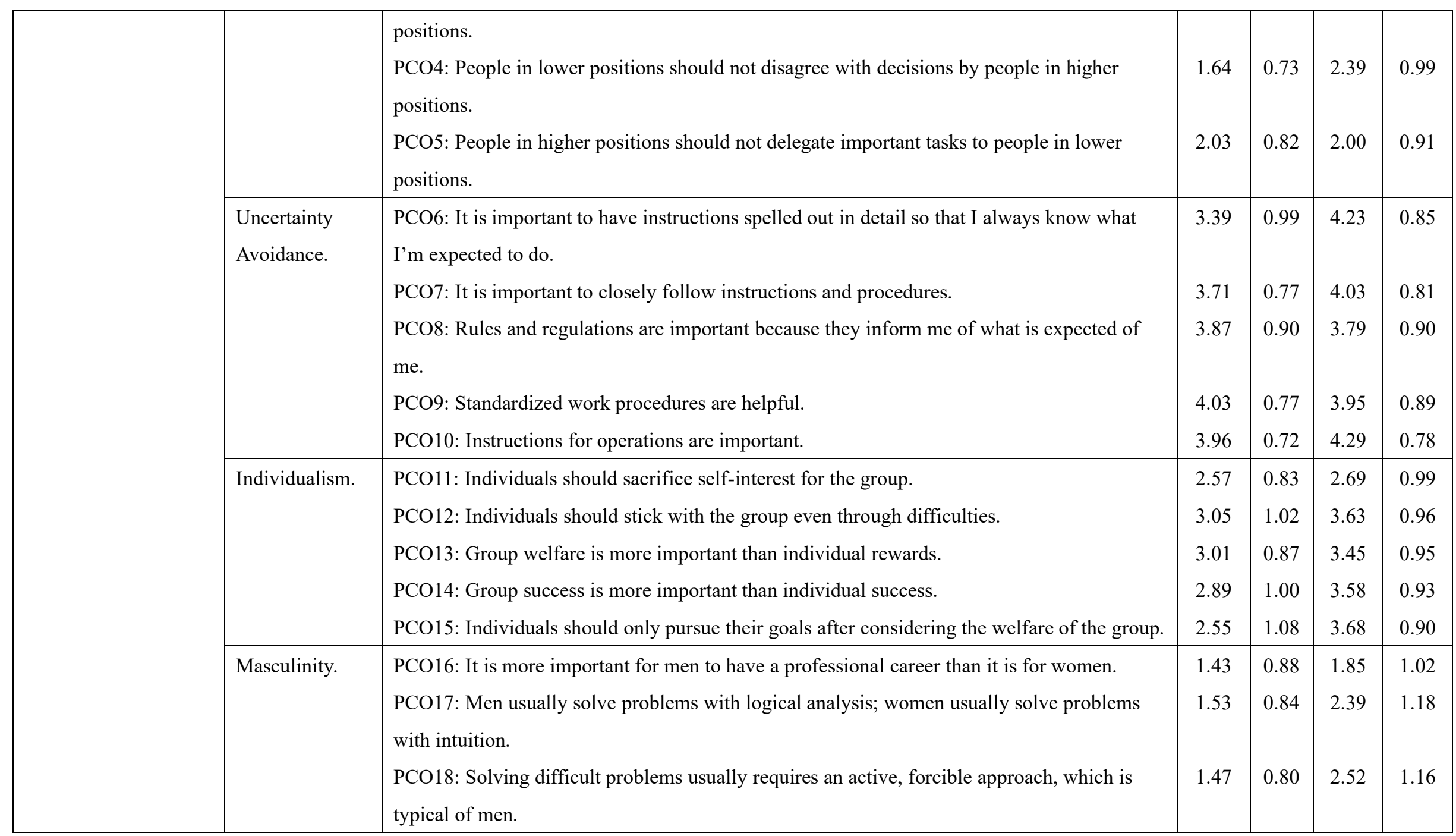




\begin{tabular}{|c|c|c|c|c|c|c|}
\hline & & PCO19: There are some jobs that a man can always do better than a woman. & 1.89 & 1.25 & 2.94 & 1.2 \\
\hline \multirow{10}{*}{$\begin{array}{l}\text { Level of Product } \\
\text { Involvement. } \\
\text { (Mittal, 1989) }\end{array}$} & \multirow{5}{*}{$\begin{array}{l}\text { Low } \\
\text { Involvement } \\
\text { (product). }\end{array}$} & MOD1: I have a strong interest in bodywash. & 3.05 & 1.10 & 3.17 & 1.01 \\
\hline & & MOD2: Bodywash is very important to me. & 3.45 & 1.09 & 3.14 & 1.06 \\
\hline & & MOD3: I would choose my bodywash very carefully. & 2.99 & 1.23 & 3.01 & 1.09 \\
\hline & & MOD4: Choosing bodywash is an important decision for me. & 2.58 & 1.27 & 2.65 & 1.09 \\
\hline & & MOD5: Which bodywash I buy matters a lot to me. & 2.71 & 1.33 & 2.80 & 1.13 \\
\hline & \multirow{5}{*}{$\begin{array}{l}\text { High } \\
\text { Involvement } \\
\text { (product). }\end{array}$} & MOD6: I have a strong interest in smart phones. & 3.64 & 1.22 & 3.78 & 0.92 \\
\hline & & MOD7: A smart phone is very important to me. & 4.19 & 1.09 & 4.22 & 0.85 \\
\hline & & MOD8: I would choose my smart phone very carefully. & 4.02 & 1.17 & 4.05 & 0.92 \\
\hline & & MOD9: Choosing a smart phone is an important decision for me. & 4.01 & 1.13 & 4.16 & 0.86 \\
\hline & & MOD10: Which smart phone I buy matters a lot to me. & 3.79 & 1.28 & 3.96 & 0.91 \\
\hline
\end{tabular}




\subsubsection{Testing for effect size differences in data collection modes in New Zealand}

Due to different modes of data collection within the New Zealand study (on-line and paper-based data collection), I wanted to test if there were any significant differences in the results from the two different data collection modes. Table 5 presents mean scores and standard deviations at the level of each individual variable (corresponding to an individual item of a reflective latent construct - i.e. COS1 corresponds to the first item of the consumer cosmopolitan construct; please refer again back to Table 4). To assess the difference in the mean scores, I decided to use so-called power analysis, where I calculated the actual differences in the effect sizes using Cohen's d effect size statistic. Given the small nature of both samples and the imbalance between the size of the online sub-sample and the much larger paper-based sample, calculation of effect size statistics is statistically more appropriate than running a simple independent samples' t-test (Cohen, 1988; Cohen, 1992). In terms of the reference values for Cohen's d statistic, the coefficient ranges between 0 (no effect size) to 1 (large effect size). According to Cohen (1988), the following guidelines for effect sizes apply: $d<0.3$ (small effect), $d$ $<0.5$ (moderate effect), $\mathrm{d}<0.8$ (large effect). As we can see from Table 5, there are only three indicators out of all forty-one that displayed effect sizes above 0.5 (and were additionally related also to different sub-dimensions of the construct). This suggests overall effect size differences were quite small. This means that the difference between the paper-based and on-line modes of data collection is rather minimal and that the mode of data collection within the New Zealand study did not affect the results in most cases. 
Table 5: Online vs. Paper-based Mean Score Differences within the NZ Sample

\begin{tabular}{|c|c|c|c|c|c|c|}
\hline Construct & $\begin{array}{l}\text { Online } \\
\text { Mean }\end{array}$ & $\begin{array}{l}\text { Paper } \\
\text { Mean }\end{array}$ & $\begin{array}{c}\text { Mean } \\
\text { Difference }\end{array}$ & $\begin{array}{l}\text { Online } \\
\text { S.D. }\end{array}$ & $\begin{array}{l}\text { Paper } \\
\text { S.D. }\end{array}$ & $\begin{array}{c}\text { Cohen's d } \\
\text { Statistic }\end{array}$ \\
\hline COS1 & 2.1 & 2.15 & 0.05 & 1.05 & 1.07 & 0.042 \\
\hline COS2 & 1.73 & 2 & 0.27 & 1.04 & 0.84 & 0.281 \\
\hline COS3 & 1.39 & 1.12 & 0.26 & 0.33 & 0.66 & 0.528 \\
\hline COS4 & 1.66 & 1.59 & 0.08 & 0.83 & 0.69 & 0.098 \\
\hline COS5 & 1.96 & 2.2 & 0.23 & 0.89 & 0.78 & 0.276 \\
\hline COS6 & 3.27 & 3.73 & 0.47 & 0.94 & 0.97 & 0.483 \\
\hline COS7 & 3.7 & 3.76 & 0.06 & 0.9 & 0.71 & 0.072 \\
\hline COS8 & 3.79 & 4.07 & 0.28 & 0.97 & 0.86 & 0.308 \\
\hline COS9 & 4.09 & 3.85 & 0.24 & 0.9 & 0.7 & 0.296 \\
\hline COS10 & 3.8 & 4.39 & 0.59 & 0.62 & 0.69 & 0.898 \\
\hline COS11 & 2.56 & 2.59 & 0.03 & 0.85 & 0.82 & 0.031 \\
\hline COS12 & 2.99 & 3.22 & 0.23 & 0.9 & 1.05 & 0.233 \\
\hline PCO1 & 2.94 & 3.22 & 0.28 & 0.95 & 0.83 & 0.317 \\
\hline $\mathrm{PCO} 2$ & 2.8 & 3.12 & 0.32 & 1.02 & 0.98 & 0.321 \\
\hline PCO3 & 2.45 & 2.8 & 0.36 & 1.13 & 1.04 & 0.324 \\
\hline PCO4 & 1.38 & 1.56 & 0.18 & 1.19 & 0.73 & 0.191 \\
\hline PCO5 & 1.48 & 1.68 & 0.21 & 0.87 & 0.82 & 0.242 \\
\hline PCO6 & 1.42 & 1.61 & 0.19 & 0.85 & 0.77 & 0.230 \\
\hline PCO7 & 1.61 & 2.63 & 1.03 & 1.57 & 0.97 & 0.802 \\
\hline PCO8 & 4.43 & 4.17 & 0.26 & 0.91 & 0.68 & 0.325 \\
\hline PCO9 & 4.35 & 4.41 & 0.07 & 0.88 & 0.6 & 0.088 \\
\hline PCO10 & 4.47 & 4.56 & 0.09 & 0.7 & 0.64 & 0.137 \\
\hline PCO11 & 4.37 & 4.54 & 0.17 & 0.67 & 0.67 & 0.251 \\
\hline PCO12 & 4.17 & 4.2 & 0.02 & 0.97 & 0.92 & 0.022 \\
\hline PCO13 & 4.54 & 4.46 & 0.08 & 0.63 & 0.57 & 0.129 \\
\hline PCO14 & 4.44 & 4.44 & 0 & 0.73 & 0.78 & 0.002 \\
\hline PCO15 & 2.9 & 2.93 & 0.03 & 1.11 & 1.16 & 0.024 \\
\hline PCO16 & 4.09 & 4.1 & 0.01 & 0.91 & 0.75 & 0.007 \\
\hline PCO17 & 4.18 & 3.98 & 0.21 & 1.02 & 0.92 & 0.212 \\
\hline PCO18 & 4.65 & 4.8 & 0.15 & 0.45 & 0.67 & 0.271 \\
\hline PCO19 & 4.52 & 4.61 & 0.09 & 0.66 & 0.74 & 0.123 \\
\hline MOD1 & 3.03 & 3.12 & 0.09 & 0.97 & 1.15 & 0.089 \\
\hline MOD2 & 3.44 & 3.46 & 0.02 & 1.01 & 1.12 & 0.021 \\
\hline MOD3 & 2.92 & 3.2 & 0.28 & 1.35 & 1.17 & 0.218 \\
\hline
\end{tabular}




\begin{tabular}{|l|l|l|l|l|l|l|}
\hline MOD4 & 2.53 & 2.71 & 0.18 & 1.31 & 1.25 & 0.135 \\
MOD5 & 2.69 & 2.76 & 0.07 & 1.38 & 1.32 & 0.050 \\
MOD6 & 3.68 & 3.54 & 0.14 & 1.19 & 1.23 & 0.117 \\
MOD7 & 4.2 & 4.15 & 0.06 & 1.03 & 1.12 & 0.051 \\
MOD8 & 4.05 & 3.95 & 0.09 & 1.21 & 1.15 & 0.079 \\
MOD9 & 4.03 & 3.95 & 0.08 & 1.17 & 1.11 & 0.066 \\
MOD10 & 3.76 & 3.88 & 0.12 & 1.19 & 1.31 & 0.092 \\
\hline
\end{tabular}

Note: Cohen's d statistic values above 0.5 (moderate effect size) marked in bold.

\subsubsection{Sample Characteristics}

Table 6 summarizes key descriptive statistics of the New Zealand and Taiwanese country samples, which show a high level of sample matching, as per our sampling criteria and approach. The two country samples are very similar on key demographic and international experience variables, which we employed as subsequent control variables. High levels of similarities are especially shown in the male/female ratio and urban/city-living ratio. Both samples contained a somewhat higher share of female respondents (60\% range) and respondents from predominantly urban areas (above $80 \%$ ).

Various international background indicators were adapted from Cleveland and Laroche (2012) and Riefler et al. (2012). They were subsequently tested as control variables, since they may significantly impact consumer cosmopolitanism according to so-called Contact theory (Kjelgaard \& Askergaard, 2006). In terms of international experience, some levels of similarities do exist, but on average, the New Zealand sample shows higher levels of international experience compared to the Taiwan sample. I believe this is also consistent with the overall characteristics of the New Zealand population (also in terms of country migration levels highlighted in Table 2). 
Table 6: Key sample characteristics for New Zealand and Taiwan samples

\begin{tabular}{|l|c|c|}
\hline & New Zealand & Taiwan \\
\hline Sample size (n) & 150 & 192 \\
\hline$\%$ of female respondents & $60 \%$ & $60.4 \%$ \\
\hline$\%$ of urban/city & $97.3 \%$ & $81.8 \%$ \\
\hline$\%$ of mixed-cultural family background & $12 \%$ & $8.9 \%$ \\
\hline$\%$ of non-native born & $10.7 \%$ & $2.1 \%$ \\
\hline$\%$ spent over 3 months overseas (Work, study etc.) & $46.7 \%$ & $17.2 \%$ \\
\hline
\end{tabular}

\subsubsection{Testing consumer cosmopolitanism as a second-order latent}

\section{construct}

Given that Riefler and Diamantopoulos (2009) conceptualized consumer cosmopolitanism (COS) as a second-order reflective construct comprising of three dimensions (open-mindedness, diversity appreciation, consumption transcending borders), I first wanted to test if COS can indeed be tested as a second-order reflective latent construct. This was also empirically cross-validated later by Riefler et al. (2012); albeit on a diverse sample of consumers in terms of age in Austria. I began by testing COS as a second-order latent reflective construct, as per the procedure outlined by Hair et al. (2019). Figure 2 below illustrates this testing process.

\section{Figure 2: Testing COS as a second-order construct}

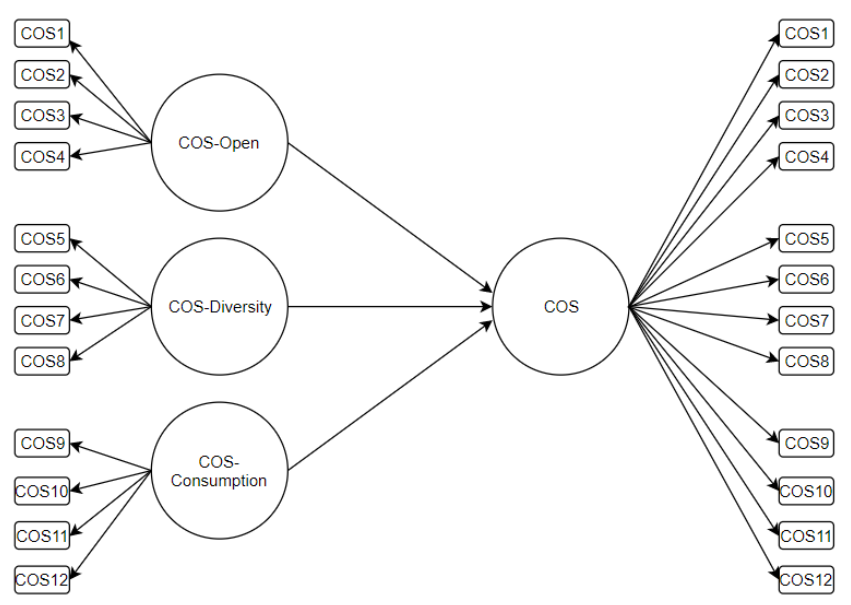


In the New Zealand sample, only one indicator (COS8) displayed a factor loading below the recommended threshold of 0.5 (Hair et al., 2019; Hullan, 1999) at 0.264 among the first eight items corresponding to open-mindedness and diversity appreciation. This item was subsequently removed. However, with regards to the third dimensions (COS-Consumption transcending borders), only one indicator displayed acceptable factor loadings above the recommended threshold value of 0.5 (Hair et al., 2019). As a result, this sub-dimension of the COS construct had to be omitted from subsequent analysis, due to measurement model issues. Thus, COS could not be tested as a three-dimensional second-order reflective latent construct, as conceptualized by Riefler and Diamantopoulos (2009) and empirically cross-validated by Riefler et al. (2012) on a sample of consumer of different ages in Austria.

Upon further consideration, I believe this may well be a result of the specific nature of this particular consumer demographic cohort, where cross-border consumption may not be determined by one's cosmopolitanism. Consumers in this age cohort may also be unaware/not understand where the product actually comes from. Once the indicators with the acceptable loadings were tested, as per Hair et al. (2019), I continued with estimating the reliability and validity of the two sub-dimensions of COS, which I treated as independent endogenous reflective constructs. The reasons for this was due to validity issues, as discussed in the next section.

Both the first and the second test results for the New Zealand sample can be found in Table 7. Following the approach outlined by Hair, Sarstedt, Ringle, and Gudergan (2018), the AVE value for COS as a two-dimension second-order reflective latent construct was well below the 0.5 threshold value at 0.347 . This pointed to a convergent 
validity issue (Hair et al., 2019). As a result, COS could not be treated even as a twodimensional second-order reflective latent construct. Instead, the two dimensions (open-mindedness, diversity appreciation) were treated as independent endogenous reflective constructs. This result is also consistent with some other studies on youngadult consumers, where COS could also not be established as a second-order construct (see Ding et al., 2020).

Table 7: Testing COS as Second-Order Construct within the NZ Sample

\begin{tabular}{|c|c|c|c|}
\hline Test & Construct & Indicator & Factor Loading \\
\hline \multirow{12}{*}{$\begin{array}{l}\text { First test with all } \\
\text { indicators }\end{array}$} & \multirow{4}{*}{$\begin{array}{l}\text { COS-Open-Mindedness } \\
\text { (COS-Open) }\end{array}$} & COS1 & 0.567 \\
\hline & & COS2 & 0.863 \\
\hline & & COS3 & 0.869 \\
\hline & & COS4 & 0.872 \\
\hline & \multirow{4}{*}{$\begin{array}{l}\text { COS-Diversity Appreciation } \\
\text { (COS-Diversity) }\end{array}$} & COS5 & 0.824 \\
\hline & & COS6 & 0.704 \\
\hline & & COS7 & 0.766 \\
\hline & & COS8 & $0.264 *$ \\
\hline & \multirow{4}{*}{$\begin{array}{l}\text { COS-Consumption Transcending } \\
\text { Borders } \\
\text { (COS-Consumption) }\end{array}$} & COS9 & $0.323 *$ \\
\hline & & COS10 & $-0.102 *$ \\
\hline & & $\cos 11$ & $0.443 *$ \\
\hline & & COS12 & 0.804 \\
\hline \multirow{6}{*}{$\begin{array}{l}\text { Second test after } \\
\text { removing low- } \\
\text { loading } \\
\text { indicators }\end{array}$} & \multirow[t]{3}{*}{ COS-Open mindedness } & $\operatorname{COS} 2$ & 0.799 \\
\hline & & COS3 & 0.804 \\
\hline & & COS4 & 0.841 \\
\hline & \multirow[t]{3}{*}{ COS-Diversity Appreciation } & COS5 & 0.819 \\
\hline & & COS6 & 0.827 \\
\hline & & COS7 & 0.709 \\
\hline
\end{tabular}

Note: Omitted items due to unsatisfactory factor loadings (below 0.5 ) shown in Italic and marked by *.

The same sequence of testing was then carried out for the Taiwan sample and can be seen below in Table 8. Similarly, COS8 also had to be removed due to a low factor loading and COS-Consumption could not be treated as a sub-dimension of COS as a 
second-order reflective latent construct. Thus, consumption across borders was also removed, like in the case of the New Zealand sample. A summary of both types of tests on the Taiwan sample can be found below in Table 8. Following the guidelines for testing second-order reflective constructs within PLS-SEM (Hair et al., 2019), the two remaining sub-dimensions (open-mindedness, diversity appreciation) could also not be treated as part of a common second-order construct, as the convergent validity criterion was again not met (AVE was 0.396 and below the 0.5 threshold value). This result indicates that in the Taiwan sample, COS-Open and COS-Diversity also needed to be treated as two separate independent endogenous constructs.

Table 8: Testing COS as Second-Order Construct within the TWN Sample

\begin{tabular}{|c|c|c|c|}
\hline Test No. & Construct & Indicator & Outer Loading \\
\hline \multirow{12}{*}{$\begin{array}{l}\text { First test with all } \\
\text { indicators }\end{array}$} & \multirow{4}{*}{$\begin{array}{l}\text { COS-Open-Mindedness } \\
\text { (COS-Open) }\end{array}$} & COS1 & 0.750 \\
\hline & & $\operatorname{COS} 2$ & 0.755 \\
\hline & & COS3 & 0.771 \\
\hline & & COS4 & 0.768 \\
\hline & \multirow{4}{*}{$\begin{array}{l}\text { COS-Diversity Appreciation } \\
\text { (COS-Diversity) }\end{array}$} & COS5 & 0.723 \\
\hline & & COS6 & 0.754 \\
\hline & & COS7 & 0.747 \\
\hline & & COS8 & $0.288 *$ \\
\hline & \multirow{4}{*}{$\begin{array}{l}\text { COS-Consumption Transcending } \\
\text { Borders } \\
\text { (COS-Consumption) }\end{array}$} & COS9 & $0.463 *$ \\
\hline & & COS10 & $0.378 *$ \\
\hline & & COS11 & $0.421 *$ \\
\hline & & COS12 & 0.709 \\
\hline \multirow{7}{*}{$\begin{array}{l}\text { Second test after } \\
\text { removing low- } \\
\text { loading indicators }\end{array}$} & \multirow[t]{4}{*}{ COS-Open-mindedness } & COS1 & 0.739 \\
\hline & & COS2 & 0.770 \\
\hline & & COS3 & 0.797 \\
\hline & & COS4 & 0.742 \\
\hline & \multirow[t]{3}{*}{ COS-Diversity Appreciation } & COS5 & 0.723 \\
\hline & & COS6 & 0.746 \\
\hline & & COS7 & 0.755 \\
\hline
\end{tabular}

Note: Omitted items due to unsatisfactory factor loadings (below 0.5) shown in Italic and marked by *. 


\subsubsection{Measurement Model Testing}

After not being able to confirm $\operatorname{COS}$ as a second-order reflective latent construct, I turned my attention to testing the full measurement model related to my conceptual model. Table 9 and 10 displays the factor loadings for each indicator, as well as the composite reliability (CR) and convergent validity (AVE) for each construct in both the New Zealand and Taiwan studies respectively. The CR value tests for reliability, where constructs with CR above the reference value of 0.7 are considered to be internally reliable (Hair et al., 2019). The AVE value tests for convergent validity, where AVE values above the reference value of 0.5 suggests convergent validity can be established (Hair et al., 2019). Goodness-of-fit statistics were unsatisfactory for a complete model with all original items for both samples, which is typical for initial measurement model testing with all indicators. For the New Zealand sample, normed fit index (NFI) values were 0.755 , Chi-Square was 926.546 and standardized root mean squared residual (SRMR) was 0.124. The latter is seen as the key goodness of fit statistic and was well above the 0.08 threshold value suggested by Hair et al. (2019). This indicated an unsatisfactory measurement model fit. For the Taiwan sample, NFI values were 0.170 , Chi-Square was 3108.835 and SRMR stood at 0.081, which again indicated unsatisfactory model fit. 
Table 9: Measurement Model Testing (Complete Data) for New Zealand Sample

\begin{tabular}{|c|c|c|c|}
\hline Sample & Construct & Indicator & Loading \\
\hline \multirow{35}{*}{ NZ } & PCO-Power Distance & PCO1 & $0.312 *$ \\
\hline & (PCO-PD) & $\mathrm{PCO} 2$ & 0.982 \\
\hline & Composite Reliability (CR): 0.575 & PCO3 & $0.269 *$ \\
\hline & \multirow[t]{2}{*}{ AVE: 0.336} & PCO4 & 0.720 \\
\hline & & PCO5 & $-0.162 *$ \\
\hline & PCO-Uncertainty Avoidance & PCO6 & $0.428 *$ \\
\hline & (PCO-UA) & PCO7 & 0.589 \\
\hline & CR: 0.666 & PCO8 & 0.730 \\
\hline & \multirow[t]{2}{*}{ AVE: 0.362} & PCO9 & $-0.087 *$ \\
\hline & & PCO10 & 0.861 \\
\hline & PCO-Individualism & PCO11 & 0.908 \\
\hline & (PCO-INV) & PCO12 & 0.817 \\
\hline & CR: 0.877 & PCO13 & 0.852 \\
\hline & \multirow[t]{2}{*}{ AVE: 0.593} & PCO14 & 0.614 \\
\hline & & PCO15 & 0.608 \\
\hline & PCO-Masculinity & PCO16 & 0.186 \\
\hline & (PCO-MAS) & PCO17 & 0.675 \\
\hline & CR: 0.835 & PCO18 & $0.445^{*}$ \\
\hline & AVE: 0.473 & PCO19 & 1.038 \\
\hline & Moderator-Bodywash & MOD1 & $0.437 *$ \\
\hline & (MOD-Body) & MOD2 & $0.057^{*}$ \\
\hline & CR: 0.856 & MOD3 & 1.022 \\
\hline & \multirow[t]{2}{*}{ AVE: 0.609} & MOD4 & 1.048 \\
\hline & & MOD5 & 0.842 \\
\hline & Moderator-Smart Phone & MOD6 & 1.086 \\
\hline & (MOD-Phone) & MOD7 & 1.026 \\
\hline & CR: 0.777 & MOD8 & $0.015^{*}$ \\
\hline & \multirow[t]{2}{*}{ AVE: 0.520} & MOD9 & $0.193 *$ \\
\hline & & MOD10 & 0.577 \\
\hline & COS-Open & COS2 & 0.754 \\
\hline & CR: 0.856 & COS3 & 0.878 \\
\hline & AVE: 0.666 & COS4 & 0.842 \\
\hline & COS-Diversity & COS5 & 0.743 \\
\hline & CR: 0.831 & cos6 & 0.985 \\
\hline & AVE: 0.630 & COS7 & 0.607 \\
\hline
\end{tabular}


Note: Omitted items due to unsatisfactory factor loadings shown in Italic and marked by a *

Table 10: Measurement Model Testing (Complete Data) for Taiwan Sample

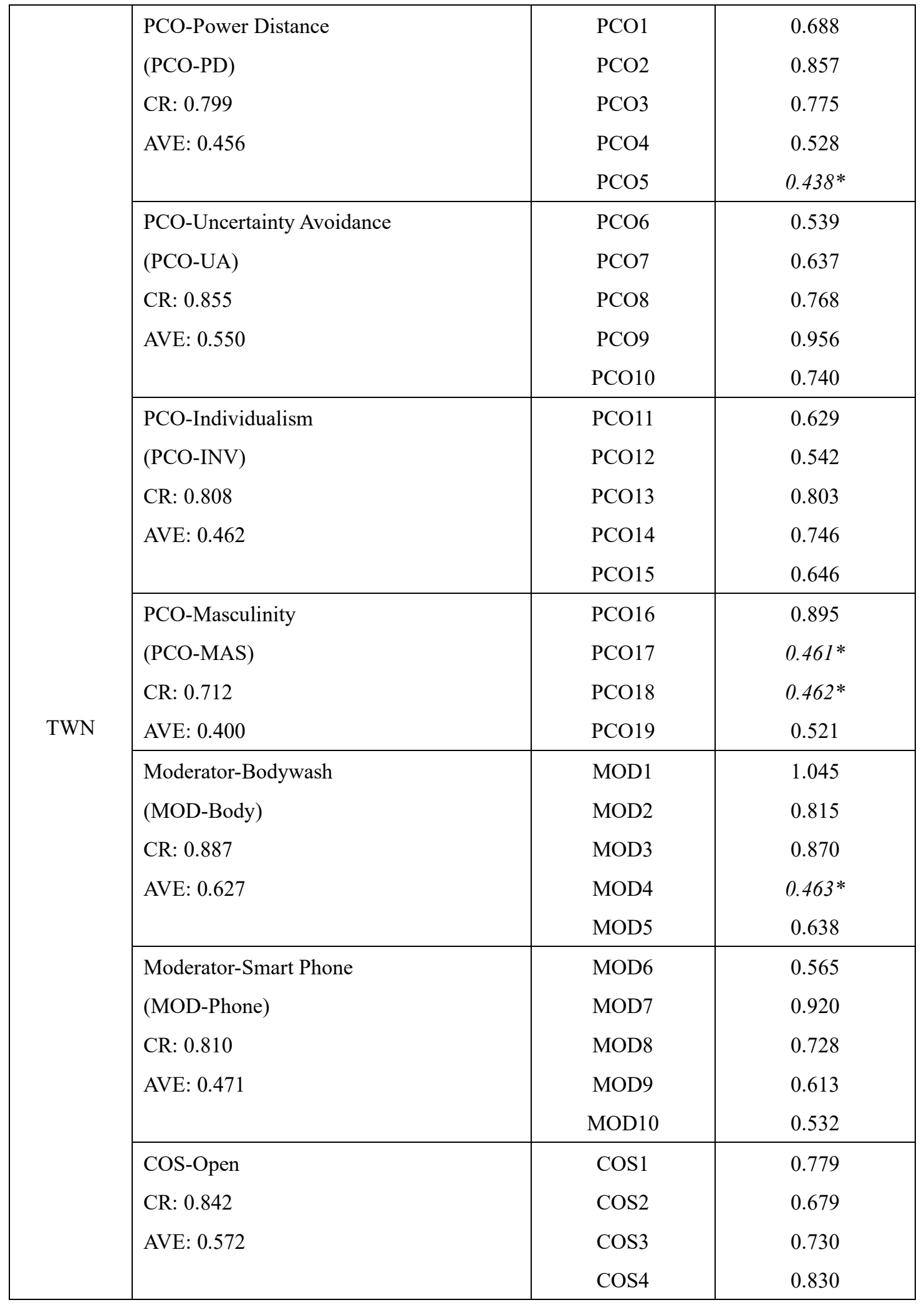




\begin{tabular}{|l|l|l|l|}
\hline & COS-Diversity & COS5 & 0.805 \\
CR: 0.781 & COS6 & 0.708 \\
& AVE: 0.545 & COS7 & 0.696 \\
\hline
\end{tabular}

Note: Omitted items due to unsatisfactory factor loadings shown in Italic and marked by a *

Indicators with loadings below the 0.5 threshold (Hulland, 1999; Hair et al., 2019) were omitted and the model was re-tested. PCO-MAS displayed unsatisfactory loadings and low levels of AVE. Hence, masculinity cannot be treated as an exogenous reflective latent construct and was therefore removed from the model due to measurement model issues and validity concerns. I have already discussed the rationale for this also in terms of external validity (not consistent with masculine values, but more with gender egalitarianism).

Table 11 and 12 present the constructs, indicators, and their respective loadings after the low-loading indicators were removed in the measurement model testing for the New Zealand and Taiwan sample respectively. The revised (streamlined) measurement model displays satisfactory CR and AVE values for all constructs. In this model, the New Zealand sample displayed NFI values of 0.549, Chi-Square value of 756.355 and SRMR value of 0.063 . The Taiwan sample displayed NFI values of 0.599, Chi-Square value of 0.73.008 and SRMR value of 0.075; thus, indicating a good model fit for both country samples.

Next, I also checked for multicollinearity issues by testing for variance inflation (VIF test) within smartPLS. VIF statistics were below the 3.0 threshold value for all constructs within the New Zealand sample, as per recommendations by Hair et al. (2019). For the Taiwan sample, VIF values were also all below the 3.0 reference 
threshold, suggesting there weren't any major multicollinearity issues.

Table 11: Final Measurement Model for the New Zealand Sample

\begin{tabular}{|c|c|c|c|}
\hline Sample & Construct & Indicator & Loadings \\
\hline \multirow{26}{*}{$\mathrm{NZ}$} & PCO-Power Distance & $\mathrm{PCO} 2$ & 1.039 \\
\hline & (PCO-PD) & $\mathrm{PCO} 4$ & 0.575 \\
\hline & CR: 0.816 & & \\
\hline & AVE: 0.705 & & \\
\hline & PCO-Uncertainty Avoidance & $\mathrm{PCO} 7$ & 0.996 \\
\hline & (PCO-UA) & $\mathrm{PCO} 8$ & 0.758 \\
\hline & CR: 0.836 & PCO10 & 0.594 \\
\hline & AVE: 0.639 & & \\
\hline & PCO-Individualism & PCO11 & 0.883 \\
\hline & (PCO-INV) & PCO12 & 0.804 \\
\hline & CR: 0.840 & PCO13 & 0.728 \\
\hline & AVE: 0.572 & PCO15 & 0.587 \\
\hline & Moderator-Bodywash & MOD3 & 0.880 \\
\hline & (MOD-Body) & MOD4 & 1.065 \\
\hline & CR: 0.938 & MOD5 & 0.776 \\
\hline & AVE: 0.837 & & \\
\hline & Moderator-Smart Phone & MOD6 & 0.931 \\
\hline & (MOD-Phone) & MOD7 & 0.884 \\
\hline & CR: 0.903 & & \\
\hline & AVE: 0.824 & & \\
\hline & COS-Open & COS2 & 0.788 \\
\hline & CR: 0.856 & $\mathrm{COS} 3$ & 0.835 \\
\hline & AVE: 0.664 & COS4 & 0.821 \\
\hline & COS-Diversity & COS5 & 0.733 \\
\hline & CR: 0.831 & cos6 & 0.986 \\
\hline & AVE: 0.630 & COS7 & 0.616 \\
\hline
\end{tabular}


Table 12: Final Measurement Model for the Taiwan Sample

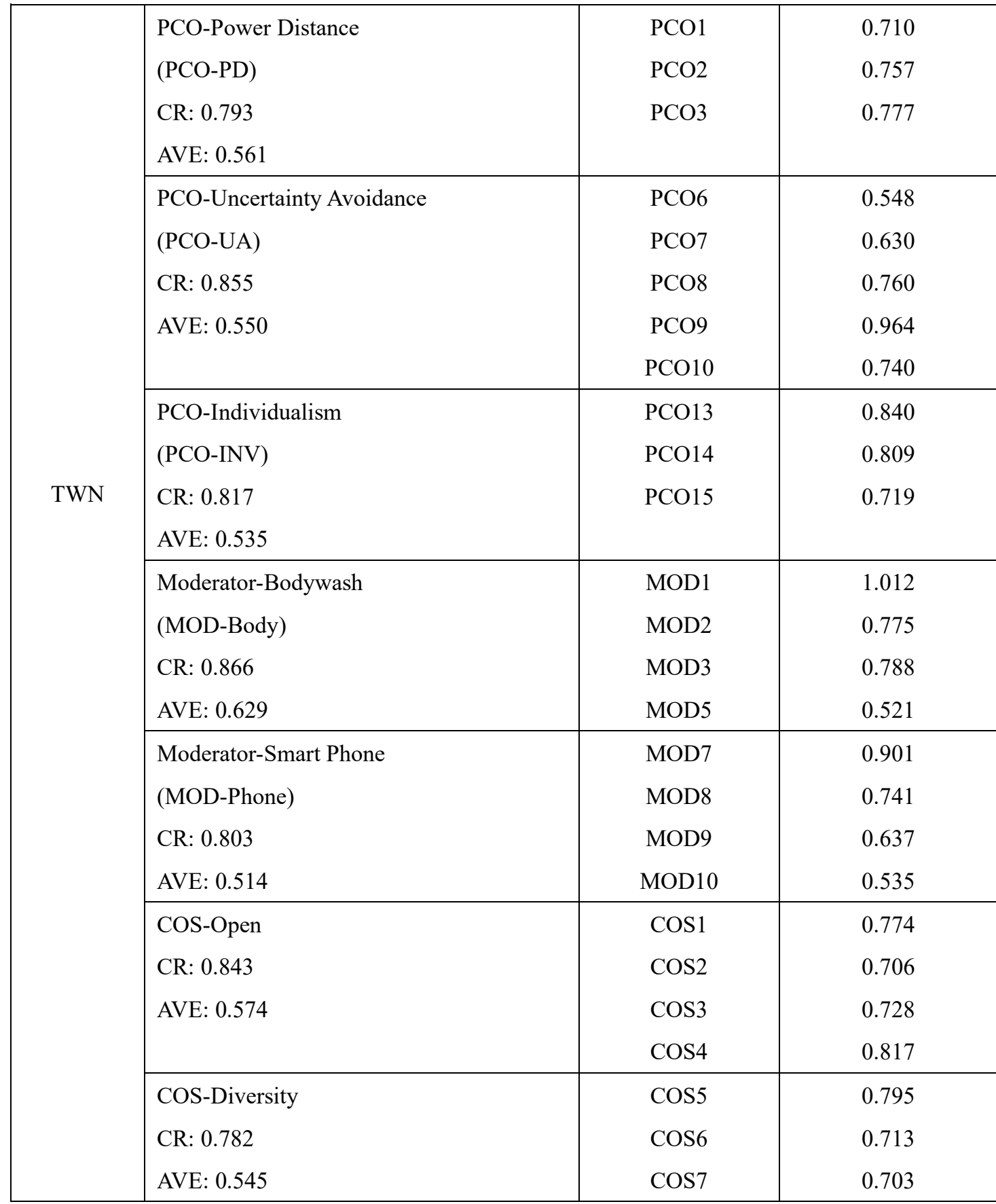

Table 13 and 14 display key descriptive statistics for the New Zealand and Taiwan country samples, as well as the corresponding correlation matrix for the analysed reflective latent constructs in the model. Internal reliability checks show satisfactory levels of CR (ranging between $0.7-0.95$ ) and satisfactory convergent validity (AVE > 
0.5), as recommended by Hair et al (2019). In terms of the correlation matrix, pair-wise correlation coefficient generally point to relatively low pair-wise correlation coefficients between constructs for the New Zealand sample and no major issues for the Taiwan country sample. Checking for discriminant validity (i.e. square root of AVE values shown on the diagonal and checked against pair-wise correlation coefficients), the so-called Fornell-Larcker criterion (Fornell \& Larcker, 1981) shows square root of AVE for each construct are higher than any pair-wise correlation coefficient below the correlation matrix diagonal for all distinct pairs of constructs. In the New Zealand country sample, most pair-wise correlation coefficients were less than 0.1 with only a few in the 0.2 range, but no higher than 0.3 . In the Taiwan country sample, although most pair-wise correlation coefficients were also less than 0.1 , a few more pair-wise correlations coefficients were in the range above 0.3 , with a pair-wise correlation coefficient between COS-Open and COS-Diversity being 0.549 . However, overall each pair-wise correlation coefficient within both country samples was well below the square root of AVE, which suggests there were no discriminant validity issues (Hair et al., 2019). 
Table 13: Pair-wise correlation matrix for the New Zealand country sample and discriminant validity check

\begin{tabular}{|c|c|c|c|c|c|c|c|c|c|}
\hline & $\mathrm{CR}$ & AVE & COS-Diversity & COS-Open & MOD-Body & MOD-Phone & PCO-INV & PCO-PD & PCO-UA \\
\hline COS-Diversity & 0.831 & 0.630 & 0.794 & & & & & & \\
\hline COS-Open & 0.856 & 0.664 & 0.235 & 0.815 & & & & & \\
\hline MOD-Body & 0.938 & 0.837 & -0.298 & -0.102 & 0.915 & & & & \\
\hline MOD-Phone & 0.903 & 0.824 & -0.171 & -0.175 & -0.140 & 0.908 & & & \\
\hline PCO-INV & 0.840 & 0.572 & -0.010 & -0.259 & 0.073 & -0.069 & 0.756 & & \\
\hline PCO-PD & 0.816 & 0.705 & 0.168 & -0.170 & -0.076 & 0.023 & 0.045 & 0.840 & \\
\hline PCO-UA & 0.836 & 0.639 & -0.111 & -0.014 & 0.057 & 0.136 & 0.051 & -0.014 & 0.800 \\
\hline
\end{tabular}

Note: Square root of AVE shown on the diagonal in bold (discriminant validity check). MOD-Body relates to bodywash. MOD-Phone relates to a smartphone.

Table 14: Pair-wise correlation matrix for the Taiwanese country sample and discriminant validity check

\begin{tabular}{|c|c|c|c|c|c|c|c|c|c|}
\hline & $\mathrm{CR}$ & AVE & COS-Diversity & COS-Open & MOD-Body & MOD-Phone & PCO-INV & PCO-PD & PCO-UA \\
\hline COS-Diversity & 0.782 & 0.545 & 0.738 & & & & & & \\
\hline COS-Open & 0.843 & 0.574 & 0.549 & 0.757 & & & & & \\
\hline MOD-Body & 0.866 & 0.629 & 0.300 & 0.135 & 0.793 & & & & \\
\hline MOD-Phone & 0.803 & 0.514 & 0.439 & 0.307 & 0.078 & 0.717 & & & \\
\hline PCO-INV & 0.817 & 0.535 & 0.144 & 0.223 & 0.089 & 0.082 & 0.731 & & \\
\hline PCO-PD & 0.793 & 0.561 & -0.061 & -0.326 & -0.037 & -0.077 & 0.171 & 0.746 & \\
\hline PCO-UA & 0.855 & 0.550 & 0.299 & 0.208 & 0.109 & 0.213 & 0.429 & -0.039 & 0.742 \\
\hline
\end{tabular}

Note: Square root of AVE shown on the diagonal in bold (discriminant validity check). MOD-Body relates to bodywash. MOD-Phone relates to a smartphone. 


\subsubsection{Structural model testing}

To help test all my research hypotheses, Table 16 summarizes the results of the structural model testing with corresponding path coefficients and significance estimates based on bootstrapping (5,000 samples, path coefficient estimation) for both the New Zealand and Taiwan country samples. To test for H1a and H1b, standard deviation and mean scores from Table 4 were used compared the level of the two dimensions of COS (open-mindedness, diversity appreciation) between the two country samples. Firstly, mean scores for every indicator used in the final model in both COS constructs in the New Zealand sample are higher compared to the Taiwan sample by a small margin, which partially supports H1a. Using Cohen's d statistic (Cohen, 1988; Cohen, 1992), I wanted to test the effect size of the differences between the level of COS between the two samples. Looking at Table 15, the results of effect size difference testing are rather mixed. Three out of seven COS indicators have a moderate effect size difference $(\mathrm{d}>0.5)$, whilst another three COS indicators display small effect size differences $(\mathrm{d}<0.3)$. Overall, H1a remains partially supported, as the difference in the level of COS between the two samples can still be seen, but not fully supported, as this difference is not consistent across all COS indicators. Second, low and consistent standard deviation scores for both samples indicate comparable low levels of variance for the two samples. Based on this, I inferred that H1b could not be supported. 
Table 15: Testing for COS mean scores difference between NZ and TWN samples

\begin{tabular}{|c|c|c|c|}
\hline & NZ Sample & TWN Sample & Cohen's D statistic \\
\hline COS1 & $\begin{array}{l}\text { Mean: } 4.36 \\
\text { S.D.: } 0.76\end{array}$ & $\begin{array}{l}\text { Mean: } 4.15 \\
\text { S.D.:0.72 }\end{array}$ & 0.28 \\
\hline COS2 & $\begin{array}{l}\text { Mean: } 4.37 \\
\text { S.D.:0.69 }\end{array}$ & $\begin{array}{l}\text { Mean: } 3.98 \\
\text { S.D.:0.83 }\end{array}$ & 0.51 \\
\hline COS3 & $\begin{array}{l}\text { Mean: } 4.49 \\
\text { S.D.:0.66 }\end{array}$ & $\begin{array}{l}\text { Mean: } 4.09 \\
\text { S.D.:0.82 }\end{array}$ & 0.54 \\
\hline $\cos 4$ & $\begin{array}{l}\text { Mean: } 4.41 \\
\text { S.D.:0.68 }\end{array}$ & $\begin{array}{l}\text { Mean: } 4.32 \\
\text { S.D.:0.69 }\end{array}$ & 0.13 \\
\hline COS5 & $\begin{array}{l}\text { Mean: } 4.18 \\
\text { S.D.:0.93 }\end{array}$ & $\begin{array}{l}\text { Mean: } 4.10 \\
\text { S.D.:0.86 }\end{array}$ & 0.09 \\
\hline Cos6 & $\begin{array}{l}\text { Mean: } 4.52 \\
\text { S.D.:0.59 }\end{array}$ & $\begin{array}{l}\text { Mean: } 4.20 \\
\text { S.D.:0.67 }\end{array}$ & 0.51 \\
\hline $\cos 7$ & $\begin{array}{l}\text { Mean: } 4.44 \\
\text { S.D.:0.77 }\end{array}$ & $\begin{array}{l}\text { Mean: } 4.10 \\
\text { S.D.:0.80 }\end{array}$ & 0.43 \\
\hline
\end{tabular}

In terms of estimating the path coefficients in the structural model, uncertainty avoidance had no significant influence on COS except on COS-Diversity in the Taiwan sample (with a path coefficient $\beta=0.147, \mathrm{p}=0.033$ ). This effect is positive, but is contrary to the negative relationship originally hypothesized. Overall, H2a could not be supported. Individualism has an effect on COS-Open in both the New Zealand country sample $(\beta=-0.218, p=0.002)$ and the Taiwan country sample $(\beta=0.164, p=0.030)$; but no significant effect on COS-Diversity. Individualism's positive, but weak effect on COS-Open in the Taiwan country sample supports the original H2b hypothesis. However, its negative and moderate effect on COS-Open in the New Zealand country sample suggests individualism is likely to have a positive effect on open-mindedness, as an aspect of COS. However, H2b can be only partially supported. Power distance has a negative and moderate effect on COS-Open in both the New Zealand country sample $(\beta=-0.179, \mathrm{p}=0.05)$ and the Taiwan country sample $(\beta=-0.272, \mathrm{p}=0.000)$. 
Therefore, H2c was supported for the COS-Open dimension, but not for the COSDiversity dimension. Hence, $\mathrm{H} 2 \mathrm{c}$ can only be partially supported. As mentioned, the effect of masculinity as a PCO on COS could not be tested, since this exogenous reflective latent construct had to be omitted in the measurement model testing stage. Hence, the corresponding hypothesis $(\mathrm{H} 2 \mathrm{~d})$ could not be tested.

Of all twenty-four moderation effects of product involvement on the relationship between PCO and COS, no significant path coefficients can be observed for any of the three PCO-COS relationships. As no significant effects can be observed, H3a-H3d could not be supported. Thus, in my research, product involvement does not play a moderating role between any of the PCOs and COS. Hence, H3 could not be supported.

The control variables had a much weaker effect on COS than anticipated. I was able to test only two control variables, which related to overseas experience and family background. Overseas experience captured whether the respondents spent over three months overseas for work, study, or simply living. Family background captured whether the respondents were born in a culturally-mixed family. Both of these control variables were anticipated to have an effect on COS in accordance with prior literature. However, these effects were observed only within the New Zealand sample. Overseas experience has an effect only on COS-Open $(\beta=0.209, \mathrm{p}=0.011)$, whilst family background has only an effect on COS-Diversity $(\beta=0.177, p=0.007)$. No significant effects were observed within the Taiwanese country sample.

In the end, the model fit statistics for the final models were satisfactory for both the New Zealand and Taiwan country samples. The SRMR value was 0.061 for the New 
Zealand country sample and 0.072 for the Taiwan country sample. Both values are lower than the 0.08 threshold values, as suggested by Hair et al. (2019). The NFI and Chi-square statistics could not be estimated. A summary of the hypotheses testing can be found in Table 17.

Table 16: Final results of PLS-SEM testing for both country samples

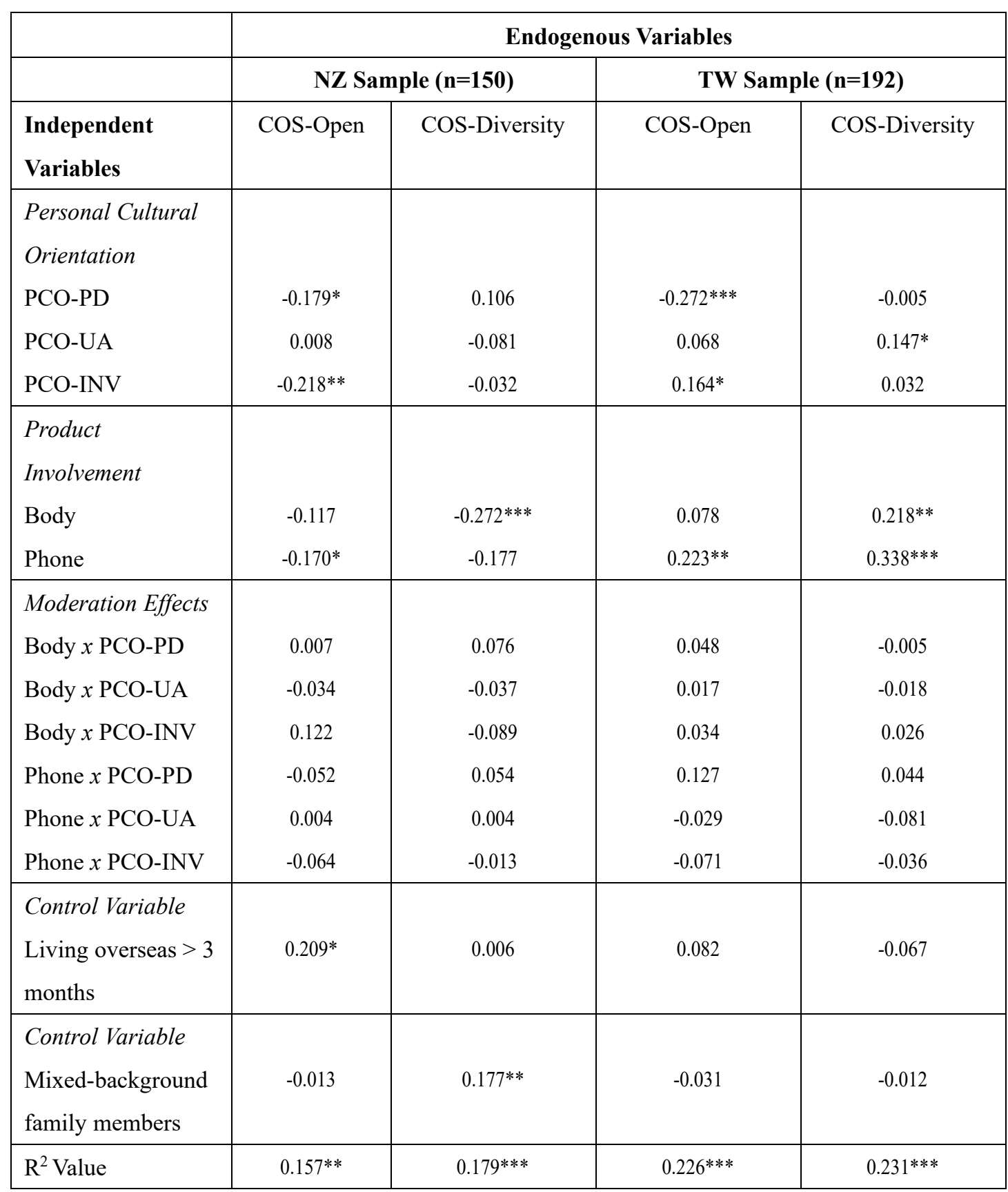

$* * * \mathrm{p}<0.001, * * \mathrm{p}<0.01,{ }^{*} \mathrm{p}<0.05$ 
Table 17: Summary of Hypotheses Testing.

\begin{tabular}{|c|c|c|}
\hline Hypothesis & Result & Comment \\
\hline $\begin{array}{l}\text { H1a: There will be differences in the level of COS } \\
\text { between young-adult consumers between the two } \\
\text { countries. }\end{array}$ & Partially supported & $\begin{array}{l}\text { Very low but observable differences in the mean scores between the New Zealand and } \\
\text { Taiwan sample in both COS constructs. }\end{array}$ \\
\hline $\begin{array}{l}\text { H1b: There will be differences in the level of COS } \\
\text { between young-adult consumers within both countries. }\end{array}$ & Not supported & $\begin{array}{l}\text { Very low levels of standard deviation scores for both COS constructs in both samples } \\
\text { suggests low variance in the level of COS between young-adult consumers in both samples. }\end{array}$ \\
\hline $\begin{array}{l}\text { H2a: Individuals who have higher uncertainty avoidance } \\
\text { will be less cosmopolitan (and vice versa). }\end{array}$ & Not supported & $\begin{array}{l}\text { Only one out of four effects between uncertainty avoidance and COS was significant. Effect } \\
\text { was significant at } p=0.033 \text { but at opposite direction to hypothesis. }\end{array}$ \\
\hline $\begin{array}{l}\text { H2b: More individualistic individuals will display higher } \\
\text { levels of cosmopolitan (and vice versa). }\end{array}$ & Partially supported & $\begin{array}{l}\text { Individualism has an effect on COS-Open in both samples, however, direction of effect was } \\
\text { opposite in the two samples. Overall individualism is likely to have an effect on COS, but } \\
\text { direction is unclear. }\end{array}$ \\
\hline $\begin{array}{l}\text { H2c: Individuals with higher levels of PD will be less } \\
\text { cosmopolitan compared to individuals with lower levels } \\
\text { of PD. }\end{array}$ & Partially supported & $\begin{array}{l}\text { PD has a weak-moderate effect on COS-Open in both samples, and the effect direction is } \\
\text { consistent with hypothesis. No effect was observed on COS-Diversity however. }\end{array}$ \\
\hline $\begin{array}{l}\mathrm{H} 2 \mathrm{~d} \text { : Individuals that show higher levels of masculinity } \\
\text { will be less cosmopolitan (and vice versa). }\end{array}$ & Not applicable & Masculinity was removed from model due to poor indicator loadings and low AVE values. \\
\hline $\begin{array}{l}\text { H3: Product involvement will have a general effect on } \\
\text { the relationship between COS and PCO. }\end{array}$ & Not supported & $\begin{array}{l}\text { No significant effects were observed for all moderation effects tested, therefore product } \\
\text { involvement does not play a moderating role between PCO and COS. }\end{array}$ \\
\hline $\begin{array}{l}\text { H3a-d: The relationship between UA/INV/PD/MAS and } \\
\text { COS will be moderated by product involvement. }\end{array}$ & Not supported & No significant effects observed. \\
\hline
\end{tabular}


As seen in Table 16, no initial hypotheses could be fully supported. However, a few hypotheses were partially supported. This is however directly related to the fact that COS could not be tested as a second-order reflective construct, but had to be decomposed into two separate endogenous constructs of open-mindedness and diversity appreciation. As no moderation effects were significant, this suggests that product involvement does not moderate the relationship between PCO and COS-Open or COS-Diversity in our case. The original hypotheses were made on the assumption that COS can be treated as a second-order construct indicated by COS-Open, COSDiversity, and COS-Consumption. After COS-Consumption was removed and COSOpen and COS-Diversity were separated into two independent constructs, no hypotheses can be fully confirmed, unless they showed significant relationships for both COS-Open and COS-Diversity. 


\section{Chapter 5: Implications and Limitations}

\subsection{Implications}

This study sought to test the impact of select PCOs on COS among young-adult consumers and the potential moderating role of product involvement in New Zealand and Taiwan. Based on empirical analysis of my data and the results from my research hypotheses testing, I will discuss the theoretical and managerial implications arising from my research. I have also attempted to draw some policy implications related to my research and findings.

\subsubsection{Theoretical Implications}

As consumer cosmopolitanism (COS) was the central focus of my research, I shall start off my discussion of the theoretical implications relating to COS. First, in this study, one of the dimensions of COS, namely consumption transcending borders (COSConsumption), could not be tested at the measurement model stage, due to internal reliability and convergent validity issues. In both country samples, the COSConsumption dimension had to be excluded from final (structural model) analysis using PLS-SEM. Interestingly, the one remaining indicator, which did load satisfactory in the confirmatory factor analysis stage, was identical in both samples. However, a single indicator is insufficient to test a reflective latent construct in SEM (Hair et al., 2019). The indicator in question was item $\operatorname{COS} 12$ "I like trying out things that are consumed elsewhere in the world". The other three indicators had to be removed due to insufficiently high factor loadings and focused specifically on movies, music, and food respectively. For the young-adult consumers in our sample, this suggests that their interests in consuming foreign goods/services may be specific to a given category of 
good/service. Rather, it might be a broad interest in trying out (experimenting with) foreign "things" in general; as per the original wording by Riefler et al. (2012) in their C-COSMO scale. I believe it is likely that movies, music, and food are all categories of popular culture, which might not be perceived as either foreign or domestic by this consumer generation, but simply as part of their (popular) culture. This view appears to be consistent with the general premise laid out by Kjeldgaard and Askegaard (2006) in their seminal study of young-adult consumers and their acculturation trends to a common global (popular) consumer culture. Young adults are heavily influenced by global media and trends (Cleveland \& Laroche, 2007; Durvasula \& Lysonski, 2016; Raskovic et al., 2016), as well as marketing practices of multinational enterprises. They are also dominated by a common lingua franca (usually English) and travel often (Raskovic et al., 2016). As both New Zealand and Taiwan are relatively small, open and western-oriented export economies, it is likely that young adults in these two markets enjoy western-style movies, fast food, music and popular culture on a daily basis. For the general population, these global trends can be considered more as "foreign". However, for a demographic cohort that is so heavily invested in global trends and perceives themselves as global citizens (Raskovic et al., 2016), it is likely they do not consider such movies, music, and food as "foreign" but rather as simply part of their dominant and increasingly globalized culture. Often, these global trends are so heavily integrated into the local community/environment, we simply do not consider their specific origins; such as, for example, thinking "I'm enjoying an American movie" when watching a Hollywood blockbuster.

Riefler et al. (2012) describe cosmopolitanism as an enduring personal orientation towards "the outside". Thinking of cosmopolitanism as a particular consumer 
orientation, introduces the concept of self-identity. Previous research suggests such orientations towards foreign products and brands are based on identity construal, as per social identity theory (Brewer \& Gardner, 1996); particularly among this generational cohort (Raskovic et al., 2016). Such orientations seem to be associated with ways for individuals to construct and project their social identities based on social categorization and derive their self-worth based on in-group and out-group classification, according to the Social Identity Theory (Brickson, 2000). From a consumerism perspective, a consumer scoring high on COS has a consumption orientation that "transcends any particular culture, locality or community” (Riefler \& Diamantopoulos, 2009, p.415). Riefler et al. (2012) do not further elaborate on the link between self-identity and COS. However, from their wording, one can derive that cosmopolitan consumers fulfil their self-identity and evaluate their self-worth based upon identification as global citizens (Raskovic et al., 2019). Yet, in this context it is important to emphasize that outsidership actually relates to something being "local", not "global".

The original study by Riefler et al. (2012) was, however, based on a sample of 429 Austrian consumers aged between 19 and 93 years, with an average age of 46.6 years. Contrary to their study, my study focused on young-adult consumers (in their 20s), as a very distinct age-bound demographic cohort with a particular type of shared experience of "coming of age" (Raskovic et al., 2019). For young-adult consumers, their consumption of foreign goods/services is instrumental in finding and portraying their self-identity in a process of social learning (Badaoui et al., 2018; Raskovic et al., 2016). For young-adult consumers, consuming border-transcending goods/services contributes to their identity formation through the mechanisms of discovering novel things, experimenting and engaging in creative expression (Gentina et al., 2014; 
Raskovic et al., 2016). More importantly, young adults' consumption habits are heavily influenced by their peers and global trends (Kjeldgaard \& Askegaard, 2006; Hung et al., 2007). Combined with their generally high consumption of global media, youngadult consumers are likely to consume foreign goods/services frequently, particularly if they are globally popular. Therefore, young-adult consumers are not as likely to consider foreign products/services that are not globally trending compared to those that are.

With regards to the COS-Consumption dimension, I would also like to emphasize that in the original study of Riefler et al. (2012), this first-order latent construct displayed significantly lower internal reliability and convergent validity statistics compared to the other two first-order constructs relating to open-mindedness (COS-Open) and diversity appreciation (COS-Diversity). Although being borderline acceptable for newlydeveloped scale in terms of convergent validity (AVE $>0.45)$, the AVE value for consumption transcending across borders was only 0.47 (Riefler et al., 2012). This is below the typical recommended threshold value of 0.5 , which points to some validity issues already in the original C-COSMO scale construction (Hair et al., 2019). However, these seem to have been brushed under the rug in the cross-validation of the C-COSMO scale (Riefler et al., 2012). These issues, while moderate when testing on a diverse population of consumer of different ages, seem to have become amplified when testing on a specific demographic cohort of young-adult consumers due to all the previously discussed specifics.

Second, and relating to the first point, I was unable to establish COS as a second-order reflective latent construct, either with three or just two sub-dimensions. This is contrary 
to Riefler and Diamantopoulos' (2009) original conceptualization of COS, or their subsequent empirical cross-validation of the C-COSMO scale (Riefler et al., 2012). After removing indicators with low factor loadings and the COS-Consumption firstorder construct (sub-dimension), appropriate convergent validity criteria (AVE $>0.5$ ) could still not be achieved adopting the approach for second-order reflective latent construct testing in PLS-SEM outlined by Hair et al. (2019); even for the remaining two dimensions related to open-mindedness and diversity appreciation. A plausible explanation for this is again the difference in respondents sampled by Riefler et al. (2012) and in this study. As the scale developed by Riefler et al. (2012) was built upon a more age-diverse and much older sample, it is possible the C-COSMO scale may not be applicable to a more age-specific demographic cohort at the forefront of globalization (Raskovic et al., 2016). Related evidence on consumer ethnocentrism (CET), another identity-based consumer disposition towards foreign products, has shown that age seems to have a positive impact on more negative dispositions towards foreign products via mechanisms of valuing tradition, being more nostalgic and becoming more conservative (see Raskovic et al., 2019). Further, when COS-Open and COS-Diversity were used as two separate reflective latent constructs, PLS-SEM testing showed instances where a significant effect was found in both samples for COS-Open but not COS-Diversity, or vice versa. This also suggests that the difference in how and why consumers consume foreign goods/services between samples used in Riefler et al. (2012) and this study is likely to have caused differences in conceptualization of COS.

It is also important to note that the study of COS is still very much a developing field of research in the marketing and international business literature and is increasingly transcending the binary logic of global-local consumer cultures (Steenkamp, 2019). 
Currently, the C-COSMO scale by Riefler et al. (2012) lacks widespread crossvalidation. Some studies have cross-validated segments of the 12-item scale (see i.e. Han \& Won, 2018). Other studies, also focusing on young-adult consumers, did crossvalidate the full C-COSMO scale. For example, Ding (2020) found similar issues in that COS could not be treated as a second-order construct, but as a set of two independent constructs. Overall, future studies should focus on cross-validating the CCOSMO scale, both across markets and cultural contexts, as well as different consumer age cohorts. It appears highly likely that the use of the C-COSMO scale may be applied only to age-diverse consumer settings.

Third, the PCO value scores in both country samples were mostly as expected. Since this study employs Hofstede-type cultural dimensions, but at the individual level (as PCOs), some differences to national level culture scores were expected. As this study samples from a more specific generational cohort, greater level of similarity was expected in terms of their PCOs, especially for young adults (Sobol et al., 2018; Kjeldgaard, \& Askegaard, 2006). An interesting finding that differs from the previous literature relates to the level of uncertainty avoidance, which was in the 3.5-to-4 range (on a 5-point scale) for both samples. This indicates that respondents in both country samples were less comfortable with uncertainty than one would generally assume (of the young generation). As previous literature on young-adult consumers suggests, they are more willing to try unfamiliar products and brands, which corresponds to higher level of so-called consumer innovativeness (Tellis et al., 2009). However, this might be more related to so-called experimental consumption and social learning (Raskovic et al., 2016), and less with their general personal orientations towards risk and uncertainty in life. It is also possible that this difference has been observed due to the context of 
uncertainty, as the wording of the indicators relating to uncertainty avoidance in the Yoo et al. (2011) scale focuses on work procedures. It is completely possible that in our sample, significant differences in the level of uncertainty avoidance for young adults can exist when placed in different contexts, such as consumption or work. Some evidence on work values of millennials in Slovenia and China (Zupan et al., 2015) seems to show that this generational cohort has relatively clear and high expectations when it comes to work and their (future) employers (the so-called anticipated psychological contract), which may mean they are less willing to accept deviations from those expectations. Thus, this may not necessarily imply they do not like uncertainty, but simply know what they want or at least don't want.

Fourth, I was unable to test and include the masculinity PCO in my analysis. As already discussed, factor loading issues and validity issues meant only one indicator loaded satisfactory from the original four proposed by Yoo et al. (2011); which is insufficient for testing a reflective latent construct (Hair et al., 2019). Hofstede's original masculinity-femininity dimension focused on the degree to which a society values the display of masculine-type values, such as competition and assertiveness, vs feminine values of compassion and caring (Hofstede, 2001). In the adaption by Yoo et al. (2011), however, indicators for masculinity focused on stereotypical gender roles and gender equality statement. In terms of face validity, this significantly differs from Hofstede's original concept and is in some ways closer to the gender egalitarianism dimension within the GLOBE project cultural framework (House et al., 2004). In both New Zealand and Taiwan, values such as democracy and freedom of speech are highly valued. Both countries are often praised for their openness and acceptance of all types of sexual identification and orientations (e.g. both legalized same-sex marriage). 
Therefore, Yoo et al. (2011)'s operationalization of masculinity is not likely to accurately measure this dimension, as intended by Hofstede; especially within this demographic cohort where gender and identity interact in much more complex ways.

For young adults, their understanding of gender and gender roles is likely to be significantly different from older generations. Stereotypical gender roles are more common amongst older generations with more traditional and conservative views, whereas younger generations generally hold a more liberal view and place greater importance on gender equality and fluidity. Our understanding of genders and sexuality is still expanding today (Oakley, 2016; Katz-Wise \& Hyde, 2015), more and more individuals identify with a non-binary gender/sexuality and fluidity in gender and sexuality is more common. Due to these newer understandings of gender and sexuality, younger generations are likely to have significantly different perspectives on gender and gender roles.

Fifth, within-country differences appear to be smaller than across-country differences. Highlighted by hypotheses H1a and H1b, despite a high level of universality, small but observable differences exist for COS across the two country samples. For example, the New Zealand sample displayed higher levels of COS on all indicators, except for one (related to local products) compared to the Taiwan sample. On the other hand, very low standard deviations in both samples for each indicator suggest differences in the level of COS within countries are rather small; or rather there is little variation in the two country samples, which is also a result of high levels of demographic matching. PCO values across the two samples show slightly higher levels of standard deviations within countries and more instances of similarity across countries. Overall, this is not 
consistent with previous cross-cultural research in the IB literature, which suggest cultural values differ significantly at the individual level due to differences in individuals' experiences (Peterson et al., 2018; Peterson \& Barreto, 2014). Again, such research was done on more diverse respondent populations, not a specific demographic cohort with distinct social experiences (Raskovic et al., 2019). My findings have implications for the general assumption that within-country differences are considerably larger than across-country differences, when it comes to cultural value studies (Taras et al., 2016). Thus, when focusing on a specific demographic generational cohort, it seems that even when it comes to representatives from two very diverse cultural backgrounds, one grounded in a more Western and Protestant-based cultural context with more independent identity construal and the other in a more Eastern and Confucian-based cultural context with more interdependent identity construal (Browaeys \& Price, 2015), my evidence shows greater tendency towards a generational archetype understand of young adults (Sobol et al., 2018), rather than the 80-20 culture difference rule within vs between countries, when it comes to values (Taras et al., 2016). Again, however, it is also possible these differences are observed due limitations arising from my samples, which will be further discussed in the limitations section.

Sixth, product involvement had no moderating effect on the relationship between the four PCOs and two COS constructs. As discussed, different levels of product involvement add to the complexity of purchase decision, which makes a consumer more risk averse (and less willing to try unfamiliar foreign goods) when the level of product involvement is higher, and vice versa. However, my study found no significant effects in terms of possible moderation. To the best of my knowledge, product involvement has not been tested with COS in previous studies. Thus, the absence of significant 
moderation effects is an important finding in itself but needs to be again interpreted in the specific generationally-bound frame of my research and issues related to the secondorder nature of my COS construct. Future studies should explore the relationship between product involvement and COS across different age groups.

Lastly, none of the hypotheses relating to PCOs as determinants of COS could be fully supported. A few past studies which tested cultural orientations and COS have found significant relationships between Hofstede's national cultural orientations and COS (see Cleveland et al., 2011; Han \& Won, 2018). However, both of these studies utilized Hofstede's cultural dimensions at the national level and used a single-dimension operationalization of COS (not based on the C-COSMO scale). In this study, cultural dimensions were conceptualized at the individual level (as PCOs) and COS was operationalized as two distinct reflective latent constructs (open-mindedness and diversity appreciation). In the study by Cleveland et al. (2011), Cleveland et al. (2011) found masculinity and individualism to be significantly related to COS, but only in one of their two country samples. Similar to this study, Cleveland et al. (2011) used student samples and found mixed results when applying Hofstede's cultural dimensions even at the national level. Cleveland et al. (2011) then used Schwartz's value inventory, a non-Hofstede values survey that operationalizes completely different dimensions intended to capture individual values. Of the seventeen paths tested, Cleveland et al. (2011) found nine significant relationships. Due to the similarity of Yoo et al. (2011)'s PCO dimensions to Hofstede's original framework, it is highly likely these dimensions do not adequately capture the value orientations of young-adults; at least those relevant to COS. Future studies seeking to test the impact of individual-level value dimensions on COS should consider scales that have been specifically conceptualized at the 
individual level, such as Schwartz's value inventory utilized by Cleveland et al. (2011) or Sharma's 40-item PCO scale and not employ simple adaptations of Hofstede's national culture framework, like Yoo et al. (2011).

\subsubsection{Managerial Implications}

Based on the findings of my study, the following recommendations should be useful to international (marketing) managers. First, in terms of marketing towards young-adult consumers in Taiwan and New Zealand, unlike what other cross-cultural research suggests (Taras et al., 2016), there are relatively small across-country and especially within-country differences when it comes to individual-level PCOs for this particular age cohort. Thus, marketers can view this generational cohort as a relatively more homogenous type of "market", which is defined less by geography and national cultures, but more by generational identity and shared experiences. This carries important implications for the standardization and adaptation of marketing strategies across markets (Raskovic et al., 2016). When comparing this to other consumer age groups, this homogeneity is very high, which implies greater potential for marketing standardization. In terms of COS, minimal differences exist at the within-country level between young-adult consumers in New Zealand and Taiwan. At the cross-country level, although a very small difference can be observed (with young adults in New Zealand displaying slightly higher levels of COS), young adults in both countries display a similarly high level of COS. Therefore, standardized marketing strategies targeted at cosmopolitan individuals can be considered when marketing towards young-adult consumers, as a specific demographic consumer cohort in New Zealand and Taiwan. In catering to this consumer cohort, a strong appeal to global citizenship should be made and re-enforced by a distinct generational identity message. 
Second, although young-adult consumers are often thought to be the archetypal global generation with high levels of COS (Sobol et al., 2018; Kjeldgaard, \& Askegaard, 2006), this study suggests COS dispositions within this cohort are not all identical, nor is COS identical to dispositions of other age cohorts. As discussed previously, young-adult consumers may exhibit cosmopolitan consumption orientations for different reasons and purposes compared to cosmopolitan consumers in other generation cohorts. For example, due to their large consumption of global media and trends, it is likely a large percentage of young-adult consumers' foreign product purchases are driven by global trends and peers. Therefore, simply being foreign won't help you attract the segment of young-adult consumers. A link must be made to global citizenship, which requires a need to understand what roles to specific "foreign" products play in the "identityscape" of young-adult consumers. This may be different to the COS dispositions of older generations, for whom foreign purchases are more likely to be driven by the exotic nature and authenticity of foreign products, world mindedness or (so-called) intellectualism. To target young-adult consumers, being aware of globally trendy products, characteristic, and marketing trends will help ensure you can reach and communicate your marketing message and formulate marketing strategies across diverse country markets and cultural backgrounds more effectively. For fashion and apparel industries, for example, researching popular media outlets may help you understand trendy product types, while researching popular social media platforms may provide information on what may be the most suitable marketing style for young-adult consumers. The function of role models and endorsers is also particularly important and should be given a lot of attention (Raskovic et al., 2016). 


\subsubsection{Implications for Policy Makers}

For educators, especially those in countries that understand the younger generation (young adults or even adolescents) have a different perspective on cosmopolitanism due to deeper-level globalization or socio-economic transformation, it is important to appropriately educate them as global citizens with a glocal understanding, where "global" and "local" co-exist (Raskovic et al., 2016). As discussed in this study, strong generational differences in levels of COS and its determinants are likely to exist due to the differing ways younger generations acquire information and various sources, particularly through global media and trends. The mindset of younger generations may be overly rooted in a global perspective, which may imply they might struggle with local identification and connection to their local environment. For the younger generation, growing up with purely a global perspective may mean they lack an understanding of national boundaries, foreign affairs, awareness of matters in less “popular" countries/cultures, and an appreciation of local culture, customs and history. Without an awareness of these topics, the younger generation will also not have a sufficient understanding of how their demand and consumption of foreign products and services play into the global economy or impact their local economy and society. They will also not be equipped to understand how national boundaries and foreign affairs play into global trade and affect the price and availability of foreign products. They may also experience a loss of connection to local perspectives resulting in delocalization and even loss of one's (indigenous) identity (Thompson, 1995). This may lead to identity confusion and marginalization which hinders self-identity development and may facilitate deviant behaviour (Arnett, 2002; Berry, 1993; 1997). To educate the younger generation how to be better global citizens with an appropriate glocal understanding, educators needs to ensure they can educate the younger generation to 
have a more balanced perspective (not overly global nor local).

This is especially relevant in the current times, as discussed, when the world is experiencing a rise in anti-globalization sentiment, trade war dynamics, and other nationalistic behaviours across markets (Meyer, 2017; Witt, 2019). Even proglobalization phenomena, such as multilateral trade and global value chains, are being discussed in different terms compared to the past (Inglehart \& Norris, 2016). Educators must ensure during these times the younger generation can be well informed and have a balanced perspective on where their country stands globally and how this will affect them.

For political actors, it is also crucial to understand the differing (cosmopolitan) views the younger generations hold compared to their other constituents. With a different perspective to other generations, younger generations are likely to have different opinions, world views and needs, which older generations may not easily understand. While this may be said really for any generational cohort, the type of self-identity construal and world view is somewhat unique for the young generation, who engages with the world in a completely different way through technology, media, travel and consumption. This generation, in particular, seems to be less switched into political and economic debates, or actually politically engaged. More importantly, politicians, especially political leaders or others that sit in positions of power, must ensure the perspectives of younger generations can be heard and represented when making decisions, which requires finding ways of appealing to them and making them part of the discussion. An example of this relates to one of the sample countries in this study, Taiwan. At the time of writing, Taiwan is nearing its quadrennial presidential election. 
A strong candidate has openly discussed the need for the voice of the young generation to be heard through placing greater emphasis on political parties' youth wing and greater number of young adults in government sectors. In particular, he emphasized how he will appoint a minister of culture proficient in English and under the age of 40 .

\subsection{Limitations}

In interpreting the results of this study, some limitations must also be discussed and considered. Firstly, this study's used university students as representatives of youngadult consumers. Student samples (and young adults overall) have been criticized in the past for low generalizability and validity; as young adults can often change attitudes frequently and be more malleable to social influences (Sears, 1986; Bello et al., 2009). Incorporating respondents in a similar 20-30 age group, who are non-students and may be into their first or second job (e.g. those in their late 20's) may have well produced completely different results, perhaps more similar to those by Riefler et al. (2012) or Cleveland et al. (2011). However, I would like to point out that university students have been employed as a representative sample for studying young-adult consumer behaviour in IB and marketing; particularly in multi-country and cross-cultural studies (Raskovic et al., 2016; Ding et al., 2018; Raskovic et al., 2019).

This study used a mix of on-line and paper-based questionnaires to collect data from respondents, which was completely self-reported. Self-reported data can be inaccurate, especially among younger generations who are still developing their self-identity (Sears, 1986). Self-reported data can often lead to problems such as common method variance, the so-called consistency motif, and social desirability biases (Podsakoff \& Organ, 1986). In addition to this, this research is also subject to all the "standard" limitations 
of survey-based cross-sectional studies; particularly in terms of causality (Raskovic et al., 2019). I am also aware that when conducting cross-cultural research testing for measurement invariance is also recommended and is a usual step in CB-PLS (Steenkamp \& Baumgartner, 1998). However, this is somewhat more difficult in PLSSEM for which some other (more complicated) procedures have been developed (see Hair et al., 2019), which I was unable to master, due to being a novice to the SEM methodology.

The results of this study may have been limited by its small sample size. Through discussions with my supervisor, a minimum of 150 respondents was set to ensure a PLS-SEM approach can be used. In the end, 192 responses were collected for the Taiwanese sample while the New Zealand sample just reached 150 responses near the end of the collection timeframe. Although sufficient for PLS-SEM, a larger sample size would have enabled me to employ CB-SEM testing, which is methodologically "stricter" and has a set of corresponding goodness of fit statistics. 


\section{Chapter 6: Conclusions}

The aim of this study has been to test whether four specific PCOs act as psychographic antecedents of COS, and whether product involvement moderates these relationships. The results of this study found no general support for the specific PCOs as antecedents of COS, and no evidence of product involvement serving as a moderator. However, this is more likely the result of underlying issues in this study's PCO-COS relationships than a clear evidence there is no moderation taking place. By comparing the level of COS between the two samples of this study, cosmopolitan dispositions of young-adult consumers were somewhat greater across as opposed to within countries in our sample. However, they were still quite moderate, if we compare to dispositions of other consumer demographic cohorts, which is different to general evidence from crosscultural studies which has shown $80 \%$ of cultural differences are within countries and only $20 \%$ between countries (Taras et al., 2016). Further, the low standard deviation of COS indicators in both samples suggests that there are unlikely to be distinct sub-groups of different types of cosmopolitan consumers among young adults in our two sample countries. This is again different to evidence by Riefler et al. (2012), who have found distinct sub-profiles of global and regional cosmopolitan consumers.

This study found that COS could not be tested as second-order three-dimensional reflective latent construct, as conceptualized by Riefler and Diamantopoulos (2009) and tested by Riefler et al. (2012) through the C-COSMO scale. The findings of this study suggest that different generations may have differing perspectives on COS, as a consumer disposition. For young adults, their overly global perspective and identification may blur the distinction between what is "global" and "local". 
Operationalizing COS differently is likely to have complicated the overall relationship, which caused the lack of general support for PCOs as an antecedent of COS. Further, current research on antecedents of COS has typically lacked compelling evidence, especially when testing on a wide range of consumers (in terms of their age). Research replicating the conceptualization and operationalization of COS based on Riefler et al. (2012) is even more scarce, despite it being the most valid and reliable scale currently available on COS (Terasaki, 2016; Han \& Won, 2018). Overall, more replication and cross-validation of $\operatorname{COS}$ is needed in future research across markets and age demographic backgrounds of respondents. More importantly, recognizing and incorporating variables that influences consumer dispositions into the conceptualization of COS should be considered, especially generational differences.

This study used matched samples of young-adult consumers (university students in their 20s) from New Zealand and Taiwan. New Zealand and Taiwan were selected to provide a cross-cultural contrast between traditional Confucian (Eastern) and AngloSaxon (Western) cultural perspectives, while maintaining matching in terms of size, geo-strategic position, export orientation and both being island nations. Our analysis found very high levels of similarity both between and within countries in terms of the four PCOs tested and levels of COS. Hence, this study supports past literature that views young-adult consumers as the archetypal consumer segment (Sobol et al., 2018). 


\section{References}

Alden, D. L., Steenkamp, J. B. E., \& Batra, R. (1999). Brand positioning through advertising in Asia, North America, and Europe: The role of global consumer culture. The Journal of Marketing, 63, 75-87.

Anić, I. D., Škare, V., \& Milaković, I. K. (2016). Determinants and behavioural consequences of online privacy concerns among young consumers in Croatia. Ekonomski pregled, 67(5), 377-398.

Arnett, J. J. (2002). The psychology of globalization. American psychologist, 57(10), 774-783.

Badaoui, K., Lebrun, A.-M., Su, C.-J., \& Bouchet, P. (2018). The influence of personal and social identity on the clothing consumption of adolescents. Canadian Journal of Administrative Science, 35, 65-78.

Balabanis, G., \& Diamantopoulos, A. (2004). Domestic country bias, country-of-origin effects, and consumer ethnocentrism: a multidimensional unfolding approach. Journal of the academy of marketing science, 32(1), 80-95.

Balabanis, G., \& Diamantopoulos, A. (2016). Consumer xenocentrism as determinant of foreign product preference: A system justification perspective. Journal of International Marketing, 24(3), 58-77.

Bartsch, F., Riefler, P., \& Diamantopoulos, A. (2016). A taxonomy and review of positive consumer dispositions toward foreign countries and globalization. Journal of International Marketing, 24(1), 82-110.

Bearden, W. O., Money, R. B., \& Nevins, J. L. (2006). Multidimensional versus unidimensional measures in assessing national culture values: The Hofstede VSM 94 example. Journal of Business Research, 59(2), 195-203.

Beck, U., \& Beck-Gernsheim, E. (2009). Global generations and the trap of methodological nationalism for a cosmopolitan turn in the sociology of youth and generation. European sociological review, 25(1), 25-36.

Beckmann, S., Douglas, S., Botschen, G., Botschen, M., Friese, S., \& Nijssen, E. (2001). The world minded consumer: An emic exploration. In M.C. Gilly \& J. MeyersLevy (Eds), Advances in consumer research, 28, 138-144.

Bello, D., Leung, K., Radebaugh, L., Tung, R. L., \& Van Witteloostuijn, A. (2009). From the editors: Student samples in international business research. Journal of International Business Studies, 40(3), 361-364.

Berry, J. W. (1993). Ethnic identity in plural societies. In M. E. Bernal \& G. P. Knight (Eds.), Ethnic identity: Formation and transmission among Hispanics and other minorities (pp. 271-296). New York, United States: State University of New York Press. 
Berry, J. W. (1997). Immigration, acculturation, and adaptation. International Journal of Applied Psychology, 46, 5-34

Bornstein, R. F., \& D'Agostino, P. R. (1992). Stimulus Recognition and the Mere Exposure Effect. Journal of Personality and Social Psychology, 63(4), 545-552.

Brewer, P. \& Venaik, S. (2014). The Ecological Fallacy in National Culture Research. Organization Studies, 35(7), 1063-1086.

Brewer, M. B., \& Gardner, W. (1996). Who is this" We"? Levels of collective identity and self-representations. Journal of personality and social psychology, 71(1), 83.

Brickson, S. (2000). The impact of identity orientation on individual and organizational outcomes in demographically diverse settings. Academy of management Review, 25(1), 82-101.

Brislin, R. W. (1970). Back-translation for cross-cultural research. Journal of crosscultural psychology, 1(3), 185-216.

Browaeys, M-J. \& Price, R. (2015). Understanding Cross-Cultural Management. 3ed. Harlow, UK: Pearson.

Buil, I., de Chernatony, L., \& Martínez, E. (2012). Methodological issues in crosscultural research: An overview and recommendations. Journal of Targeting, Measurement and Analysis for Marketing, 20(3-4), 223-234.

Cannon H. M., S. J. Yoon, L. McGowan \& A. Yaprak (1994). In search of the global consumer. Proceedings for the 1994 Annual Meeting of the Academy of International Business, Boston, MA.

Cannon, H. M., \& A. Yaprak (2002). Will the real-world citizen please stand up! Then many faces of cosmopolitan consumer behaviour. Journal of International Marketing, 10(4), 30-52.

Carpenter, J. M., Moore, M., Alexander, N., \& Doherty, A. M. (2013). Consumer demographics, ethnocentrism, cultural values, and acculturation to global consumer culture. Journal of Marketing Management, 29(3-4), 271-291.

Caprar, D. V., Devinney, T. M., Kirkman, B. L., \& Caligiuri, P. 2015. Conceptualizing and measuring culture in international business and management: From challenges to potential solutions. Journal of International Business Studies, 46(9), 1011-1027.

Chua, B. H. (2012). Structure, audience and soft power in East Asian pop culture (Vol. 1). Hong Kong University Press.

Cleveland, M., \& Laroche, M. (2007). Acculturation to the global consumer culture: Scale development and research paradigm. Journal of Business Research, 60(3), 249-259.

Cleveland, M., Laroche, M., \& Papadopoulos, N. (2009). Cosmopolitanism, consumer ethnocentrism, and materialism: An eight-country study of antecedents and outcomes. Journal of International Marketing, 17(1), 116-146. 
Cleveland, M., Erdogan, S., Arikan, G., \& Poyraz, T. (2011). Cosmopolitanism, individual level values and cultural-level values: A cross-cultural study. Journal of Business Research, 64(9), 934-943.

Cleveland, M., \& Laroche, M. (2012). Becoming and Being a Cosmopolitan Consumer. In M. Prince (Ed.), Consumer Cosmopolitanism in the Age of Globalization. (pp. 51-99). New York, U.S: Business Expert Press.

Cleveland, M., Rojas-Méndez, J. I., Laroche, M., \& Papadopoulos, N. (2016). Identity, culture, dispositions and behavior: A cross-national examination of globalization and culture change. Journal of Business Research, 69(3), 1090-1102.

Cleveland, M. (2018). Acculturation to the global consumer culture: Ten years after and agenda for the next decade. Journal of Global Scholars of Marketing Science, 28(3), 257-271.

Cleveland, M., \& Bartsch, F. (2018). Global consumer culture: epistemology and ontology. International Marketing Review. https://doi.org/10.1108/IMR-10-20180287

Cohen, J. 1988. Statistical power and analysis for the behavioral sciences. Hillsdale, NJ: Erlbaum.

Cohen, J. 1992. A power primer. Psychological Bulletin, 112(1), 155-159.

Contractor, F. J. (2017). Global Leadership in an Era of Growing Nationalism, Protectionism, and Anti-Globalization. Rutgers Business Review, 2(2), 163-185.

Davies, H., \& Raskovic, M. (2017). Understanding a Changing China: Key Issues for Business. London: Routledge.

Diamantopoulos, A., Davydova, O., \& Arslanagic-Kalajdzic, M. (2018). Modeling the role of consumer xenocentrism in impacting preferences for domestic and foreign brands: A mediation analysis. In press in Journal of Business Research, https://doi.org/10.1016/j.jbusres.2018.12.007.

Ding, Z., Vuchkovski, D., Zabkar, V., Hirose, M., \& Rašković, M. (2018). Ljubljana to Tokyo: Understanding Drivers of Young-Adult Consumer Innovativeness and the Role of Regionalism in Eastern Europe and East Asia. JEEMS Journal of East European Management Studies, 23(3), 502-522.

Ding, Z. (Forthcoming 2020). Young-adult consumer characteristics in China: From international comparison to intra-national complexity. Unpublished doctoral dissertation. Ljubljana: University of Ljubljana, School of Economics and Business. 
Dogan, M., \& Yaprak, A. (2017). Self-Construal and Willingness to Purchase Foreign Products: The Mediating Roles of Consumer Cosmopolitanism and Ethnocentrism. In Stieler M. (ed.), Creating Marketing Magic and Innovative Future Marketing Trends. Developments in Marketing Science: Proceedings of the Academy of Marketing Science. Cham: Springer. https://doi.org/10.1007/978-3-319-455969277

Douglas, S. P., \& Samuel Craig, C. (2011). The role of context in assessing international marketing opportunities. International Marketing Review, 28(2), 150-162.

Durvasula, S., \& Lysonski, S. (2008). How offshore outsourcing is perceived: why do some consumers feel more threatened?. Journal of International Consumer Marketing, 21(1), 17-33.

Durvasula, S., \& Lysonski, S. (2016). Finding cross-national consistency: Use of GTheory to validate acculturation to global consumer culture measure. Journal of Global Marketing, 29(2), 57-70.

Flere, S., \& Lavric, M. (2008). On the Validity of Cross-Cultural Social Studies Using Student Samples. Field Methods, 20(4), 399-412.

Ford, J. B. (2016). Cost vs credibility: the student sample trap in business research. European Business Review, 28(6), 652-656.

Fornell, C., \& Larcker, D. F. (1981). Evaluating structural equation models with unobservable variables and measurement error. Journal of marketing research, 18(1), 39-50.

Featherstone, M. (1990). Global culture: An introduction. In M. Featherstone (Ed), Global culture: Nationalism, globalization, and modernity, 1-14. London: Sage.

Foxall, G. R., \&amp; Goldsmith, R. E. (1994). Consumer Psychology for Marketing. London and New York: Routledge.

Gentina, E., Butori, R., Rose, G. M., \& Bakir, A. (2014). How national culture impacts teenage shopping behavior: Comparing French and American consumers. Journal of Business Research, 67(4), 464-470.

Ger, G. (1999). Localizing in the global village: Local firms competing in global markets. California Management Review, 41(4), 64-83.

Gouldner, A. W. (1957). Cosmopolitans and locals: Toward an analysis of latent social roles I. Administrative Science Quarterly, 2(3), 281-306.

Grimwade, N. (2000), International Trade: New Patterns of Trade, Production and Investment, 2nd ed. London: Routledge.

Grinstein, A., \& Wathieu, L. (2012). Happily (mal) adjusted: Cosmopolitan identity and expatriate adjustment. International Journal of Research in Marketing, 29(4), 337345. 
Gupta, A. K., \& Govindarajan, V. (2002). Cultivating a global mindset. Academy of Management Perspectives, 16(1), 116-126.

Hair, J. F., Risher, J. J., Sarstedt, M., \& Ringle, C. M. (2019). When to use and how to report the results of PLS-SEM. European Business Review, 31(1), 2-24.

Hair, J. F., Sarstedt, M., Ringle, C. M., \& Gudergan, S. P. 2018. Advanced Issues in Partial Least Squares Structural Equation Modelling (PLS-SEM). Thousand Oaks, CA: Sage.

Hair, J. F., Sarstedt, M., Ringle, C. M., \& Mena, J. A. (2012). An assessment of the use of partial least squares structural equation modeling in marketing research. Journal of the academy of marketing science, 40(3), 414-433.

Han, C. M., \& Won, S. B. (2018). Cross-country differences in consumer cosmopolitanism and ethnocentrism: A multilevel analysis with 21 countries. Journal of Consumer Behaviour, 17(1), e52-e66.

Hannerz, U. (1990). Cosmopolitans and locals in world culture. Theory, Culture, and Society, 7, 237-251.

Hannerz U. (1992). Cultural complexity: studies in the social organization of meaning. New York, United States: Columbia University Press.

Hofstede, G. (1980). Culture's consequences: International differences in work related values. Beverly Hills, Califronia: Sage.

Hofstede, G. (1991). Cultures and organizations: software of the mind. London: McGraw Hill.

Hofstede, G. (2001). Culture's consequences: Comparing values, behaviors, institutions and organizations across nations. New York, U.S.: Sage publications.

Hofstede, G., \& McCrae, R. R. (2004). Personality and culture revisited: Linking traits and dimensions of culture. Cross-Cultural Research, 38, 52-88.

Hofstede, G. (2019). Hofstede Insights. Accessed on June $25^{\text {th }}$ 2019. Retrieved from: https://www.hofstede-insights.com/product/compare-countries/

Homer, P. M., \& Kahle, L. R. (1988). A structural equation test of the value-attitudebehavior hierarchy. Journal of Personality and social Psychology, 54(4), 638.

House, R. J., Hanges, P. J., Javidan, M., Dorfman, P. W., \& Gupta, V. (2004). Culture, Leadership and Organizations: The GLOBE study of 62 Societies. Thousand Oaks, CA: Sage Publishing.

Houston, M. J., \& Rothschild, M. L. (1978). Conceptual and methodological perspectives on involvement. Research frontiers in marketing: Dialogues and directions, 184-187.

Hout, T., Porter, M.E. and Rudden, E. (1982), "How global companies win out", Harvard Business Review, 60(5), 98-108. 
Hulland, J. (1999). Use of partial least squares (PLS) in strategic management research: A review of four recent studies. Strategic Management Journal, 20(2), 195-204.

Hung, K. H., Gu, F. F., \& Yim, C. K. (2007). A social institutional approach to identifying generation cohorts in China with a comparison with American consumers. Journal of International Business Studies, 38(5), 836-853.

Inglehart, R., \& Baker, W. E. (2000). Modernization, cultural change, and the persistence of traditional values. American sociological review, 65(1), 19-51.

Jaffe, E., \& Nebenzahl, I.D. (2006). It's all in the eyes of the consumer. National Image and Competitive Advantage: The Theory and Practice of Place Branding. 79-109.

Javidan, M., House, R. J., Dorfman, P. W., Hanges, P. J., \& De Luque, M. S. (2006). Conceptualizing and measuring cultures and their consequences: a comparative review of GLOBE's and Hofstede's approaches. Journal of international business studies, 37(6), 897-914.

Jin, Z., Lynch, R., Attia, S., Chansarkar, B., Gülsoy, T., Lapoule, P., Liu, X., Newburry, W., Nooraini, M. S., Parente, R., Purani, K., \& Ungerer, M. (2015). The relationship between consumer ethnocentrism, cosmopolitanism and product country image among younger generation consumers: The moderating role of country development status. International Business Review, 24(3), 380-393.

Katz-Wise, S. L., \& Hyde, J. S. (2015). Sexual fluidity and related attitudes and beliefs among young adults with a same-gender orientation. Archives of Sexual Behavior, 44(5), 1459-1470.

Kirkman, B. L., Lowe, K. B., \& Gibson, C. B. (2017). A retrospective on Culture's Consequences: The 35-year journey. Journal of International Business Studies, 48(1), 12-29.

Kjeldgaard, D., \& Askegaard, S. (2006). The glocalization of youth culture: The global youth segment as structures of common difference. Journal of consumer research, $33(2), 231-247$.

Konrad, G. (1984). Antipolitics. Califronia, United States: Harcourt.

Kurasawa, F. (2004). A cosmopolitanism from below: Alternative globalization and the creation of a solidarity without bounds. European Journal of Sociology/Archives europeennes de sociologie, 45(2), 233-255.

Lee, K. T., Lee, Y. I., \& Lee, R. (2014). Economic nationalism and cosmopolitanism: A study of interpersonal antecedents and differential outcomes. European Journal of Marketing, 48(5/6), 1133-1158.

Markus, H. R., \& Kitayama, S. (1991). Culture and the self: Implications for cognition, emotion, and motivation. Psychological review, 98(2), 224. 
Martínez-López, F. J., Gázquez-Abad, J. C., \& Sousa, C. M. (2013). Structural equation modelling in marketing and business research: Critical issues and practical recommendations. European Journal of Marketing, 47(1/2), 115-152.

Meyer, K. E. (2017). International business in an era of anti-globalization. Multinational Business Review, 25(2), 78-90.

Merton, R. K. (1957). Patterns of influence: Local and cosmopolitan influential. In R. K. Merton (Ed.) Social Theory and Social Structure (pp. 387-420), New York, United States: The Free Press.

Miller, J. G. (1999). Cultural psychology: Implications for basic psychological theory. Psychological Science, 10, 85-91

Minkov, M. (2013). Cross-Cultural Analysis: The Science and Art of Comparing the World's Modern Societies and Their Cultures. London, UK: Sage Publications.

Mittal, B. (1989). A theoretical analysis of two recent measures of involvement. Advances in Consumer Research, 16, 697-702.

Mueller, R. D., Wang, G. X., Liu, G., \& Cui, C. C. (2016). Consumer xenocentrism in China: an exploratory study. Asia Pacific Journal of Marketing and Logistics, 28(1), 73-91.

Nijssen, E., \& Van Herk, H. (2005). Consumer ethnocentrism's effects on ongoing cross-border service relationships. Working Paper Series on Research in Relationship Management, Nijmegen School of Management.

Oakley, A. (2016). Sex, gender and society. Oxfordshire, UK: Routledge.

Oberecker, E. M., Riefler, P., \& Diamantopoulos, A. (2008). The consumer affinity construct: Conceptualization, qualitative investigation, and research agenda. Journal of International Marketing, 16(3), 23-56.

Ozsomer, A., \& Altaras, S. (2008). Global Brand Purchase Likelihood: A Critical Synthesis and an Integrated Conceptual Framework. Journal of International Marketing, 16(4), 1-28.

Oyserman, D., Kemmelmeier, M., \& Coon, H. M. (2002b). Cultural psychology, a new look: reply to Bond (2002), Fiske (2002), Kitayama (2002), and Miller. Psychological Bulletin, 128(1), 110-117.

Peterson, M. F. 2016. A culture theory commentary on Meyer and Peng's theoretical probe into Central and Eastern Europe. Journal of International Business Studies, 47(1): 33-43.

Peterson, M. F., \& Barreto, T. S. 2014. The like it or not proposition: Implications of societal characteristics for the cultural expertise and personal values of organization members. Journal of Organization Behavior, 35(8): 1134-1152. 
Peterson, R. A., \& Merunka, D. R. (2014). Convenience samples of college students and research reproducibility. Journal of Business Research, 67(5), 1035-1041.

Peterson, M. F., Søndergaard, M., \& Kara, A. (2018). Traversing cultural boundaries in IB: The complex relationships between explicit country and implicit cultural group boundaries at multiple levels. Journal of International Business Studies, 49(8), 1081-1099.

Phillips, T. \& P. Smith (2008). Cosmopolitan beliefs and cosmopolitan practices. Journal of Sociology, 44(4), 391- 399

Podsakoff, P. M., \& Organ, D. W. (1986). Self-reports in organizational research: Problems and prospects. Journal of management, 12(4), 531-544.

Prince, M. (2012). Consumer Cosmopolitanism in the Age of Globalization. New York, U.S.: Business Expert Press.

Prince, M., Davies, M. A. P., Cleveland, M., \& Palihawadana, D. (2016). Here, there, and everywhere: a study of consumer centrism. International Marketing Review, 33(5), 715-754.

Rašković, M., Makovec Brenčič, M., \& Jaklič, M. (2013). Antecedents and evolution of the Bartlett and Ghoshal transnational typology. Multinational Business Review, 21(2), 148-173.

Rašković, M., Ding, Z., Škare, V., Došen, Đ. O., \& Žabkar, V. (2016). Comparing consumer innovativeness and ethnocentrism of young-adult consumers. Journal of Business Research, 69(9), 3682-3686.

Raskovic, M., Ding, Z., Hirose, M., Zabkar, V., \& Fam, K. S. (2018). Consumer Decision-Making Styles of Young-Adult Consumers in East Asia and Central and Eastern Europe: A Global Segment or Glocal Constellations?. Under review in Journal of Business Research.

Rašković, M., Ding, Z., Hirose, M., Žabkar, V., \& Fam, K. S. (2019). Segmenting young-adult consumers in East Asia and Central and Eastern Europe-The role of consumer ethnocentrism and decision-making styles. Journal of Business Research. https://doi.org/10.1016/j.jbusres.2019.04.013.

Reynolds, N. L., Simintiras, A. C., \& Diamantopoulos, A. (2003). Theoretical justification of sampling choices in international marketing research: key issues and guidelines for researchers. Journal of international business studies, 34(1), 80-89.

Richter, N. F., Sinkovics, R. R., Ringle, C. M., Schlägel, C. (2016). A critical look at the use of SEM in international business research. International Marketing Review, $33(3), 376-404$. 
Riefler, P., \& Diamantopoulos, A. (2007). Consumer animosity: a literature review and a reconsideration of its measurement. International Marketing Review, 24(1), 87119.

Riefler, P. (2012). Segmentation strategies for cosmopolitan consumers. In M. Prince (Ed.), Consumer Cosmopolitanism in the Age of Globalization. (pp.143-161). New York, U.S: Business Expert Press.

Riefler, P., \& Diamantopoulos, A. (2009). Consumer cosmopolitanism: Review and Replication of the CYMYC scale. Journal of Business Research, 62(4), 407-419.

Riefler, P., Diamantopoulos, A., \& Siguaw, J. A. (2012). Cosmopolitan consumers as a target group for segmentation. Journal of International Business Studies, 43(3), 285-305.

Schuiling, I., \& Kapferer, J. N. (2004). Real differences between local and international brands: strategic implications for international marketers. Journal of international Marketing, 12(4), 97-112.

Schwartz, S. H. (1994). Beyond individualism/collectivism: New cultural dimensions of values. In U. Kim, H. C. Triandis, C. Kagitcibasi, S. Choi, \& G. Yoon (Eds.), Individualism and collectivism: Theory, method, and applications (p.85-119). Thousand Oaks: Sage.

Sears, D. O. (1986). College sophomores in the laboratory: Influences of a narrow data base on social psychology's view of human nature. Journal of personality and social psychology, 51(3), 515.

Shankarmahesh, M. N. (2006). Consumer ethnocentrism: an integrative review of its antecedents and consequences. International marketing review, 23(2), 146-172.

Sharma, P. (2010). Measuring personal cultural orientations: Scale development and validation. Journal of the Academy of Marketing Science, 38(6), 787-806.

Shimp, T. A., \& Sharma, S. (1987). Consumer ethnocentrism: construction and validation of the CETSCALE. Journal of marketing research, 24(3), 280-289.

Shook, C. L., Ketchen Jr, D. J., Hult, G. T. M., \& Kacmar, K. M. (2004). An assessment of the use of structural equation modeling in strategic management research. Strategic management journal, 25(4), 397-404.

Sin, L. Y., Cheung, G. W., \& Lee, R. (1999). Methodology in cross-cultural consumer research: A review and critical assessment. Journal of International Consumer Marketing, 11(4), 75-96.

Skrbis, Z., G. Kendall \& I. Woodward (2004). Locating cosmopolitanism: Between humanist ideal and grounded social category. Theory, Culture \& Society, 21(6), 115-136. 
Sobol, K., Cleveland, M., \& Laroche, M. (2018). Globalization, national identity, biculturalism and consumer behavior: A longitudinal study of Dutch consumers. Journal of Business Research, 82(1), 340-353.

Steenkamp, J. B. E. (2019). Global Versus Local Consumer Culture: Theory, Measurement, and Future Research Directions. Journal of International Marketing, 27(1), 1-19.

Steenkamp, J. B. E., \& Baumgartner, H. (1998). Assessing measurement invariance in cross-national consumer research. Journal of consumer research, 25(1), 78-90.

Steenkamp, J. B. E., \& Baumgartner, H. (2000). On the use of structural equation models for marketing modeling. International Journal of Research in Marketing, 17(2-3), 195-202.

Szerszynski, B., \& Urry, J. (2002). Cultures of cosmopolitanism. The Sociological Review, 50(4), 461-481.

Tajfel, H. (1982). Social psychology of intergroup relations. Annual review of psychology, 33(1), 1-39.

Tajfel, H., \& Turner, J. C. (1979). "An integrative theory of intergroup conflict". In W. G. Austin \& S. Worchel (eds.). The social psychology of intergroup relations. Monterey, CA: Brooks/Cole.

Tambyah, S. K. \& D, Chen (2012). Cosmopolitans go shopping. In M. Prince (Ed.) Consumer Cosmopolitanism in the Age of Globalization (pp. 3-28), New York, United States: Business Expert Press.

Taras, V., Steel, P., \& Kirkman, B. L. (2016). Does country equate with culture? Beyond geography in the search for cultural boundaries. Management International Review, 56(4), 455-487.

Tellis, G. J., Yin, E., \&amp; Bell, S. (2009). Global consumer innovativeness: Crosscountry differences and demographic commonalities. Journal of International Marketing, 17(2), 1-22.

Terasaki, S. (2016). Cosmopolitan consumers: Research overview and research opportunities. Journal of International Business Research, 15(1), 32.

Thompson, J. B. (1995). The media and modernity. Cambridge, England: Polity Press.

Thompson, C. J. \& S. K. Tambyah (1999). Trying to be cosmopolitan. Journal of Consumer Research, 26, 214-241.

Tisdell, C. A. (2006). Economic prospects for small island economies,

particularly in the South Pacific, in a globalising world (No. 43, p. 1-18). The University of Queensland, School of Economics.

Tung, R. L., \& Stahl, G. K. (2018). The tortuous evolution of the role of culture in IB research: What we know, what we don't know, and where we are headed. Journal of International Business Studies, 49(9), 1167-1189. 
Wetzels, M., Odekerken-Schröder, G., \& van Oppen, C. (2009). Using PLS path modeling for assessing hierarchical construct models: guidelines and empirical illustration. MIS Quarterly, 33(1), 177-195.

Witt, M. A. (2019). De-Globalization: Theories, Predictions, and Opportunities for International Business Research. Journal of International Business Studies, Forthcoming.

Xu, J., Shim, S., Lotz, S., \& Almeida, D. (2004). Ethnic identity, socialization factors, and culture-specific consumption behavior. Psychology \& Marketing, 21(2), 93112.

Yoo, B., Donthu, N., \& Lenartowicz, T. (2011). Measuring Hofstede's five dimensions of cultural values at the individual level: Development and validation of CVSCALE. Journal of International Consumer Marketing, 23(3-4), 193-210.

Yoon, S. J., Cannon, H. M., \& Yaprak, A. (1996). Evaluating the CYMYC cosmopolitanism scale on Korean consumers. Advances in international marketing, 7(1), 211-232.

Yoon, S. J., Cannon, H. M., \& Yaprak, A. (2001). A cross-cultural study of the "cosmopolitanism" construct: validation of a new cosmopolitanism scale. Working paper.

Zaheer, S. (1995). Overcoming the liability of foreignness. Academy of Management journal, 38(2), 341-363.

Zeugner-Roth, K. P., Žabkar, V., \& Diamantopoulos, A. (2015). Consumer ethnocentrism, national identity, and consumer cosmopolitanism as drivers of consumer behavior: A social identity theory perspective. Journal of international marketing, 23(2), 25-54.

Zhou, N., \& Belk, R. W. (2004). Chinese consumer readings of global and local advertising appeals. Journal of Advertising, 33(3), 63-76.

Zhou, J. X., Arnold, M. J., Pereira, A., \& Yu, J. (2010). Chinese consumer decisionmaking styles: A comparison between the coastal and inland regions. Journal of Business Research, 63(1), 45-51.

Zupan, N., Kase, R., Raskovic, M., Yao, K. \& Wang, C. (2015). Getting ready for the young generation to join the workforce: a comparative analysis of the work values of Chinese and Slovenian business students. Journal of East European Management Studies, 20(2), 174-201. 


\section{Appendices}

\section{Appendix 1: English Survey (New Zealand)}

\section{Survey of young-adult consumer characteristics in New Zealand and Taiwan}

My name is Justin Chen and I am a master's student of International Business at Victoria University of Wellington in New Zealand. If you are in your 20s and from either New Zealand or Taiwan, I am kindly asking you to take part in this study, which looks at the influence of individual-level cultural orientations on consumer cosmopolitanism. Participation in the survey takes about 15-20 minutes and is completely anonymous. Should you have any questions, please feel free to contact me at: chenmuen@myvuw.ac.nz.

1. The first set of questions is related to your personal cultural orientations. On a 5-point ordinal scale, please indicate the level of agreement with the provided statements below, where the answers correspond to: 1-strongly disagree, 3-neither disagree/nor agree (neutral), 5-strongly agree.

\begin{tabular}{|l|l|l|l|l|c|}
\hline & $\begin{array}{c}1 \\
\text { Strongly } \\
\text { disagree }\end{array}$ & 2 & $\begin{array}{c}3 \\
\text { Neither/Nor } \\
\text { (Neutral) }\end{array}$ & 4 & $\begin{array}{c}5 \\
\text { Strongly } \\
\text { agree }\end{array}$ \\
\hline $\begin{array}{l}\text { People in higher positions should make } \\
\text { most decisions without consulting } \\
\text { people in lower positions. }\end{array}$ & & & & & \\
\hline $\begin{array}{l}\text { People in higher positions should not } \\
\text { ask the opinions of people in lower } \\
\text { positions too frequently. }\end{array}$ & & & & & \\
\hline $\begin{array}{l}\text { People in higher positions should avoid } \\
\text { social interaction with people in lower } \\
\text { positions. }\end{array}$ & & & & & \\
\hline $\begin{array}{l}\text { People in lower positions should not } \\
\text { disagree with decisions by people in } \\
\text { higher positions. }\end{array}$ & & & & & \\
\hline
\end{tabular}




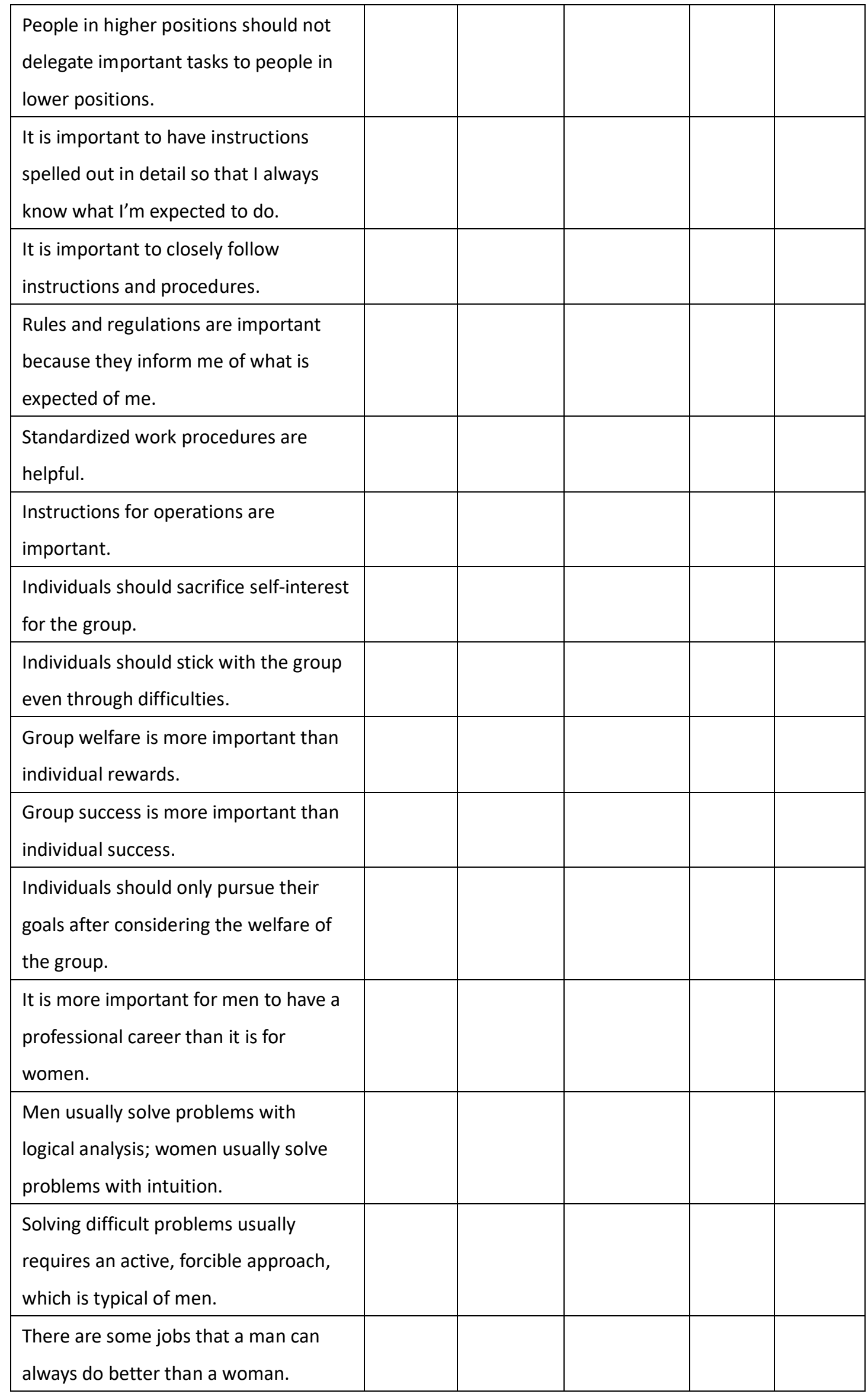


2. The second set of questions is related to consumer cosmopolitanism. On a 5-point ordinal scale, please indicate the level of agreement with the provided statements below, where the answers correspond to: 1-strongly disagree, 3-neither disagree/nor agree (neutral), 5-strongly agree.

\begin{tabular}{|c|c|c|c|c|c|}
\hline & $\begin{array}{c}1 \\
\text { Strongly } \\
\text { disagree }\end{array}$ & 2 & $\begin{array}{c}3 \\
\text { Neither/ } \\
\text { Nor } \\
\text { (Neutral) }\end{array}$ & 4 & $\begin{array}{c}5 \\
\text { Strongly } \\
\text { agree }\end{array}$ \\
\hline $\begin{array}{l}\text { When traveling, I make a conscious effort } \\
\text { to get in touch with the local culture and } \\
\text { traditions. }\end{array}$ & & & & & \\
\hline $\begin{array}{l}\text { I like having the opportunity to meet } \\
\text { people from many different countries. }\end{array}$ & & & & & \\
\hline $\begin{array}{l}\text { I like to have contact with people from } \\
\text { different cultures. }\end{array}$ & & & & & \\
\hline $\begin{array}{l}\text { I have got a real interest in other } \\
\text { countries. }\end{array}$ & & & & & \\
\hline $\begin{array}{l}\text { Having access to products coming from } \\
\text { many different countries is valuable to } \\
\text { me. }\end{array}$ & & & & & \\
\hline $\begin{array}{l}\text { The availability of foreign products in the } \\
\text { domestic market provides valuable } \\
\text { diversity. }\end{array}$ & & & & & \\
\hline $\begin{array}{l}\text { I enjoy being offered a wide range of } \\
\text { products coming from various countries. }\end{array}$ & & & & & \\
\hline $\begin{array}{l}\text { Always buying the same local products } \\
\text { becomes boring over time. }\end{array}$ & & & & & \\
\hline $\begin{array}{l}\text { I like watching movies from different } \\
\text { countries. }\end{array}$ & & & & & \\
\hline I like listening to music of other cultures. & & & & & \\
\hline $\begin{array}{l}\text { I like trying original dishes from other } \\
\text { countries. }\end{array}$ & & & & & \\
\hline $\begin{array}{l}\text { I like trying out things that are consumed } \\
\text { elsewhere in the world. }\end{array}$ & & & & & \\
\hline
\end{tabular}


3. The third set of questions is related to product involvement and country attitudes. On a 5 -point ordinal scale, please indicate the level of agreement with the provided statements below, where the answers correspond to: 1-strongly disagree, 3-neither disagree/nor agree (neutral), 5-strongly agree.

\begin{tabular}{|c|c|c|c|c|c|}
\hline & $\begin{array}{c}1 \\
\text { Strongly } \\
\text { disagree }\end{array}$ & 2 & $\begin{array}{c}3 \\
\text { Neither/Nor } \\
\text { (Neutral) }\end{array}$ & 4 & $\begin{array}{l}5 \\
\text { Strongly } \\
\text { agree }\end{array}$ \\
\hline I have a strong interest in bodywash. & & & & & \\
\hline Bodywash is very important to me. & & & & & \\
\hline $\begin{array}{l}\text { I would choose my bodywash very } \\
\text { carefully. }\end{array}$ & & & & & \\
\hline $\begin{array}{l}\text { Choosing bodywash is an important } \\
\text { decision for me. }\end{array}$ & & & & & \\
\hline $\begin{array}{l}\text { Which bodywash I buy matters a lot to } \\
\text { me. }\end{array}$ & & & & & \\
\hline I have a strong interest in smart phones & & & & & \\
\hline A smart phone is very important to me. & & & & & \\
\hline $\begin{array}{l}\text { I would choose my smart phone very } \\
\text { carefully. }\end{array}$ & & & & & \\
\hline $\begin{array}{l}\text { Choosing a smart phone is an important } \\
\text { decision for me. }\end{array}$ & & & & & \\
\hline $\begin{array}{l}\text { Which smart phone I buy matters a lot } \\
\text { to me. }\end{array}$ & & & & & \\
\hline
\end{tabular}

4. The last set of questions is related to your demographic characteristics and level of international experience.

a) How many countries have you visited in your life? If you are not sure, please provide and approximate estimate: \# countries visited.

(Note: Airport transfers do not count).

b) Have you ever visited Taiwan/New Zealand:

$$
\text { 1-YES O-No }
$$


c) Have you been born in another country than New Zealand/Taiwan?

$$
\text { 1-YES 0-No }
$$

If yes, please indicate where:

d) Have you ever lived in another country (spent more than 3 months away from home in another country as a child, for study, travel and/or work, or simply living):

$$
\text { 1-YES } \quad 0 \text {-No }
$$

e) Do you come from a mixed-cultural family background?

(Are your parents and/or legal guardians from different cultural and/or ethnic backgrounds?)

$$
\text { 1-YES } \quad 0-\text { No }
$$

f) Do you identify yourself as belonging to more than one national culture (i.e. one parent/guardian from New Zealand, another from India; have been raised in a mixed cultural background)?

$$
\text { 1-YES } \quad 0-\text { No }
$$

If yes, which cultures do you identify with:

g) Besides your mother tongue, are you fluent in any other foreign languages?

$$
\text { 1-YES 0-No }
$$

If yes, how many OTHER FOREIGN languages do you speak: \# __ of foreign languages spoken

(Note: If you live in or are from a country with multiple official languages, do not count these).

h) Do you currently have, or have you ever had a partner and/or spouse from another culture?

$$
\text { 1-YES } \quad 0-\text { No }
$$

i) Your gender:

1-Female 
2-Male

3-Other

j) Place of residence:

1-capital city of my country

2-large urban area

3-rural area

4-Other (which):

Thank you for taking part in this survey.

If you wish to receive a summary of the study upon its completion, please feel free to leave your email address below and we will update you on our study's progress. (Note: Your email address will NOT be used for any other purposes nor will it be passed onto a third-party. Your anonymity will be ensured.) 